\title{
WestVirginiaUniversity
}

THE RESEARCH REPOSITORY @ WVU

Graduate Theses, Dissertations, and Problem Reports

2013

\section{Association of Individual and Combined Metabolic Risk Factors with Cancer}

Ruchi Bhandari

West Virginia University

Follow this and additional works at: https://researchrepository.wvu.edu/etd

\section{Recommended Citation}

Bhandari, Ruchi, "Association of Individual and Combined Metabolic Risk Factors with Cancer" (2013). Graduate Theses, Dissertations, and Problem Reports. 378.

https://researchrepository.wvu.edu/etd/378

This Dissertation is protected by copyright and/or related rights. It has been brought to you by the The Research Repository @ WVU with permission from the rights-holder(s). You are free to use this Dissertation in any way that is permitted by the copyright and related rights legislation that applies to your use. For other uses you must obtain permission from the rights-holder(s) directly, unless additional rights are indicated by a Creative Commons license in the record and/ or on the work itself. This Dissertation has been accepted for inclusion in WVU Graduate Theses, Dissertations, and Problem Reports collection by an authorized administrator of The Research Repository @ WVU.

For more information, please contact researchrepository@mail.wvu.edu. 


\title{
Association of Individual and Combined Metabolic Risk Factors with Cancer
}

\section{Ruchi Bhandari, M.P.A., M.B.A.}

\author{
Dissertation submitted \\ to the School of Public Health \\ at West Virginia University \\ in partial fulfillment of the requirements for the degree of \\ Doctor of Philosophy in \\ Public Health Sciences
}
Ian R.H. Rockett, Ph.D., Chair Matthew J. Gurka, Ph.D. Joel A. Halverson, Ph.D. George A. Kelley, Ph.D. Juhua Luo, Ph.D.
Department of Epidemiology

Morgantown, West Virginia 2013

Keywords: Metabolic syndrome, metabolic risk factors, cancer, meta-analysis, breast cancer Copyright 2013 Ruchi Bhandari 


\section{Abstract \\ Association of individual and combined metabolic risk factors with cancer}

Ruchi Bhandari, M.P.A., M.B.A.

Introduction: The prevalence of metabolic risk factors (MRFs), individually and in the aggregate, is growing rapidly. There is limited biologic and epidemiologic evidence indicating an association between MRFs and cancer. The goal of this dissertation was to examine the association between individual and combined MRFs with subsequent risk of overall and sitespecific cancers of the breast, digestive system, and lung.

Methods: A systematic review with meta-analysis on the association between metabolic syndrome (a cluster of MRFs) and breast cancer was conducted. In addition, associations between MRFs and risk of overall and site-specific cancers were assessed by multivariable Cox proportional hazards regression models. Lastly, associations between MRFs and age at cancer onset were examined by multiple linear regression analyses, using the general linear model. Data were derived from the NHANES I Epidemiologic Follow-up Study, and comprised participants ages 25 to 74 years at baseline. The primary metabolic risk factors were obesity (measured by BMI), high blood pressure, high total serum cholesterol, and diabetes. Analyses were adjusted for age, race, education, family income, physical activity, smoking status, and family history of cancer, and stratified by age and gender. All analyses incorporated the complex sample design and sample weights to produce national estimates.

Results: Results from the meta-analysis show that metabolic syndrome was modestly associated with an increased risk for breast cancer in adult women. Findings from the study on the association between individual and combined MRFs and cancer risk suggest that diabetes independently, and presence of a combination of MRFs, may serve as markers for postmenopausal breast cancer risk. The association between diabetes and a combination of three or four MRFs and earlier age at onset was observed not only for postmenopausal breast cancer, but also for overall cancer in women 50 and older, digestive cancer in women, and lung cancer in males.

Conclusion: Future research needs to examine this association between MRFs and site-specific cancers using specific, objective metabolic markers. The positive association of MRFs with postmenopausal breast cancer points toward the need to develop public health strategies to manage these risk factors.

Keywords: Metabolic syndrome, metabolic risk factors, cancer, meta-analysis, breast cancer 


\section{ACKNOWLEDGMENTS}

I am immensely and truly grateful to my mentor, Dr. Ian Rockett. His guidance, support, and constant encouragement ("onwards and upwards, Ruchi") have been critical in this research, and throughout my program. I thank my committee member, Dr. George Kelley, whose expertise and knowledge convinced me to take up the task of conducting a systematic review and metaanalysis as part of my dissertation. I am truly grateful to him for working with me incessantly to carve out the first research paper in this dissertation. I sincerely thank my committee members, Dr. Matthew Gurka and Dr. Juhua Luo, for their expertise, their valuable guidance in employing an accurate methodology for my papers, and for their knowledgeable answers to my numerous queries. I thank my committee member, Dr. Joel Halverson, for his support and guidance early on in this research initiative and all through the program.

I offer my special thanks to my colleague and friend, Dr. Tara Hartley, who kindly agreed to take on the required role of a second researcher in the meta-analysis paper. Without her help and diligence, the paper would be lacking in an important aspect. I would also like to thank all my friends who have always supported me, and patiently encouraged me to keep going.

I had the opportunity to interact with several faculty members of the erstwhile Department of Community Medicine and several other programs at WVU. The courses I took with them have certainly helped me in this dissertation, but will also be helpful in the longer journey.

I thank my family members whose prayers and wishes made my pursuit achievable. My darling daughter, Aarohi, I thank you for your support and understanding all through this process. I am very proud of you. Above all, I thank my best friend, guide, and soul mate, my husband, Dr. Abhishek Srivastava. You are the wind beneath my wings. 


\section{TABLE OF CONTENTS}

CHAPTER 1. INTRODUCTION...............................................................

1.1 Introduction..................................................................................... 2

1.2 Study 1 Background.............................................................................. 3

1.3 Study 2 Background................................................................................

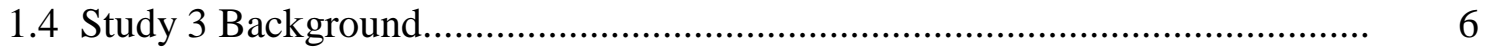

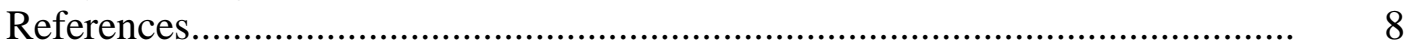

CHAPTER 2. METABOLIC SYNDROME IS ASSOCIATED WITH

INCREASED BREAST CANCER RISK: A SYSTEMATIC REVIEW WITH

META-ANALYSIS............................................................................ 14

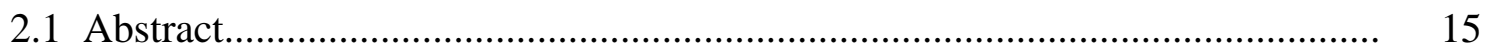

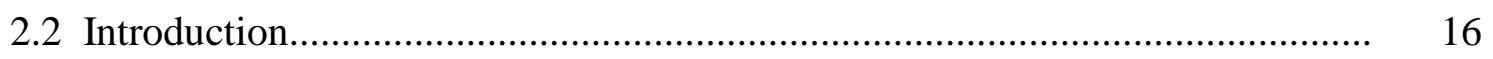

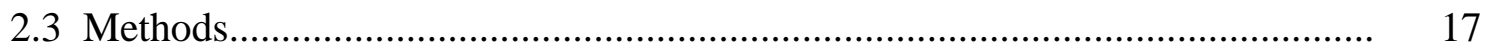

2.3.1 Study Eligibility ..................................................................................... 17

2.3.2 Data Sources................................................................................. 18

2.3.3 Study Selection................................................................................ 19

2.3.4 Data Extraction................................................................................... 19

2.3.5 Risk of Bias Assessment....................................................................... 19

2.3.6 Statistical Analysis....................................................................... 20

2.4 Results............................................................................. 21

2.4.1 Study Characteristics........................................................................... 21

2.4.2 Risk of Bias Assessment...................................................................... 22

2.4.3 Statistical Analysis........................................................................... 23

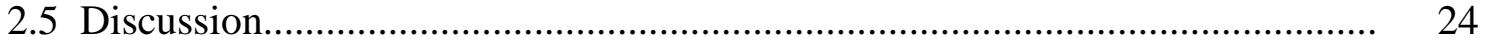

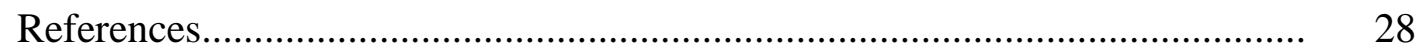

CHAPTER 3. ASSOCIATION BETWEEN INDIVIDUAL AND COMBINED

METABOLIC RISK FACTORS AND CANCER RISK …………….................... 38

3.1 Abstract..................................................................................... 39

3.2 Introduction...................................................................................... 41

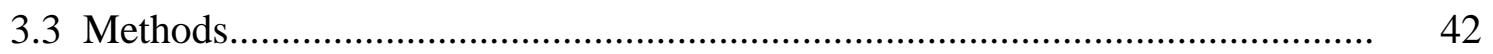

3.3.1 Data Source and Study Population............................................................. 42

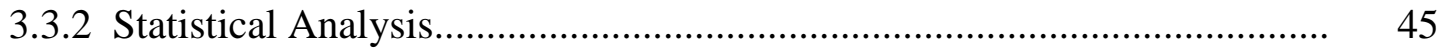

3.4 Results..................................................................................... 4

3.5 Discussion....................................................................................... 48

References..................................................................................... 52

CHAPTER 4. ASSOCIATION BETWEEN METABOLIC RISK FACTORS AND AGE AT CANCER ONSET............................................................... 58

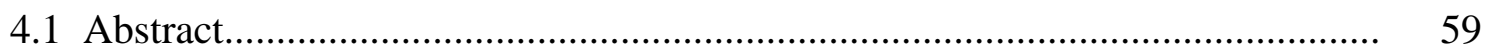

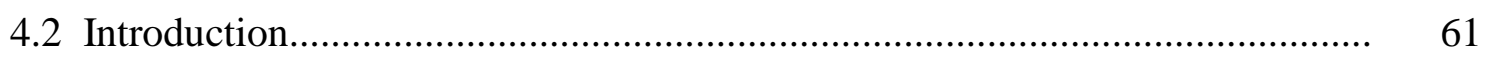

4.3 Methods............................................................................................... 63

4.3.1 Data Source and Study Population........................................................... 63

4.3.2 Statistical Analysis............................................................................. 65 


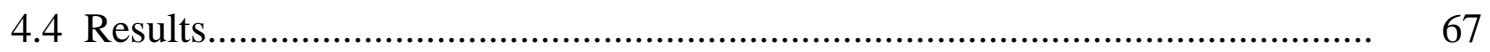

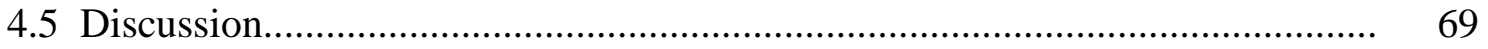

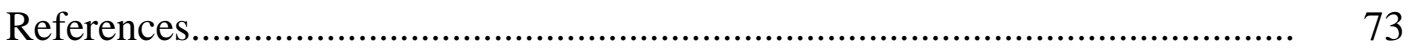

CHAPTER 5. DISCUSSION .................................................................... 80

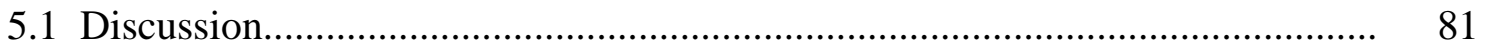

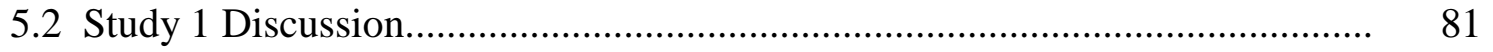

5.3 Study 2 Discussion........................................................................... 82

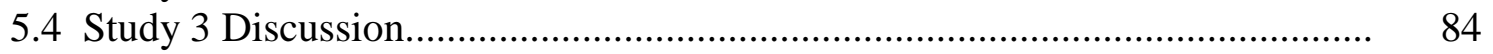

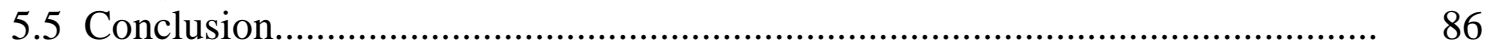

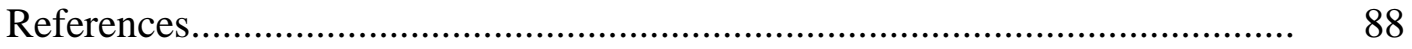

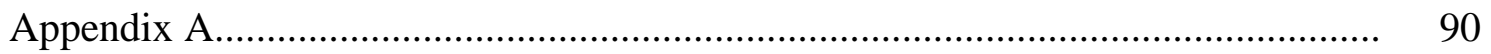

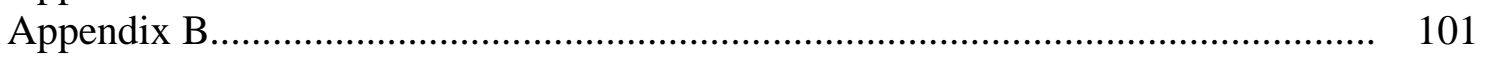

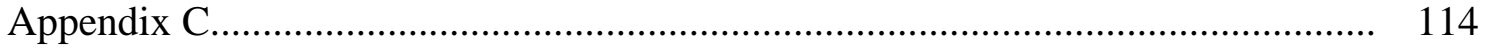


CHAPTER 1. INTRODUCTION 


\subsection{Introduction}

Cancer, the "plague of our generation," ${ }^{1}$ will have been diagnosed in 1.7 million men and women in the US in $2013 .^{2}$ Accounting for one in four deaths, cancer is the second most common cause of death in the United States (US) after heart disease. ${ }^{3}$ There are four important causes of cancer: (a) genetic factors, (b) lifestyle factors, (c) infections, and (d) environmental exposures. ${ }^{4}$ Only $5-10 \%$ of all cancers can be attributed to genetic causes. ${ }^{4}$ Lifestyle factors play a significant role in cancer development and progression. The World Cancer Research Fund estimates that $25-33 \%$ of new cancer cases in the US in 2013 are related to behavioral and lifestyle factors, such as overweight or obesity, physical inactivity, and poor nutrition. ${ }^{5}$ Research studies estimate half of the cancer burden can be prevented or significantly reduced by modifying lifestyle factors. ${ }^{6,7}$

Lifestyle factors can generate metabolic abnormalities that include overweight and obesity, and high blood pressure, cholesterol, and blood glucose. Epidemiologic evidence supports the association between each of these individual metabolic risk factors (MRFs) and cancer risk. ${ }^{8-22} \mathrm{~A}$ few studies have also reported that cancer risk increases with the number of MRFs. $^{23-33}$

Several complex biological mechanisms have been proposed to show metabolic risk factors promoting carcinogenesis. In brief, metabolic risk factors, functioning through various mechanisms, including increased inflammatory markers, such as tumor necrosis factor-alpha and interleuken-6, increased adipokines such as leptin, and decreased adiponectin, increased levels of free fatty acids and triglycerides, insulin resistance, increased insulin-like growth factor-1, and increased oxidative stress, can cause angiogenesis, cell migration, mitogenesis, and DNA damage. $^{34}$ 
Despite the epidemiologic studies and limited experimental evidence supporting the biological role of MRFs in cancer development and progression, results from studies examining the association between individual and combined MRFs and overall cancer are inconsistent. Therefore, the goal of this dissertation was to assess the individual and combined effects of MRFs on subsequent risk of cancer. It comprises three inter-related studies on cancer risk from metabolic risk factors. The background and methods of each of the three papers from the dissertation are discussed briefly.

\subsection{Study 1 Background: Metabolic Syndrome is associated with increased breast cancer risk: A systematic review with meta-analysis}

In the first paper of this dissertation, a systematic review with meta-analysis was conducted to comprehensively synthesize existing literature on the association between metabolic syndrome and breast cancer incidence. The most common cancer in women worldwide is breast cancer, which accounted for 1.38 million new cases in 2008, comprising approximately a quarter $(23 \%)$ of all new cancer cases. ${ }^{35}$ Traditional risk factors for breast cancer are well known as age, family history of cancer, and reproductive and menstrual history, but lifestyle risk factors such as overweight, lack of physical activity, and consumption of alcohol are also crucial. ${ }^{36}$ Several of these risk factors are associated with metabolic syndrome $(\mathrm{MS}) .^{37}$

Metabolic syndrome (MS) is a cluster of pathophysiological disorders comprising central obesity, insulin resistance, high blood pressure, and dyslipidemia. ${ }^{37} \mathrm{MS}$ has been identified as a risk factor for several cancers, particularly breast, pancreatic, colorectal, and prostate cancers. ${ }^{25}$, 26, 28, 30-32, 38-45 Individual components of MS are positively associated with the development of

certain cancers, most notably breast cancer. ${ }^{46-52}$ Yet, studies show mixed results in these 
associations. ${ }^{29,33,53}$ Although some of the components of MS may not be strongly associated with the development of breast cancer, they may all work together to elevate the risk. ${ }^{34}$ This possibility suggests that MS may influence breast tumorigenesis by activating different molecular pathways through endocrine, metabolic, and immune cell changes. ${ }^{54}$

However, results from previous epidemiologic studies are inconsistent with respect to MS and breast cancer risk. Given the conflicting results from individual studies of MS and breast cancer risk in all adult women, this study used the aggregate data meta-analytic approach to examine the association between MS and BC risk in women. Studies were retrieved by searching four electronic reference databases [PubMed, Cumulative Index to Nursing and Allied Health Literature (CINAHL), Web of Science, and PROQUEST - June 30, 2012], and cross-referencing from retrieved articles. Eligible for inclusion were longitudinal studies that reported associations between MS and breast cancer risk among females aged 18 years and older. Relative risks (RR) and associated $95 \%$ confidence intervals (95\% CI) were calculated for each study, and then pooled using fixed and random-effects models. Publication bias was assessed both quantitatively (trim and fill) ${ }^{55}$ and qualitatively (funnel plots). Heterogeneity was examined using Q and $I^{2}$ statistics. $^{56}$

\subsection{Study 2 Background: Association between individual and combined metabolic risk factors and subsequent risk of cancer}

Comprehensive reviews provide evidence of association between individual MRFs, such as obesity, hypertension, diabetes, hypercholesterolemia, and overall and site-specific cancers. Epidemiologic reviews provide evidence of individuals with diabetes at a higher risk for most

cancers. ${ }^{9,10,12,16,18,49}$ Studies also show an association between obesity and several cancers. ${ }^{11,13-}$ 
15, 17, 47, 48, 57-59 However, results are less consistent for studies examining the association between blood pressure, cholesterol, and cancer. ${ }^{19,20,60-66}$

There is adequate evidence that the risk for heart disease and stroke increases with number of MRFs. ${ }^{67,68}$ A combination of three or more of the MRFs is generally termed as metabolic syndrome. ${ }^{37}$ Metabolic syndrome is estimated to be prevalent in over a third of US adults. ${ }^{69}$ A recent meta-analysis found that the combination of MRFs (metabolic syndrome) also elevated the risk for several cancers. ${ }^{24}$

Findings from observational as well as intervention studies have raised the hypothesis of an etiologic link between the clustering of MRFs and elevated risk of cancer. ${ }^{70}$ Several complex biological mechanisms have been proposed to show that MRFs promote carcinogenesis. The prevalence of hyper-insulinemia and insulin resistance is higher in obese individuals. Hyperinsulinemia reduces the production of insulin-like growth factor (IGF) binding protein, resulting in increased bioavailability of IGF-1. ${ }^{8}$ IGF-1 may promote tumor development by stimulating cell proliferation and inhibiting apoptosis. Increased circulating insulin can also reduce the levels of sex-hormone-binding-globulin, thereby increasing endogenous sex-steroid levels. ${ }^{8}$ Breast, endometrial, and colorectal cancers may be affected by this mechanism. ${ }^{71}$ Another carcinogenic mechanism involves cytokines. Increased adiposity raises cytokine production in obese women, which in turn can induce estradiol production. ${ }^{34}$ Estradiol is a strong growth factor for breast and endometrial cancers. Leptin, another adipocyte-specific hormone, is directly related to adiposity and insulin resistance. It has direct stimulatory effects on cancer cells and may serve as an important link between obesity and carcinogenesis. ${ }^{34}$

However, studies are not consistent in predicting an elevated cancer risk from MRFs. With the background of increasing prevalence of metabolic syndrome, and epidemiologic 
evidence and biologic possibility of the association between MRFs and cancer risk, this study examined the association of MRFs (obesity, high blood pressure, high total serum cholesterol, and diabetes), individually and in combination, and subsequent risk of overall and site-specific cancers of the breast, digestive system, and lung respectively.

Data were derived from the NHANES I Epidemiologic Follow-up Study, and comprised participants ages 25 to 74 years at baseline. Multivariable Cox proportional hazards regression models were fitted to assess the association between individual and combined MRFs and cancer incidence. Analyses were adjusted for age, race, education, family income, physical activity, smoking status, and family history of cancer, and stratified by age and gender. All analyses incorporated the complex sample design and sample weights in order to generate national estimates.

\subsection{Study 3 Background: Association between metabolic risk factors and age at cancer onset}

Several epidemiologic studies have shown that MRFs elevate the risk of overall and several site-specific cancers. ${ }^{8-22,23-33}$ However, very few studies have examined whether MRFs are associated with earlier age at cancer onset. There are a few studies showing overweight, obesity, and hypertension being associated with earlier age at cancer onset. ${ }^{59,66,72}$

Animal studies suggest that mechanisms which prevent metabolic abnormalities, by reducing serum IGF-1 or androgen concentrations, may delay the growth and progression of breast and prostate cancers. ${ }^{73}$ An animal study found that mammary tumors developed earlier in diet-induced obese rats than in lean rats, supporting the role of hormones and adipokines (produced by adipose tissue) in cell proliferation and carcinogenesis. ${ }^{74}$ 
The aim of this study was to examine whether MRFs, either individually or in combination, were associated with age at onset of all-site cancer, and cancer of the breast, digestive system, and lung respectively. It is an important research question for several reasons. First, studies show that age at onset of certain cancers, such as breast, cervical, and prostate cancers, is temporally decreasing. ${ }^{75}$ Second, earlier cancer onset shortens life expectancy, signifying major loss of potential years of life. ${ }^{76-78}$ Third, compared with older patients, younger cancer patients are likely to have more aggressive cancers, less favorable prognosis, and poorer outcomes. ${ }^{76-78}$ Fourth, earlier age at cancer onset in a family may increase cancer risk for the next generation. $^{79,80}$

Data were derived from the NHANES I Epidemiologic Follow-up Study, and comprised participants ages 25 to 74 years at baseline. The outcome variable was age at cancer onset, and the primary metabolic risk factors were obesity, high blood pressure, high total serum cholesterol, and diabetes. Analyses were adjusted for age, race, education, family income, physical activity, smoking status, and family history of cancer, and stratified by age and gender. Multiple linear regression analyses, using the general linear model, were conducted to assess the relationship between MRFs and age at cancer onset. All analyses incorporated the complex sample design and sample weights to produce national estimates.

Each of the three papers is presented in detail in the next three chapters (Chapters 2-4). The last chapter (Chapter 5) summarizes the findings from each of the papers and raises key discussions points before concluding this research study. 


\section{Reference List}

(1) Mukherjee S. The Emperor of All Maladies: A Biography of Cancer. Scribner; 2010.

(2) Howlader N, Noone AM, Krapcho M, Garshell J, et al. SEER Cancer Statistics Review, 1975-2010. Bethesda, MD: National Cancer Institute; 2013.

(3) Siegel R, Naishadham D, Jemal A. Cancer statistics, 2013. CA Cancer J Clin 2013;63(1):11-30.

(4) Anand P, Kunnumakkara AB, Sundaram C et al. Cancer is a preventable disease that requires major lifestyle changes. Pharm Res 2008;25(9):2097-2116.

(5) World Cancer Research Fund/American Institute for Cancer Research. Policy and Action for Cancer Prevention. Food, Nutrition, and Physical Activity: a Global Perspective. Washington DC: American Institute for Cancer Research; 2009.

(6) Colditz G, DeJong D, Hunter D, Trichopoulos D, Willett W. Harvard report on cancer: Causes of human cancer. Cancer Causes Control 1996;7:1-59.

(7) Stein CJ, Colditz GA. Modifiable risk factors for cancer. Br J Cancer 2004;90(2):299303.

(8) Giovannucci E, Harlan DM, Archer MC et al. Diabetes and cancer: a consensus report. Diabetes Care 2010;33(7):1674-1685.

(9) Larsson SC, Orsini N, Wolk A. Diabetes mellitus and risk of colorectal cancer: a metaanalysis. J Natl Cancer Inst 2005;97(22):1679-1687.

(10) Larsson SC, Orsini N, Brismar K, Wolk A. Diabetes mellitus and risk of bladder cancer: a meta-analysis. Diabetologia 2006;49(12):2819-2823.

(11) Larsson SC, Orsini N, Wolk A. Body mass index and pancreatic cancer risk: A metaanalysis of prospective studies. Int J Cancer 2007;120(9):1993-1998.

(12) Larsson SC, Mantzoros CS, Wolk A. Diabetes mellitus and risk of breast cancer: a metaanalysis. Int J Cancer 2007;121(4):856-862.

(13) Larsson SC, Wolk A. Obesity and the risk of gallbladder cancer: a meta-analysis. $\mathrm{Br} J$ Cancer 2007;96(9):1457-1461.

(14) Larsson SC, Wolk A. Obesity and colon and rectal cancer risk: a meta-analysis of prospective studies. Am J Clin Nutr 2007;86(3):556-565.

(15) Larsson SC, Wolk A. Overweight, obesity and risk of liver cancer: a meta-analysis of cohort studies. Br J Cancer 2007;97(7):1005-1008. 
(16) Larsson SC, Wolk A. Diabetes mellitus and incidence of kidney cancer: a meta-analysis of cohort studies. Diabetologia 2011;54(5):1013-1018.

(17) Renehan AG, Tyson M, Egger M, Heller RF, Zwahlen M. Body-mass index and incidence of cancer: a systematic review and meta-analysis of prospective observational studies. Lancet 2008;371(9612):569-578.

(18) Shikata K, Ninomiya T, Kiyohara Y. Diabetes mellitus and cancer risk: review of the epidemiological evidence. Cancer Sci 2013;104(1):9-14.

(19) Stocks T, Van HM, Manjer J et al. Blood pressure and risk of cancer incidence and mortality in the Metabolic Syndrome and Cancer Project. Hypertension 2012;59(4):802810.

(20) Strohmaier S, Edlinger M, Manjer J et al. Total serum cholesterol and cancer incidence in the Metabolic syndrome and Cancer Project (Me-Can). PLoS One 2013;8(1):e54242.

(21) World Cancer Research Fund/American Institute for CancerResearch. Food, Nutrition, Physical Activity, and the Prevention of Cancer: a Global Perspective. Washington DC: AICR; 2007.

(22) World Health Organization. IARC Handbook of Cancer Prevention - Weight Control and Physical Activity. World Health Organization; 2002.

(23) Chen W, Lu F, Liu SJ et al. Cancer risk and key components of metabolic syndrome: a population-based prospective cohort study in Chinese. Chin Med J (Engl) 2012;125(3):481-485.

(24) Esposito K, Chiodini P, Colao A, Lenzi A, Giugliano D. Metabolic syndrome and risk of cancer: a systematic review and meta-analysis. Diabetes Care 2012;35(11):2402-2411.

(25) Esposito K, Chiodini P, Capuano A et al. Effect of metabolic syndrome and its components on prostate cancer risk: Meta-analysis. J Endocrinol Invest 2013;36(2):132139.

(26) Esposito K, Chiodini P, Capuano A et al. Colorectal cancer association with metabolic syndrome and its components: a systematic review with meta-analysis. Endocrine 2013.

(27) Esposito K, Chiodini P, Capuano A, Bellastella G, Maiorino MI, Giugliano D. Metabolic syndrome and endometrial cancer: a meta-analysis. Endocrine 2013.

(28) Esposito K, Chiodini P, Capuano A et al. Metabolic syndrome and postmenopausal breast cancer: systematic review and meta-analysis. Menopause 2013.

(29) Kabat GC, Kim M, Chlebowski RT et al. A longitudinal study of the metabolic syndrome and risk of postmenopausal breast cancer. Cancer Epidemiol Biomarkers Prev 2009;18(7):2046-2053. 
(30) Osaki Y, Taniguchi S, Tahara A, Okamoto M, Kishimoto T. Metabolic syndrome and incidence of liver and breast cancers in Japan. Cancer Epidemiol 2012;36(2):141-147.

(31) Rosato V, Bosetti C, Talamini R et al. Metabolic syndrome and the risk of breast cancer in postmenopausal women. Ann Oncol 2011;22(12):2687-2692.

(32) Rosato V, Tavani A, Bosetti C et al. Metabolic syndrome and pancreatic cancer risk: a case-control study in Italy and meta-analysis. Metabolism 2011;60(10):1372-1378.

(33) Russo A, Autelitano M, Bisanti L. Metabolic syndrome and cancer risk. Eur J Cancer 2008;44(2):293-297.

(34) Cowey S, Hardy RW. The metabolic syndrome: A high-risk state for cancer? Am J Pathol 2006;169(5):1505-1522.

(35) Jemal A, Bray F, Center MM, Ferlay J, Ward E, Forman D. Global cancer statistics. CA Cancer J Clin 2011;61(2):69-90.

(36) National Cancer Institute. Breast Cancer - risk factors. http://www cancer gov/cancertopics/wyntk/breast/page4 2012.

(37) Grundy SM, Brewer HB, Jr., Cleeman JI, Smith SC, Jr., Lenfant C. Definition of metabolic syndrome: Report of the National Heart, Lung, and Blood Institute/American Heart Association conference on scientific issues related to definition. Circulation 2004;109(3):433-438.

(38) Agnoli C, Berrino F, Abagnato CA et al. Metabolic syndrome and postmenopausal breast cancer in the ORDET cohort: a nested case-control study. Nutr Metab Cardiovasc Dis 2010;20(1):41-48.

(39) Ahmed RL, Schmitz KH, Anderson KE, Rosamond WD, Folsom AR. The metabolic syndrome and risk of incident colorectal cancer. Cancer 2006;107(1):28-36.

(40) Bjorge T, Lukanova A, Jonsson $\mathrm{H}$ et al. Metabolic syndrome and breast cancer in the mecan (metabolic syndrome and cancer) project. Cancer Epidemiol Biomarkers Prev 2010;19(7):1737-1745.

(41) Capasso I, Esposito E, Pentimalli F et al. Metabolic syndrome affects breast cancer risk in postmenopausal women: National Cancer Institute of Naples experience. Cancer Biol Ther 2011;10(12):1240-1243.

(42) Lund HL, Wisloff TF, Holme I, Nafstad P. Metabolic syndrome predicts prostate cancer in a cohort of middle-aged Norwegian men followed for 27 years. Am J Epidemiol 2006;164(8):769-774.

(43) Pelucchi C, Serraino D, Negri E et al. The metabolic syndrome and risk of prostate cancer in Italy. Ann Epidemiol 2011;21(11):835-841. 
(44) Porto LA, Lora KJ, Soares JC, Costa LO. Metabolic syndrome is an independent risk factor for breast cancer. Arch Gynecol Obstet 2011;284(5):1271-1276.

(45) Siddiqui AA. Metabolic syndrome and its association with colorectal cancer: a review. Am J Med Sci 2011;341(3):227-231.

(46) van den Brandt PA, Spiegelman D, Yaun SS et al. Pooled analysis of prospective cohort studies on height, weight, and breast cancer risk. Am J Epidemiol 2000;152(6):514-527.

(47) Huang Z, Hankinson SE, Colditz GA et al. Dual effects of weight and weight gain on breast cancer risk. JAMA 1997;278(17):1407-1411.

(48) Harvie M, Hooper L, Howell AH. Central obesity and breast cancer risk: a systematic review. Obes Rev 2003;4(3):157-173.

(49) Michels KB, Solomon CG, Hu FB et al. Type 2 diabetes and subsequent incidence of breast cancer in the Nurses' Health Study. Diabetes Care 2003;26(6):1752-1758.

(50) de WF, Baanders-van Halewijn EA. A prospective study in general practice on breastcancer risk in postmenopausal women. Int J Cancer 1974;14(2):153-160.

(51) Mink PJ, Shahar E, Rosamond WD, Alberg AJ, Folsom AR. Serum insulin and glucose levels and breast cancer incidence: the atherosclerosis risk in communities study. Am J Epidemiol 2002;156(4):349-352.

(52) Tornberg SA, Holm LE, Carstensen JM. Breast cancer risk in relation to serum cholesterol, serum beta-lipoprotein, height, weight, and blood pressure. Acta Oncol 1988;27(1):31-37.

(53) Inoue M, Noda M, Kurahashi $\mathrm{N}$ et al. Impact of metabolic factors on subsequent cancer risk: results from a large-scale population-based cohort study in Japan. Eur J Cancer Prev 2009;18(3):240-247.

(54) Healy LA, Ryan AM, Carroll P et al. Metabolic syndrome, central obesity and insulin resistance are associated with adverse pathological features in postmenopausal breast cancer. Clin Oncol (R Coll Radiol ) 2010;22(4):281-288.

(55) Duval S, Tweedie R. Trim and fill: A simple funnel-plot-based method of testing and adjusting for publication bias in meta-analysis. Biometrics 2000;56(2):455-463.

(56) Higgins JP, Thompson SG. Quantifying heterogeneity in a meta-analysis. Stat Med 2002;21(11):1539-1558.

(57) Carmichael AR, Bates T. Obesity and breast cancer: a review of the literature. Breast 2004;13(2):85-92.

(58) Giovannucci E, Michaud D. The role of obesity and related metabolic disturbances in cancers of the colon, prostate, and pancreas. Gastroenterology 2007;132(6):2208-2225. 
(59) Li D, Morris JS, Liu J et al. Body mass index and risk, age of onset, and survival in patients with pancreatic cancer. JAMA 2009;301(24):2553-2562.

(60) Ahn J, Lim U, Weinstein SJ et al. Prediagnostic total and high-density lipoprotein cholesterol and risk of cancer. Cancer Epidemiol Biomarkers Prev 2009;18(11):28142821.

(61) Grove JS, Nomura A, Severson RK, Stemmermann GN. The association of blood pressure with cancer incidence in a prospective study. Am J Epidemiol 1991;134(9):942947.

(62) Kitahara CM, Berrington de GA, Freedman ND et al. Total cholesterol and cancer risk in a large prospective study in Korea. J Clin Oncol 2011;29(12):1592-1598.

(63) Schatzkin A, Hoover RN, Taylor PR et al. Site-specific analysis of total serum cholesterol and incident cancer in the National Health and Nutrition Examination Survey I Epidemiologic Follow-up Study. Cancer Res 1988;48(2):452-458.

(64) Sidney S, Farquhar JW. Cholesterol, cancer, and public health policy. Am J Med 1983;75(3):494-508.

(65) Vatten LJ, Foss OP. Total serum cholesterol and triglycerides and risk of breast cancer: a prospective study of 24,329 Norwegian women. Cancer Res 1990;50(8):2341-2346.

(66) Xie L, Wu K, Xu N, Chen D, Chen J, Lu S. Hypertension is associated with a high risk of cancer. J Hum Hypertens 1999;13(5):295-301.

(67) Grundy SM. Obesity, metabolic syndrome, and cardiovascular disease. J Clin Endocrinol Metab 2004;89(6):2595-2600.

(68) Isomaa B, Almgren P, Tuomi T et al. Cardiovascular morbidity and mortality associated with the metabolic syndrome. Diabetes Care 2001;24(4):683-689.

(69) Ervin R. Prevalence of metabolic syndrome among adults 20 years of age and over, by sex, age, race and ethnicity, and body mass index: United States, 2003-2006. National health statistics reports; no. 13. Hyattsville, MD. National Center for Health Statistics. 2009.

(70) Zhou JR, Blackburn GL, Walker WA. Symposium introduction: metabolic syndrome and the onset of cancer. Am J Clin Nutr 2007;86(3):s817-s819.

(71) Kaaks R, Lukanova A. Energy balance and cancer: the role of insulin and insulin-like growth factor-I. Proc Nutr Soc 2001;60(1):91-106.

(72) Rulyak SJ, Lowenfels AB, Maisonneuve P, Brentnall TA. Risk factors for the development of pancreatic cancer in familial pancreatic cancer kindreds. Gastroenterology 2003;124(5):1292-1299. 
(73) Zhou JR, Li L, Pan W. Dietary soy and tea combinations for prevention of breast and prostate cancers by targeting metabolic syndrome elements in mice. Am J Clin Nutr 2007;86(3):s882-s888.

(74) Hakkak R, Holley AW, Macleod SL et al. Obesity promotes 7,12dimethylbenz(a)anthracene-induced mammary tumor development in female zucker rats. Breast Cancer Res 2005;7(5):R627-R633.

(75) Newby JA, Busby CC, Howard CV, Platt MJ. The cancer incidence temporality index: an index to show temporal changes in the age of onset of overall and specific cancer (England and Wales, 1971-1999). Biomed Pharmacother 2007;61(10):623-630.

(76) Ahn SH, Son BH, Kim SW et al. Poor outcome of hormone receptor-positive breast cancer at very young age is due to tamoxifen resistance: nationwide survival data in Korea--a report from the Korean Breast Cancer Society. J Clin Oncol 2007;25(17):23602368.

(77) Han W, Kang SY. Relationship between age at diagnosis and outcome of premenopausal breast cancer: age less than 35 years is a reasonable cut-off for defining young age-onset breast cancer. Breast Cancer Res Treat 2010;119(1):193-200.

(78) Lee CH, Lee KW, Fang FM et al. The use of tobacco-free betel-quid in conjunction with alcohol/tobacco impacts early-onset age and carcinoma distribution for upper aerodigestive tract cancer. J Oral Pathol Med 2011;40(9):684-692.

(79) Brune KA, Lau B, Palmisano E et al. Importance of age of onset in pancreatic cancer kindreds. J Natl Cancer Inst 2010;102(2):119-126.

(80) Hemminki K, Li X. Familial and second primary pancreatic cancers: a nationwide epidemiologic study from Sweden. Int J Cancer 2003;103(4):525-530. 
CHAPTER 2. METABOLIC SYNDROME IS ASSOCIATED WITH INCREASED BREAST CANCER RISK: A SYSTEMATIC REVIEW WITH META-ANALYSIS 


\subsection{Abstract}

\section{Background}

While positive and statistically significant associations between individual metabolic risk factors and breast cancer risk have been reported, controversy surrounds risk of breast cancer from metabolic syndrome (MS). We report the first systematic review and meta-analysis of the association between MS and breast cancer risk in all adult females.

\section{Methods}

Studies were retrieved by searching four electronic reference databases [PubMed, Cumulative Index to Nursing and Allied Health Literature (CINAHL), Web of Science, and PROQUEST - June 30, 2012], and cross-referencing from retrieved articles. Eligible for inclusion were longitudinal studies that reported associations between MS and breast cancer risk among females aged 18 years and older. Relative risks (RR) and associated $95 \%$ confidence intervals (95\% CI) were calculated for each study, and then pooled using random-effects models. Publication bias was assessed both quantitatively (trim and fill) and qualitatively (funnel plots). Heterogeneity was examined using $\mathrm{Q}$ and $I^{2}$ statistics.

\section{Results}

Representing nine independent cohorts and 97,277 adult females, eight studies met the inclusion criteria. A modest, positive association was observed between MS and breast cancer risk (RR: 1.47, 95\% CI, 1.15-1.87; $\left.\mathrm{z}=3.13 ; \mathrm{p}=0.002 ; \mathrm{Q}=26.28, \mathrm{p}=.001 ; I^{2}=69.55 \%\right)$. No publication bias was observed.

\section{Conclusions}

MS is associated with an increased risk for breast cancer in adult women. 


\subsection{Introduction}

Breast cancer, the most common cancer in women worldwide, accounted for 1.38 million new cases in 2008 , comprising approximately a quarter $(23 \%)$ of all new cancer cases. ${ }^{1}$ While traditional risk factors for breast cancer include age, family history of cancer, and reproductive and menstrual history, the National Cancer Institute also recognizes overweight, lack of physical activity, and consumption of alcohol as risk factors. ${ }^{2}$ Several of these risk factors are associated with metabolic syndrome. ${ }^{3}$

Metabolic syndrome (MS) is a cluster of pathophysiological disorders comprising central obesity, insulin resistance, high blood pressure, and dyslipidemia. Reaven's definition of MS in $1988^{4}$ was followed by definitions from the World Health Organization, ${ }^{5}$ National Cholesterol Education Program's Adult Treatment Panel III (NCEP ATP III), ${ }^{6}$ American Heart Association/National Heart, Lung, and Blood Institute, ${ }^{7}$ and the International Diabetes Federation. ${ }^{8}$ The NCEP's ATP III guidelines are the most commonly used criteria in the U.S. ${ }^{6}$ These criteria include the presence of three or more of the following ${ }^{3}$ : abdominal obesity (waist circumference $\geq 35$ inches in women), triglycerides $\geq 150 \mathrm{mg} / \mathrm{dL}$, high density lipoprotein cholesterol (HDL-C) $<50 \mathrm{mg} / \mathrm{dL}$, blood pressure $(\mathrm{BP}) \geq 130 / 85 \mathrm{mmHg}$, and fasting glucose $\geq$ $110 \mathrm{mg} / \mathrm{dL}$. MS is estimated to be prevalent in at least a quarter of the adults in the Americas, in Europe, and in India. ${ }^{9}$

MS has been identified as a risk factor for several cancers, particularly breast, pancreatic, colorectal, and prostate cancers. ${ }^{10-15}$ Individual components of MS, for example, abdominal obesity, high blood glucose, high BP, high triglycerides, and low HDL, are positively associated with the development of certain cancers, most notably breast cancer. ${ }^{16-27}$ While studies show a positive association of breast cancer with diabetes ${ }^{19,28-33}$ and obesity, ${ }^{16,34,35}$ others show a 
negative association with obesity in premenopausal women. ${ }^{36-38}$ Mixed results also characterize hypertension $^{22,23,39,40}$ and dyslipidemia ${ }^{22,41,42}$ as risk factors for breast cancer.

Although individual components of MS may not be strongly associated with the development of breast cancer, their combination may elevate the risk. ${ }^{13,14,43-56}$ For example, MS may activate different molecular pathways through endocrine, metabolic, and immune cell changes, which in turn influence breast tumorigenesis. ${ }^{47}$ Such pathways that enhance breast cancer cell proliferation and inhibit apoptosis, include: (1) increased levels of circulating estrogen, e.g., estradiol, ${ }^{52,54,57}$ (2) higher levels of insulin, ${ }^{58,59}$ (3) decreased level of circulating adiponectin, ${ }^{60}$ and (4) increased plasma leptin concentration. ${ }^{60}$

Results from previous epidemiologic studies are inconsistent with respect to MS and breast cancer risk. For example, only four ${ }^{13,14,43,51}$ of eight studies ${ }^{13,14,43,48,51,61-63}$ reported a statistically significant association between MS and risk of breast cancer. Therefore, one might conclude that the association between MS and breast cancer risk is unknown. However, such a conclusion would be based on the vote-counting approach, an approach that ignores the magnitude of the association. ${ }^{64}$

A recent systematic review and meta-analysis of MS and postmenopausal breast cancer found that MS was moderately associated with the risk of postmenopausal breast cancer. ${ }^{10}$ However, to the best of our knowledge, no meta-analytic research has addressed the conflicting results from individual studies of MS and breast cancer risk in all adult women. Therefore, the purpose of this study was to use the aggregate data meta-analytic approach to examine the association between MS and breast cancer risk in women.

\subsection{Methods}

\subsubsection{Study Eligibility}


The a priori inclusion criteria for this study were as follows: (1) observational studies using cohort (both prospective and retrospective), case-control, or nested case-control study designs; (2) studies examining the association between MS (presence of a cluster of three or more metabolic abnormalities) and breast cancer incidence, as defined by the authors; (3) studies with adult females $\geq 18$ years of age as participants; (4) English-language studies published as journal articles, doctoral dissertations, or masters' theses; (5) published and indexed studies up to June 30, 2012; and (6) studies reporting sufficient data (e.g., rate ratios, risk ratios, odds ratios, standardized incidence ratios, hazard ratios, or frequencies) for calculating a common effect size.

Studies not meeting all inclusion criteria were excluded from this review. Excluded studies were those that: (1) were not published as full reports, such as conference abstracts and letters to editors; (2) only examined individual components of MS; (3) measured the MS variables at the time of cancer diagnosis; (4) used cancer mortality, rather than incidence, as the outcome; and (5) studies published in a language other than English.

\subsubsection{Data Sources}

A comprehensive and systematic search was conducted using four electronic databases: PubMed, Cumulative Index to Nursing and Allied Health Literature (CINAHL), Web of Science, and PROQUEST (from their commencement to June 30, 2012). Since the term MS dates back to the late 1950s, with variations in use as early as the 1920s, the start dates of each of the databases were used as the commencement date for study search; Web of Science (1900), CINAHL (1952), PubMed (1966), and Proquest (1861). In addition, cross-referencing from retrieved studies was also performed. Major keywords used in the search for potentially eligible studies included "metabolic syndrome" (“insulin resistance syndrome," "syndrome x,") and "breast cancer" ("neoplasm and breast"). Using the most recent publication, trials published as duplicate reports 
(parallel publications) were only included once. All electronic searches were conducted using the graphical user interface for each database. The last search was conducted on June 30, 2012.

\subsubsection{Study Selection}

At the first screening, one author screened all abstracts and selected articles for full-text examination. At the second level of the study selection process, two of the authors examined the full-text articles and then selected the included studies following mutual discussion and consensus.

\subsubsection{Data Extraction}

Two of the authors reviewed every study selected and independently extracted data from studies onto electronic coding forms. These forms could hold up to 52 items per study. Attempts were made to contact authors of three of the original studies for missing information, ${ }^{13,61,63}$ but only one provided the requested information. ${ }^{13}$ After initial coding, the two coders reviewed each item for agreement. Discrepancies were resolved by consensus. Using Cohen's kappa $(k)$ statistic, ${ }^{65}$ the overall inter-rater agreement rate prior to correcting discrepant items, was 0.96 for all included studies.

\subsubsection{Risk of Bias Assessment}

Risk of bias was assessed using a modified version of the Strengthening the Reporting of Observational Studies in Epidemiology (STROBE) checklist. ${ }^{66}$ The items assessed included: (1) study design, (2) adjustments for confounders, (3) selection of participants and their eligibility criteria, (4) measurement of predictor variables, (5) breast cancer diagnosis, (6) study size, (7) handling of missing data, and (8) reasons for non-participation of individuals at each stage of the study. A description of the criteria for risk of bias assessment is shown in Table 1. Two of the 
authors conducted all assessments, independent of each other. Disagreements were resolved through discussion. No study was excluded based on the results of the risk of bias assessment.

\subsubsection{Statistical Analysis}

Calculation of study-level effect sizes. Risk estimates were used to examine the association between MS and risk of breast cancer. These were derived from reported relative risks, odds ratios, hazard ratios, incident rate ratios, or standardized incidence ratios, together with their respective 95\% CIs, from the original studies. Where necessary and possible, all metrics were converted to risk ratios (RRs). Adjusted risk estimates from multivariable models in the original studies were pooled for analysis. However, for two case-control studies that were included, ${ }^{14,51}$ adjusted odds ratios were used because data necessary to convert to RR were not available.

Effect size pooling. All RR results were pooled using a random-effects model, an approach that incorporates between-study heterogeneity into the model. ${ }^{67} \mathrm{~A} z$-score two-tailed alpha value $\leq 0.05$ was considered as statistically significant. In addition, $95 \%$ confidence intervals (CIs) were calculated for each result from each study as well as for pooled estimates. Heterogeneity was calculated using the $\mathrm{Q}^{68}$ and $I^{2}$ statistics. ${ }^{69}$ An alpha level $\leq 0.10$ for the $\mathrm{Q}$ statistic was considered as evidence of statistically significant heterogeneity. While somewhat arbitrary, $I^{2}$ values of $25 \%, 50 \%$, and $75 \%$ were considered to represent low, moderate and high amounts of heterogeneity. ${ }^{69}$ Publication bias was assessed using the Trim and Fill approach of Duval and Tweedie. ${ }^{70}$ In addition, Rosenthal's Fail-Safe $\mathrm{N}$ test was used to compute the number of missing null studies that would be needed to nullify the overall pooled RR as being statistically significant. ${ }^{71}$ Statistically significant standardized residuals $(\mathrm{p} \leq 0.05)$ were considered as outliers. 


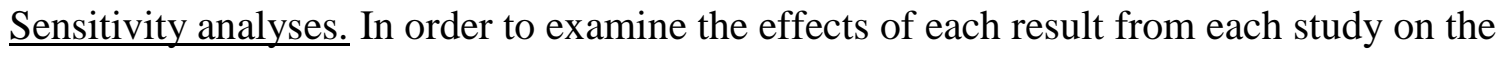
overall pooled results, influence analysis was conducted with each result from each study deleted from the model once. Cumulative meta-analysis, ranked by year, was also conducted in order to examine the accumulation of results over time. A separate pooled analysis limited to postmenopausal women was conducted because studies show that MS in postmenopausal women increases the risk of breast cancer. ${ }^{13,14,43,48,51,61}$ In addition, pooled analyses were conducted with the following caveats post hoc: (1) deletion of results from two case-control studies because odds ratios were used instead of $\mathrm{RR},{ }^{14,51}$ (2) deletion of results from studies that were not prospective cohort designs, ${ }^{13,14,51}$ and (3) limiting the results to studies that controlled for four or more of the important confounders (as listed in Table 1). ${ }^{14,43,48,51}$ All analyses were performed using Comprehensive Meta-Analysis, Version 2.2. ${ }^{72}$

\section{$2.4 \quad$ Results}

\subsubsection{Study Characteristics}

Figure 1 presents a flow diagram of the selection of studies for the meta-analysis. Of the

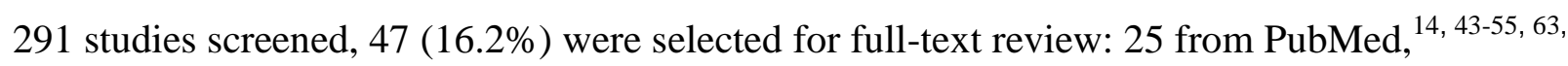
73-82 17 from the Web of Science, ${ }^{13,} 39,62,83-96$ one from CINAHL, ${ }^{97}$ and four from ProQuest. ${ }^{61,98-}$ ${ }^{100}$ Of the 47 that underwent a full-text review, eight $(17.0 \%)$ met the eligibility criteria. ${ }^{13,14,43,}$ 48, 51, 61-63 One article ${ }^{14}$ presented results for two independent cohorts; therefore, each cohort was treated independently.

A general description of the included studies is shown in Table 2. Studies were published between 2008 and 2012 and from five different countries. The study designs included four prospective cohorts, ${ }^{48,61-63}$ one retrospective cohort, ${ }^{13}$ one prospective nested case-control, ${ }^{43}$ and two case-control. ${ }^{14,51}$ The baseline year for cohort inception ranged from 1983 to 2004, with 
average follow-up ranging between 2.7 and 13.5 years. Sample sizes ranged from 792 to 49,172 (total 97,277) adult females, excluding one study that did not report this data. ${ }^{63}$ The ages of the participants ranged from 21 to 86 years. Six studies conducted analyses on postmenopausal women. $^{13,14,43,48,51,61}$ The results of each cohort or case-control study were initially reported as a hazard ratio, ${ }^{13,48,62}$ incidence rate ratio, ${ }^{43,61}$ standardized incidence ratio, ${ }^{63}$ or odds ratio. ${ }^{14,51}$ Methods for exposure assessment, cancer identification and the controlling of confounders varied across the eight included studies (Table 3). Seven of the eight studies identified the outcome

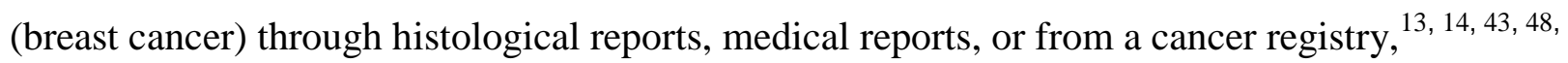
$51,61,63$ while one used self-report. ${ }^{62}$ Only three studies examined invasive breast cancer cases. ${ }^{43}$, ${ }^{48,63}$ One study also reported on the in situ breast cancer cases but there were only seven such cases in that study. ${ }^{43}$ Another study analyzed all breast cancer cases (in situ and invasive) as well as invasive cancers separately, and the results remained the same in both analyses. ${ }^{48}$

\subsubsection{Risk of Bias Assessment}

Risk of bias results are shown in Table 4. All the studies were considered to be at low risk for selection of participants and meeting eligibility criteria as well as providing adequately powered sample sizes. Out of eight studies, a majority were also considered low risk with respect to study design (six studies) and measurement of the outcome variable (seven studies). In terms of handling potential confounders, half the studies were low risk, three were high risk, and one was unclear. Missing confounding variables included education, smoking status, alcohol use, family history of cancer, contraceptive use, or hormonal history. Similarly, half the studies had objective measurements of predictor variables, while the remainder relied on self-report, and were consequently considered high risk. Four studies deleted the participants with missing variables in their analyses (high risk), while two did not report how they handled missing data. 
Lastly, six studies were considered high risk because they did not report the reasons for nonparticipation of subjects at each stage of follow-up.

\subsubsection{Statistical Analysis}

Overall Results. Overall, a statistically significant increase of $47 \%$ in the risk for incident breast cancer was observed for adult females with MS (RR: 1.47, 95\% CI, 1.15-1.87; z = 3.13; p $<0.002 ; \mathrm{Q}=26.28, \mathrm{p}<0.001 ; I^{2}=69.55 \%$ ) (Figure 2 ). With the exception of one study, ${ }^{62}$ all other studies had RR in the direction of increased risk. ${ }^{13,14,43,48,51,61,63}$ Funnel plot results for potential publication bias are shown in Figure 3. Using the Trim and Fill approach that resulted in two imputations, the risk decreased by $16 \%$ but remained significant (RR: $1.31,95 \%$ CI, 1.011.70). The fail-safe $\mathrm{N}$ was 69 , implying that 69 'null' studies would be needed to nullify the statistically significant association between MS and breast cancer risk in adult females. No statistically significant outliers were identified $(\mathrm{p}=0.06-0.82)$.

$\underline{\text { Sensitivity analysis. With each study deleted from the model once, results remained }}$ positive and statistically significant (Figure 4). As can be seen, the pooled RR fell within a range of $20 \%(\mathrm{RR}=1.36-1.56)$ and none of the CIs for the point estimates was less than 1.0.

Cumulative meta-analysis, ranked by year, revealed that results have been statistically significant since 2011 (Figure 5). Deleting the two case-control studies from the model, the RR for incident breast cancer for women with MS decreased by $18 \%$ but was still statistically significant with moderate heterogeneity (RR: $1.29,95 \% \mathrm{CI}, 1.003-1.67 ; \mathrm{z}=1.98 ; \mathrm{p}=0.05 ; \mathrm{Q}=14.13, \mathrm{p}=.01 ; I^{2}$ $=64.61 \%$ ). When limited to studies with only prospective designs, the RR decreased by $30 \%$ but remained statistically significant with very low heterogeneity $(\mathrm{RR}: 1.17,95 \% \mathrm{CI}, 1.01-1.36 ; \mathrm{z}=$ 2.04; $\left.\mathrm{p}=0.04 ; \mathrm{Q}=4.30, \mathrm{p}=0.37 ; I^{2}=7.04 \%\right)$. When limited to postmenopausal women, breast cancer risk increased by $34 \%$ and was still statistically significant with high heterogeneity (RR: 
1.81, 95\% CI, 1.28-2.56; $\left.\mathrm{z}=3.37 ; \mathrm{p}=0.001 ; \mathrm{Q}=23.36, \mathrm{p}=0.001 ; I^{2}=74.32 \%\right)$. Lastly, when limiting the results to studies that controlled for four or more of the important confounders (as listed in Table 1), ${ }^{14,43,48,51}$ breast cancer risk increased by $17 \%$ and was statistically significant with moderate heterogeneity (RR: 1.64, 95\% CI, 1.23-2.20; $\mathrm{z}=3.34 ; \mathrm{p}=0.001 ; \mathrm{Q}=8.55, \mathrm{p}$ $=0.07 ; I^{2}=53.21 \%$.

\subsection{Discussion}

The purpose of this aggregate data meta-analysis was to examine the association between MS and the risk for breast cancer in adult females. Overall results suggest that a modest positive association exists between MS and risk of breast cancer. This finding is strengthened by the robustness of results from other analyses. These include: (1) examination for publication bias, (2) influence analysis with each study deleted from the model once, (3) deletion of the two casecontrol studies with odds ratios from the overall model, (4) limiting the analysis to prospective designs, (5) including only postmenopausal women in the analysis, and (6) limiting the results to studies that controlled for four or more of the important confounders. The results from cumulative meta-analysis, ranked by year, indicate an increasingly statistically significant association since 2011 .

Assessment for risk of bias indicated that a majority of studies were at low risk regarding study design, cancer assessment, and sample size. However, a majority were at high risk or unclear risk in terms of handling of missing data and non-participation of subjects at each stage of follow-up. It is suggested that future studies provide complete information on the handling of missing data and on the non-participation of subjects at each stage of follow-up.

When limited to postmenopausal women, a stronger association between MS and breast cancer was observed. This association was stronger in case-control and retrospective cohort 
study designs compared with prospective cohort study designs. These findings concur with the recent meta-analysis on MS and breast cancer risk in postmenopausal women. ${ }^{10}$ Several studies have shown that MS in postmenopausal women increases the risk of breast cancer, ${ }^{43}, 46,101$ suggesting that the etiology of breast cancer may differ among pre and postmenopausal women.

There are several potential mechanisms linking MS with the increased risk of breast cancer. First, obese postmenopausal women produce higher levels of estrogens, which in turn increase the biologically available fraction of circulating estradiol by reducing plasma concentration of sex hormone binding globulin (SHBG). ${ }^{102}$ Low plasma SHBG levels are associated with insulin resistance ${ }^{103,104}$ and other components of MS. ${ }^{105,106}$ Second, adipose tissue produces two adipokines (cytokine-like factors), leptin and adiponectin, that affect breast cancer biology. ${ }^{107}$ Higher plasma leptin levels are associated with obesity, ${ }^{54,57,108}$ insulin resistance, ${ }^{109,110}$ and MS. ${ }^{111,112}$ Leptin stimulates human breast cancer cell lines, whereas adiponectin acts protectively, inhibiting the growth of these cell lines. ${ }^{57,107,113}$ Obesity is associated with reduced adiponectin levels. ${ }^{114}$ Third, insulin has been shown to have a mitogenic effect upon breast cancer cells in vitro through several mechanisms. ${ }^{57}$ It can act synergistically with estradiol and stimulate proliferation of the cell line. ${ }^{115}$ Insulin can also lower SHBG production, ${ }^{116}$ thereby increasing biologically available estradiol. Moreover, low serum HDL-C concentrations indicate higher circulating bioactive estrogen levels, which in turn may stimulate target breast tissue. ${ }^{76}$

The increasing prevalence of MS, and its association with breast cancer, among other comorbidities, point toward the critical need to develop public health strategies to manage MS. Given the increasingly large global burden of metabolic risk factors, even a small association with breast cancer can have a substantial public health impact. Risk assessment tools can be 
developed that incorporate MS as a risk factor for breast cancer. Healthcare providers will then be better equipped to identify high-risk women for primary and secondary prevention.

This study has several strengths. First, to the best of our knowledge, this is the first systematic review and meta-analysis to examine the association between MS and risk of breast cancer in all adult women. The analysis incorporates all women, and a sub-analysis of postmenopausal women. The overlapping meta-analysis on metabolic syndrome and breast cancer was confined to post-menopausal women only. ${ }^{10}$ Second, a number of other analyses were performed that strengthened the robustness of findings. Third, the results of this study provide direction for future research on this topic.

This study also has several potential limitations. These include (1) the different methods used to assess exposure, identify cancer, control for confounders, and define MS, (2) limiting studies to those published in English, which may have led to inflated results, ${ }^{117}$ (3) the relatively small number of studies that met the inclusion criteria, (4) the inability of some studies to provide raw data for calculating the RR, (5) the different study designs employed, and (6) the varied populations studied.

In order to inform and undergird a biological rationale for the observed positive association between MS and breast cancer risk in adult females, future studies should consist of analyses based on a standard definition of MS and employ objective and standard biomarkers for assessing each MS component. In addition, adjustments for all important potential confounders need to be made. It would be helpful if future studies examined the relationship between MS and breast cancer risk separately in perimenopausal and premenopausal women since breast cancer in women may be estrogen-independent. Along those lines, not all studies adjusted for hormone replacement therapy, a potential confounder. Future studies should report this information. 
Furthermore, future research needs to examine in situ and invasive cancers separately in relation to metabolic syndrome. Finally, a focus on obese women with respect to MS and breast cancer seems appropriate.

In conclusion, the overall results of this meta-analysis suggest that there is a modest positive association between MS and risk of breast cancer in adult females. 


\section{Reference List}

(1) Jemal A, Bray F, Center MM, Ferlay J, Ward E, Forman D. Global cancer statistics. CA Cancer J Clin 2011;61(2):69-90.

(2) National Cancer Institute. Breast Cancer - risk factors. Available online: http://www.cancer.gov/cancertopics/wyntk/breast/page4. 2012.

(3) Grundy SM, Brewer HB, Jr., Cleeman JI, Smith SC, Jr., Lenfant C. Definition of metabolic syndrome: Report of the National Heart, Lung, and Blood Institute/American Heart Association conference on scientific issues related to definition. Circulation 2004;109(3):433-438.

(4) Reaven GM. Banting lecture 1988. Role of insulin resistance in human disease. Diabetes 1988;37(12):1595-1607.

(5) World Health Organization. Definition, diagnosis and classification of diabetes mellitus and its complications: report of a WHO Consultation. Geneva, Switzerland: World Health Organization; 1999.

(6) Third Report of the National Cholesterol Education Program (NCEP) Expert Panel on Detection, Evaluation, and Treatment of High Blood Cholesterol in Adults (Adult Treatment Panel III) final report. Circulation 2002;106(25):3143-3421.

(7) Grundy SM, Cleeman JI, Daniels SR et al. Diagnosis and management of the metabolic syndrome: an American Heart Association/National Heart, Lung, and Blood Institute Scientific Statement. Circulation 2005;112(17):2735-2752.

(8) Alberti KG, Zimmet P, Shaw J. The metabolic syndrome--a new worldwide definition. Lancet 2005;366(9491):1059-1062.

(9) Grundy SM. Metabolic syndrome pandemic. Arterioscler Thromb Vasc Biol 2008;28(4):629-636.

(10) Esposito K, Chiodini P, Capuano A et al. Metabolic syndrome and postmenopausal breast cancer: systematic review and meta-analysis. Menopause 2013.

(11) Esposito K, Chiodini P, Capuano A et al. Effect of metabolic syndrome and its components on prostate cancer risk: Meta-analysis. J Endocrinol Invest 2013;36(2):132139.

(12) Esposito K, Chiodini P, Capuano A et al. Colorectal cancer association with metabolic syndrome and its components: a systematic review with meta-analysis. Endocrine 2013.

(13) Osaki Y, Taniguchi S, Tahara A, Okamoto M, Kishimoto T. Metabolic syndrome and incidence of liver and breast cancers in Japan. Cancer Epidemiol 2012;36(2):141-147. 
(14) Rosato V, Bosetti C, Talamini R et al. Metabolic syndrome and the risk of breast cancer in postmenopausal women. Ann Oncol 2011;22(12):2687-2692.

(15) Rosato V, Tavani A, Bosetti C et al. Metabolic syndrome and pancreatic cancer risk: a case-control study in Italy and meta-analysis. Metabolism 2011;60(10):1372-1378.

(16) van den Brandt PA, Spiegelman D, Yaun SS et al. Pooled analysis of prospective cohort studies on height, weight, and breast cancer risk. Am J Epidemiol 2000;152(6):514-527.

(17) Huang Z, Hankinson SE, Colditz GA et al. Dual effects of weight and weight gain on breast cancer risk. JAMA 1997;278(17):1407-1411.

(18) Harvie M, Hooper L, Howell AH. Central obesity and breast cancer risk: a systematic review. Obes Rev 2003;4(3):157-173.

(19) Michels KB, Solomon CG, Hu FB et al. Type 2 diabetes and subsequent incidence of breast cancer in the Nurses' Health Study. Diabetes Care 2003;26(6):1752-1758.

(20) de WF, Baanders-van Halewijn EA. A prospective study in general practice on breastcancer risk in postmenopausal women. Int J Cancer 1974;14(2):153-160.

(21) Mink PJ, Shahar E, Rosamond WD, Alberg AJ, Folsom AR. Serum insulin and glucose levels and breast cancer incidence: the atherosclerosis risk in communities study. Am J Epidemiol 2002;156(4):349-352.

(22) Tornberg SA, Holm LE, Carstensen JM. Breast cancer risk in relation to serum cholesterol, serum beta-lipoprotein, height, weight, and blood pressure. Acta Oncol $1988 ; 27(1): 31-37$.

(23) Soler M, Chatenoud L, Negri E, Parazzini F, Franceschi S, La VC. Hypertension and hormone-related neoplasms in women. Hypertension 1999;34(2):320-325.

(24) Largent JA, McEligot AJ, Ziogas A et al. Hypertension, diuretics and breast cancer risk. J Hum Hypertens 2006;20(10):727-732.

(25) Llaverias G, Danilo C, Mercier I et al. Role of cholesterol in the development and progression of breast cancer. Am J Pathol 2011;178(1):402-412.

(26) Gerber M, Cavallo F, Marubini E et al. Liposoluble vitamins and lipid parameters in breast cancer. A joint study in northern Italy and southern France. Int J Cancer 1988;42(4):489-494.

(27) Alexopoulos CG, Blatsios B, Avgerinos A. Serum lipids and lipoprotein disorders in cancer patients. Cancer 1987;60(12):3065-3070.

(28) Larsson SC, Mantzoros CS, Wolk A. Diabetes mellitus and risk of breast cancer: a metaanalysis. Int J Cancer 2007;121(4):856-862. 
(29) Goodman MT, Cologne JB, Moriwaki H, Vaeth M, Mabuchi K. Risk factors for primary breast cancer in Japan: 8-year follow-up of atomic bomb survivors. Prev Med 1997;26(1):144-153.

(30) Weiderpass E, Gridley G, Persson I, Nyren O, Ekbom A, Adami HO. Risk of endometrial and breast cancer in patients with diabetes mellitus. Int J Cancer 1997;71(3):360-363.

(31) Wideroff L, Gridley G, Mellemkjaer L et al. Cancer incidence in a population-based cohort of patients hospitalized with diabetes mellitus in Denmark. J Natl Cancer Inst 1997;89(18):1360-1365.

(32) Jee SH, Ohrr H, Sull JW, Yun JE, Ji M, Samet JM. Fasting serum glucose level and cancer risk in Korean men and women. JAMA 2005;293(2):194-202.

(33) Boyle P, Boniol M, Koechlin A et al. Diabetes and breast cancer risk: a meta-analysis. $\mathrm{Br}$ J Cancer 2012;107(9):1608-1617.

(34) Morimoto LM, White E, Chen Z et al. Obesity, body size, and risk of postmenopausal breast cancer: the Women's Health Initiative (United States). Cancer Causes Control 2002;13(8):741-751.

(35) World Cancer Research Fund. Food, Nutrition, Physical Activity, and the Prevention of Cancer: a Global Perspective. 2nd ed. Washington, USA: American Institute for Cancer Research; 2007.

(36) Ursin G, Longnecker MP, Haile RW, Greenland S. A meta-analysis of body mass index and risk of premenopausal breast cancer. Epidemiology 1995;6(2):137-141.

(37) Pathak DR, Whittemore AS. Combined effects of body size, parity, and menstrual events on breast cancer incidence in seven countries. Am J Epidemiol 1992;135(2):153-168.

(38) Peacock SL, White E, Daling JR, Voigt LF, Malone KE. Relation between obesity and breast cancer in young women. Am J Epidemiol 1999;149(4):339-346.

(39) Manjer J, Kaaks R, Riboli E, Berglund G. Risk of breast cancer in relation to anthropometry, blood pressure, blood lipids and glucose metabolism: a prospective study within the Malmo Preventive Project. Eur J Cancer Prev 2001;10(1):33-42.

(40) Peeters PH, van Noord PA, Hoes AW, Fracheboud J, Gimbrere CH, Grobbee DE. Hypertension and breast cancer risk in a 19-year follow-up study (the DOM cohort). Diagnostic investigation into mammarian cancer. J Hypertens 2000;18(3):249-254.

(41) Agurs-Collins T, Kim KS, Dunston GM, Adams-Campbell LL. Plasma lipid alterations in African-American women with breast cancer. J Cancer Res Clin Oncol 1998;124(34):186-190.

(42) Ha M, Sung J, Song YM. Serum total cholesterol and the risk of breast cancer in postmenopausal Korean women. Cancer Causes Control 2009;20(7):1055-1060. 
(43) Agnoli C, Berrino F, Abagnato CA et al. Metabolic syndrome and postmenopausal breast cancer in the ORDET cohort: a nested case-control study. Nutr Metab Cardiovasc Dis 2010;20(1):41-48.

(44) Beaulieu LM, Whitley BR, Wiesner TF et al. Breast cancer and metabolic syndrome linked through the plasminogen activator inhibitor-1 cycle. Bioessays 2007;29(10):10291038.

(45) Bjorge T, Lukanova A, Jonsson $\mathrm{H}$ et al. Metabolic syndrome and breast cancer in the mecan (metabolic syndrome and cancer) project. Cancer Epidemiol Biomarkers Prev 2010;19(7):1737-1745.

(46) Capasso I, Esposito E, Pentimalli F et al. Metabolic syndrome affects breast cancer risk in postmenopausal women: National Cancer Institute of Naples experience. Cancer Biol Ther 2011;10(12):1240-1243.

(47) Healy LA, Ryan AM, Carroll P et al. Metabolic syndrome, central obesity and insulin resistance are associated with adverse pathological features in postmenopausal breast cancer. Clin Oncol (R Coll Radiol ) 2010;22(4):281-288.

(48) Kabat GC, Kim M, Chlebowski RT et al. A longitudinal study of the metabolic syndrome and risk of postmenopausal breast cancer. Cancer Epidemiol Biomarkers Prev 2009;18(7):2046-2053.

(49) Maiti B, Kundranda MN, Spiro TP, Daw HA. The association of metabolic syndrome with triple-negative breast cancer. Breast Cancer Res Treat 2010;121(2):479-483.

(50) Porto LA, Lora KJ, Soares JC, Costa LO. Metabolic syndrome is an independent risk factor for breast cancer. Arch Gynecol Obstet 2011;284(5):1271-1276.

(51) Ronco AL, De SE, Deneo-Pellegrini H, Quarneti A. Diabetes, overweight and risk of postmenopausal breast cancer: a case-control study in Uruguay. Asian Pac J Cancer Prev 2012;13(1):139-146.

(52) Rose DP, Haffner SM, Baillargeon J. Adiposity, the metabolic syndrome, and breast cancer in African-American and white American women. Endocr Rev 2007;28(7):763777.

(53) Sinagra D, Amato C, Scarpilta AM et al. Metabolic syndrome and breast cancer risk. Eur Rev Med Pharmacol Sci 2002;6(2-3):55-59.

(54) Vona-Davis L, Howard-McNatt M, Rose DP. Adiposity, type 2 diabetes and the metabolic syndrome in breast cancer. Obes Rev 2007;8(5):395-408.

(55) Xue F, Michels KB. Diabetes, metabolic syndrome, and breast cancer: a review of the current evidence. Am J Clin Nutr 2007;86(3):s823-s835. 
(56) Esposito K, Chiodini P, Colao A, Lenzi A, Giugliano D. Metabolic syndrome and risk of cancer: a systematic review and meta-analysis. Diabetes Care 2012;35(11):2402-2411.

(57) Rose DP, Komninou D, Stephenson GD. Obesity, adipocytokines, and insulin resistance in breast cancer. Obes Rev 2004;5(3):153-165.

(58) Liao S, Li J, Wei W et al. Association between diabetes mellitus and breast cancer risk: a meta-analysis of the literature. Asian Pac J Cancer Prev 2011;12(4):1061-1065.

(59) Giovannucci E, Harlan DM, Archer MC et al. Diabetes and cancer: a consensus report. Diabetes Care 2010;33(7):1674-1685.

(60) Jarde T, Perrier S, Vasson MP, Caldefie-Chezet F. Molecular mechanisms of leptin and adiponectin in breast cancer. Eur J Cancer 2011;47(1):33-43.

(61) Bosco JLF. Selected medications, cardiometabolic risk factors, and breast cancer risk. 2011.

(62) Inoue M, Noda M, Kurahashi N et al. Impact of metabolic factors on subsequent cancer risk: results from a large-scale population-based cohort study in Japan. Eur J Cancer Prev 2009; 18(3):240-247.

(63) Russo A, Autelitano M, Bisanti L. Metabolic syndrome and cancer risk. Eur J Cancer 2008;44(2):293-297.

(64) Glass G, McGaw B, Smith ML. Meta-analysis in social research. Sage Publications; 1981.

(65) Cohen J. Weighted kappa: nominal scale agreement with provision for scaled disagreement or partial credit. Psychol Bull 1968;70(4):213-220.

(66) Vandenbroucke JP, Von EE, Altman DG et al. Strengthening the reporting of observational studies in epidemiology (STROBE): explanation and elaboration. Gac Sanit 2009;23(2):158.

(67) DerSimonian R, Laird N. Meta-analysis in clinical trials. Control Clin Trials 1986;7(3):177-188.

(68) COCHRAN WG. Research techniques in the study of human beings. Milbank Mem Fund $Q 1955 ; 33(2): 121-136$.

(69) Higgins JP, Thompson SG. Quantifying heterogeneity in a meta-analysis. Stat Med 2002;21(11):1539-1558.

(70) Duval S, Tweedie R. Trim and fill: A simple funnel-plot-based method of testing and adjusting for publication bias in meta-analysis. Biometrics 2000;56(2):455-463. 
(71) Rosenthal R. The "file drawer problem" and tolerance for null results. Psychological Bulletin 1979;86(3):638-641.

(72) Borenstein M, Hedges L, Higgins J, Rothstein H. Comprehensive Meta Analysis Version 2. Englewood, NJ: Biostat; 2005.

(73) Brunet J, Vazquez-Martin A, Colomer R, Grana-Suarez B, Martin-Castillo B, Menendez JA. BRCA1 and acetyl-CoA carboxylase: the metabolic syndrome of breast cancer. $\mathrm{Mol}$ Carcinog 2008;47(2):157-163.

(74) Bugianesi E. Review article: steatosis, the metabolic syndrome and cancer. Aliment Pharmacol Ther 2005;22 Suppl 2:40-43.

(75) Conroy SM, Butler LM, Harvey D et al. Metabolic syndrome and mammographic density: the Study of Women's Health Across the Nation. Int J Cancer 2011;129(7):16991707.

(76) Furberg AS, Veierod MB, Wilsgaard T, Bernstein L, Thune I. Serum high-density lipoprotein cholesterol, metabolic profile, and breast cancer risk. J Natl Cancer Inst 2004;96(15):1152-1160.

(77) Furberg AS, Jasienska G, Bjurstam N et al. Metabolic and hormonal profiles: HDL cholesterol as a plausible biomarker of breast cancer risk. The Norwegian EBBA Study. Cancer Epidemiol Biomarkers Prev 2005;14(1):33-40.

(78) Kuhl H. Breast cancer risk in the WHI study: the problem of obesity. Maturitas 2005;51(1):83-97.

(79) Oh SW, Park CY, Lee ES et al. Adipokines, insulin resistance, metabolic syndrome, and breast cancer recurrence: a cohort study. Breast Cancer Res 2011;13(2):R34.

(80) Okobia MN, Bunker CH, Zmuda JM et al. Anthropometry and breast cancer risk in Nigerian women. Breast J 2006;12(5):462-466.

(81) Wysocki PJ, Wierusz-Wysocka B. Obesity, hyperinsulinemia and breast cancer: novel targets and a novel role for metformin. Expert Rev Mol Diagn 2010;10(4):509-519.

(82) Yang CY, Peng CY, Liu YC, Chen WZ, Chiou WK. Surface anthropometric indices in obesity-related metabolic diseases and cancers. Chang Gung Med J 2011;34(1):1-22.

(83) Antoniadis AG, Petridou ET, Antonopoulos $\mathrm{CN}$ et al. Insulin resistance in relation to melanoma risk. Melanoma Res 2011;21(6):541-546.

(84) Arends J. Metabolism in cancer patients. Anticancer Res 2010;30(5):1863-1868.

(85) Carroll PA, Healy L, Lysaght J et al. Influence of the metabolic syndrome on leptin and leptin receptor in breast cancer. Mol Carcinog 2011;50(8):643-651. 
(86) Doyle SL, Donohoe CL, Lysaght J, Reynolds JV. Visceral obesity, metabolic syndrome, insulin resistance and cancer. Proc Nutr Soc 2012;71(1):181-189.

(87) Gaudet MM, Falk RT, Gierach GL et al. Do adipokines underlie the association between known risk factors and breast cancer among a cohort of United States women? Cancer Epidemiol 2010;34(5):580-586.

(88) Harris HR, Willett WC, Terry KL, Michels KB. Body fat distribution and risk of premenopausal breast cancer in the Nurses' Health Study II. J Natl Cancer Inst 2011;103(3):273-278.

(89) Heidemann C, Boeing H, Pischon T, Nothlings U, Joost HG, Schulze MB. Association of a diabetes risk score with risk of myocardial infarction, stroke, specific types of cancer, and mortality: a prospective study in the European Prospective Investigation into Cancer and Nutrition (EPIC)-Potsdam cohort. Eur J Epidemiol 2009;24(6):281-288.

(90) Liu LN, Miaskowski C, Wang JS, Chen SC, Chen ML. Accuracy of body mass index to determine obesity in women with breast cancer: an observational study of Taiwanese sample. Int J Nurs Stud 2010;47(8):994-1000.

(91) Ness KK, Oakes JM, Punyko JA, Baker KS, Gurney JG. Prevalence of the metabolic syndrome in relation to self-reported cancer history. Ann Epidemiol 2005;15(3):202-206.

(92) Papaioannou S, Tzafettas J. Anovulation with or without PCO, hyperandrogenaemia and hyperinsulinaemia as promoters of endometrial and breast cancer. Best Pract Res Clin Obstet Gynaecol 2010;24(1):19-27.

(93) Pasanisi P, Berrino F, De PM, Venturelli E, Mastroianni A, Panico S. Metabolic syndrome as a prognostic factor for breast cancer recurrences. Int J Cancer 2006;119(1):236-238.

(94) Rinaldi S, Key TJ, Peeters PH et al. Anthropometric measures, endogenous sex steroids and breast cancer risk in postmenopausal women: a study within the EPIC cohort. Int $J$ Cancer 2006;118(11):2832-2839.

(95) Stoll BA. Timing of weight gain in relation to breast cancer risk. Ann Oncol 1995;6(3):245-248.

(96) Pollak M. Insulin, insulin-like growth factors and neoplasia. Best Pract Res Clin Endocrinol Metab 2008;22(4):625-638.

(97) Chesney ET, Davis SC, Duggan L, Natarajan S. Does metabolic syndrome increase risk for certain cancers? American Journal for Nurse Practitioners 2010;14(4):25-32.

(98) Ahmed-Saucedo RL. Preview Epidemiological associations of metabolic factors with cancer risk and cancer late effects 2006. 
(99) Conroy SM. Physical activity, metabolic syndrome and insulin resistance in relation to mammographic density 2009.

(100) Ibarra-Mejia G. Exogenous environmental factors and susceptibility for breast cancer in Mexican American women 2005.

(101) Pichard C, Plu-Bureau, Neves-E Castro, Gompel A. Insulin resistance, obesity and breast cancer risk. Maturitas 2008;60(1):19-30.

(102) Stephenson GD, Rose DP. Breast cancer and obesity: an update. Nutr Cancer 2003;45(1):1-16.

(103) Goodman-Gruen D, Barrett-Connor E. Sex hormone-binding globulin and glucose tolerance in postmenopausal women. The Rancho Bernardo Study. Diabetes Care 1997;20(4):645-649.

(104) Sherif K, Kushner H, Falkner BE. Sex hormone-binding globulin and insulin resistance in African-American women. Metabolism 1998;47(1):70-74.

(105) Cikim AS, Ozbey N, Sencer E, Molvalilar S, Orhan Y. Associations among sex hormone binding globulin concentrations and characteristics of the metabolic syndrome in obese women. Diabetes Nutr Metab 2004;17(5):290-295.

(106) Hajamor S, Despres JP, Couillard C et al. Relationship between sex hormone-binding globulin levels and features of the metabolic syndrome. Metabolism 2003;52(6):724-730.

(107) Vona-Davis L, Rose DP. Adipokines as endocrine, paracrine, and autocrine factors in breast cancer risk and progression. Endocr Relat Cancer 2007;14(2):189-206.

(108) Klein S, Coppack SW, Mohamed-Ali V, Landt M. Adipose tissue leptin production and plasma leptin kinetics in humans. Diabetes 1996;45(7):984-987.

(109) Fischer S, Hanefeld M, Haffner SM et al. Insulin-resistant patients with type 2 diabetes mellitus have higher serum leptin levels independently of body fat mass. Acta Diabetol 2002;39(3):105-110.

(110) Wauters M, Considine RV, Yudkin JS, Peiffer F, De L, I, Van Gaal LF. Leptin levels in type 2 diabetes: associations with measures of insulin resistance and insulin secretion. Horm Metab Res 2003;35(2):92-96.

(111) Franks PW, Brage S, Luan J et al. Leptin predicts a worsening of the features of the metabolic syndrome independently of obesity. Obes Res 2005;13(8):1476-1484.

(112) Chu MC, Cosper P, Orio F, Carmina E, Lobo RA. Insulin resistance in postmenopausal women with metabolic syndrome and the measurements of adiponectin, leptin, resistin, and ghrelin. Am J Obstet Gynecol 2006;194(1):100-104. 
(113) Somasundar P, McFadden DW, Hileman SM, Vona-Davis L. Leptin is a growth factor in cancer. J Surg Res 2004;116(2):337-349.

(114) Scheid MP, Sweeney G. The role of adiponectin signaling in metabolic syndrome and cancer. Rev Endocr Metab Disord 2013.

(115) Panno ML, Salerno M, Pezzi V et al. Effect of oestradiol and insulin on the proliferative pattern and on oestrogen and progesterone receptor contents in MCF-7 cells. J Cancer Res Clin Oncol 1996;122(12):745-749.

(116) Plymate SR, Matej LA, Jones RE, Friedl KE. Inhibition of sex hormone-binding globulin production in the human hepatoma (Hep G2) cell line by insulin and prolactin. J Clin Endocrinol Metab 1988;67(3):460-464.

(117) Gregoire G, Derderian F, Le LJ. Selecting the language of the publications included in a meta-analysis: is there a Tower of Babel bias? J Clin Epidemiol 1995;48(1):159-163. 


\section{Tables and Figures}

The working tables and figures can be found in Appendix A. 
CHAPTER 3. ASSOCIATION BETWEEN INDIVIDUAL AND COMBINED METABOLIC RISK FACTORS AND CANCER RISK 


\subsection{Abstract}

\section{Introduction}

Cancer is the second most common cause of death in the United States. A third of the cancer burden is estimated to be associated with metabolic risk factors (MRFs), such as obesity, high blood glucose, hypertension, and dyslipidemia. However, studies have shown inconsistent results for the association between these MRFs and cancer risk. The aim of this study was to examine whether MRFs, either individually or in combination, were associated with the subsequent risk of overall and selected site-specific cancers of the breast, digestive system, and lung.

\section{Methods}

Data were derived from the NHANES I Epidemiologic Follow-up Study, and comprised participants ages 25 to 74 years at baseline. Multivariable Cox proportional hazards regression models were fitted to assess the association between individual and combined MRFs (obesity, high blood pressure, high total serum cholesterol, and diabetes) and cancer incidence. Analyses were adjusted for age, race, education, family income, physical activity, smoking status, and family history of cancer, and stratified by age and gender. All analyses incorporated the complex sample design and sample weights in order to generate national estimates.

\section{Results}

Diabetes, high BP, and the presence of a combination of three or four MRFs were associated with higher breast cancer risk among postmenopausal women. Obesity in males less than 50 years of age elevated the risk of digestive cancer.

\section{Conclusion}


In this large, prospective cohort study, MRFs, either individually or aggregated, were not consistently associated with cancer risk in either men or women. The association of individual and combined MRFs was stronger with postmenopausal breast cancer risk. 


\subsection{Introduction}

The "plague of our generation," cancer is the second most common cause of death in the United States. The American Cancer Society estimates 1.7 million new cancer cases in $2013 .^{2}$ Cancer incidence rates per 100,000 persons (age-adjusted to the 2000 US standard population) for 1995-2009 were 550.7 and 419.3 for males and females, respectively. ${ }^{2}$

Lifestyle factors, such as diet, obesity, physical activity, and smoking, play a significant role in carcinogenesis. Approximately half of the cancer burden can be prevented or significantly reduced by modifying lifestyle factors. ${ }^{3,4}$ Lifestyle factors can generate metabolic abnormalities that include overweight and obesity, and high blood pressure, cholesterol, and blood glucose.

Each of the aforementioned abnormalities has been separately implicated as a metabolic risk factor (MRF) for cancer. ${ }^{5-25}$ Comprehensive reviews provide adequate evidence of an association between obesity and several cancers in both men and women. ${ }^{14,15,17,18,26-28}$ Similarly, epidemiologic studies and reviews show that individuals with diabetes are at a higher

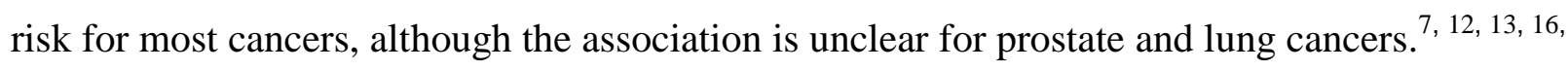
19, 29-32 Elevated blood pressure is also associated with several cancers, although the results are inconsistent across studies. ${ }^{7,10,25}$ Results for the association between total serum cholesterol and cancer are similarly inconclusive. ${ }^{33}$

Research indicates that the risk for heart disease and stroke increases with number of MRFs. ${ }^{34,35}$ A few studies have also indicated a similar pattern of increased risk for certain types of cancer from combined MRFs. ${ }^{6-10,20-23,36-38}$ A combination of three or more of the MRFs is generally termed as metabolic syndrome. ${ }^{39}$ It is estimated to be prevalent in a third of US adults. ${ }^{40}$ A meta-analysis on risk of various cancers found that metabolic syndrome elevated the risk for liver, colon, colorectal, pancreatic, thyroid, rectal, bladder, and prostate cancers in men, 
and endometrial, pancreatic, breast, rectal, liver, colorectal, colon, and ovarian cancers in women. ${ }^{6}$

Each individual MRF can promote cancer through an independent biological mechanism. In turn, these mechanisms can complement each other, and act additively to promote cancer development. MRFs, functioning through various mechanisms, including increased inflammatory markers, such as tumor necrosis factor-alpha and interleuken-6, increased adipokines such as leptin, and decreased adiponectin, increased levels of free fatty acids and triglycerides, insulin resistance, increased insulin-like growth factor-1, and increased oxidative stress, can cause angiogenesis, cell migration, mitogenesis, and DNA damage. ${ }^{41-43}$

The prevalence of MRFs is high, and continues to rise. ${ }^{44}$ At the same time, there is epidemiologic evidence of the association of MRFs with several cancers. Moreover, there are few animal studies supporting the biological role of MRFs in cancer development and progression. However, results from studies examining the association between individual and combined MRFs and overall cancer are inconsistent. Therefore, this study examined the association of MRFs (obesity, high blood pressure, high total serum cholesterol, and diabetes), individually and in combination, and subsequent risk of overall and site-specific cancers of the breast, digestive system, and lung.

\subsection{Methods}

\subsubsection{Data Source and Study Population: Data were derived from the NHANES I} Epidemiologic Follow-up Study (NHEFS). The NHEFS is a national, multi-stage, stratified probability sample of the non-institutionalized, civilian population in the U.S. ${ }^{45}$ It includes participants from the NHANES I (National Health and Nutrition Examination Survey I) cohort aged 25-74 years who completed a medical examination at baseline (1971-75). Participants were 
followed-up in 1982-84, 1986, 1987, and 1992. Only 5\% of the original NHEFS sample was lost through attrition. ${ }^{46}$

Baseline data were acquired by merging five NHANES I datasets on anthropometry, biochemistry, medical history, medical needs, and medical examination. Since the NHEFS follow-up was conducted for participants aged $\geq 25$ years and $\leq 74$ years at the time of NHANES I interview, only this group was retained for the analysis. Cancer status was determined by merging data from each of the 1982-84, 1986, 1987, and 1992 surveys, in addition to the NHEFS vital statistics data.

The status variable, incident cancer cases, was defined using the International Classification of Diseases-9th revision (ICD-9), codes 140-208, excluding ICD-173 (skin cancer), and were followed up through interview and death certificate data. All cancer cases since the baseline period were obtained from the first, second and third diagnoses of cancer, along with their location (cancer-site). Skin cancer cases were not included among total cancer cases, since their etiology is different and does not involve MRFs. For subjects with multiple cancers, only the first occurring non-skin cancer was included. Year of death was used for cancer incidence if a death certificate was the only source of cancer information.

Study participants were considered to be at risk for cancer from their date of first examination until date of diagnosis of cancer, or death, or termination of follow-up, whichever occurred first. Event times were censored for participants who had not developed cancer by the end of follow-up or died from non-cancer causes.

A total of 14,407 persons from the NHANES dataset were followed up until 1993. Of these, 684 had a cancer diagnosis at baseline (determined from the question: Has a doctor ever told you that you have malignant tumor or growth?) or who died in the same year of examination 
and were excluded from analysis. In order to reduce the possibility of reverse causation, another 146 who developed cancer in the first two years of the study were excluded from analysis. Participants with missing values on cancer status $(n=2,310)$, and on the covariates in the multivariable model $(n=573)$ were also excluded from the analysis. The final sample was 10,694 persons who were cancer-free at the beginning of their study period.

Information on the following predictor variables was obtained from the baseline examination: obesity, assessed as body mass index in $\mathrm{kg} / \mathrm{m}^{2}$; resting systolic (SBP) and diastolic (DBP) blood pressure, measured as continuous variables in $\mathrm{mmHg}$; total serum cholesterol, measured as continuous variable in $\mathrm{mg} / \mathrm{dL}$; and self-reported diabetes, coded as a dichotomous variable. Resting SBP and DBP were measured by a physician using a sphygmomanometer at the beginning of the physical examination while the subject was in a sitting position, as consistent with American Heart Association guidelines. ${ }^{47}$ All of these readings were retrieved from NHANES I medical exam questionnaire. Total serum cholesterol was assessed using a semiautomated instrument in the Centers for Disease Control and Prevention's lipid standardization laboratory. Information on diabetes was gathered from NHANES I medical history questionnaire (Has a doctor ever told you had diabetes?) or from NHANES I healthcare needs questionnaire (Did a doctor tell you had diabetes? or, do you take any diabetes medicine or insulin?).

Analyses were adjusted for the following potentially confounding variables: age, race, education, family income, physical activity, smoking status, and family history of cancer. The baseline medical history questionnaire provided information on age, race, education, family income, and physical activity. At baseline, information on smoking status was very limited, and information on family history of cancer was not collected. Therefore, smoking information was 
combined from the baseline and 1982 surveys, and information on family history of cancer was derived from the latter survey. ${ }^{48-51}$

\subsubsection{Statistical analysis}

Multivariable Cox proportional hazards regression models, with time since measurement as the time variable, and incident cancer cases as study events, were fitted to obtain hazard ratios of cancer incidence from MRFs. The model accounted for differential entry and exit times among the NHEFS participants. A time-interaction test was conducted with individual and combined MRFs in the full model with overall cancer to check whether the assumption of proportionality of hazard ratios over time was met.

Metabolic risk factors were classified as: (1) obesity: BMI $\geq 30 \mathrm{~kg} / \mathrm{m}^{2}$; (2) high blood pressure: systolic $\mathrm{BP} \geq 140 \mathrm{~mm} / \mathrm{Hg}$ and/or diastolic $\mathrm{BP} \geq 90 \mathrm{~mm} / \mathrm{Hg}$ ); (3) high cholesterol: total serum cholesterol $\geq 240 \mathrm{mg} / \mathrm{dL}$; and (4) diabetes: presence or absence of diabetes. The effect of individual MRF was assessed relative to the absence of that risk factor.

Analyses were adjusted for the following potential confounding variables: age, sex, race (white versus other), education (high school or less vs. above high school), family income $(<\$ 5,000, \$ 5,000$ to $<\$ 15,000$, and $>=\$ 15,000$, based on the poverty line for $1971-75$, which was set at or below $\$ 5,000$ as the annual income for a household of four members), physical activity (moderately active or very active vs. quite inactive), smoking (smoked 100 cigarettes in one's lifetime), and family history of cancer (dichotomous). In the NHANES I dataset, race was classified as white, black, or other at baseline. However, for this study, the latter two categories were combined and classified as nonwhite due to small numbers. ${ }^{48}$

Age was included in all models as an independent, continuous variable. In addition, analyses were further stratified by age categorized as $<50$ and $\geq 50$ years as at baseline. The 
rationale for this dichotomization was based on previous research that showed that adults 50 years and older bear the greatest cancer burden, with the largest proportion of cancer being diagnosed in this age group. ${ }^{52}$ Another consideration was the biological changes, especially in women, which occur around age 50. In addition to age, analyses were also stratified by gender. Besides examining the association between individual MRFs and cancer risk, a second analysis assessed the combined effect of MRFs on the risk of overall cancer. An additive summary of MRF scores was created by combining the individual MRFs. A score of three was assigned to participants with three or more MRFs. The summary score ranged from 0 (no MRF, the referent category) to 3 (three or four risk factors). Analyses were adjusted for the following potential confounders; age, race, education, family income, physical activity, smoking, and family history of cancer, and stratified by gender and dichotomized age.

Site-specific cancer (breast, digestive, and lung) were examined separately in evaluating an association between individual MRFs as well as the combined MRF score, and cancer risk. Cancers of the digestive system included those of the alimentary canal below the neck (i.e., esophagus, stomach, small and large intestines) and key digestive organs (i.e., pancreas, liver, and gallbladder).

In order to test the robustness of results, three different sensitivity analyses were conducted. Analysis one included all years of cancer incidence data after the baseline exam; analysis two excluded persons with missing data for diabetes; and analysis three was conducted with continuous variables for BMI, BP, and cholesterol.

All data were analyzed using the complex samples module in IBM SPSS Statistics for Windows, version 21.0 (Armonk, NY: IBM Corp). These analyses incorporated the complex sample design and sample weights in order to produce national estimates. ${ }^{53}$ 


\subsection{Results}

Time-interaction test with individual and combined MRFs in the full model with overall cancer showed that the assumption of proportional hazards was not violated in the Cox proportional hazards regression analyses. Table 1 presents the baseline characteristics of the study population, incorporating the sampling weights and design specifications. Mean age at baseline was 48.8 years. Among 10,694 persons followed-up between 1971 and 1993, 59\% were female, and most were white. Over a quarter of the sample had an annual family income below poverty level, and about three quarters had an education less than college. Most participants reported being moderately or very active in their non-recreational activity, and over half had smoked at least 100 cigarettes during their lifetime. A third of the participants reported having a family history of cancer. About $16.6 \%$ were obese, a little less than half had high BP, a third had high cholesterol, and half of the sample had one or more MRFs.

Tables 2 and 3 present the association between individual MRFs and cancer risk among males and females, respectively, after adjusting for potential confounding factors, and stratifying by age. Individual MRFs were not significantly associated with cancer risk in males in the multivariable Cox proportional hazards regression analyses, after controlling for age, race, education, family income, physical activity, smoking, and family history (Table 2). A decreased risk of overall cancer was observed among obese women 50 years of age and older (Table 3). High total cholesterol elevated the risk of overall cancer in older women. No association was observed in either gender between combined MRFs and overall cancer risk (Tables 4 and 5).

Tables 6 and 7 present the association of individual and combined MRFs respectively with breast cancer risk in all women and postmenopausal women. High BP, diabetes, and presence of a combination of three or four MRFs were associated with elevated breast cancer 
risk in postmenopausal women. Obesity in males elevated the risk of digestive cancer (Table 8). Presence of a single MRF in women was associated with reduced risk of digestive cancer (Table 9). There was no association of MRFs with lung cancer in either gender (Tables 10 and 11).

Results were consistent with the main analysis in all sensitivity analyses. However, two associations in the main analysis (high cholesterol with increased overall cancer risk, and obesity with reduced overall cancer risk in older women) were not observed in other sensitivity analyses.

\subsection{Discussion}

In this large, prospective cohort study, MRFs, either individually or in the aggregate, were not consistently associated with cancer risk in either gender. Overall, diabetes, high BP, and the presence of a combination of three or four MRFs were associated with higher breast cancer risk among postmenopausal women. Obesity in males less than 50 elevated the risk of digestive cancer.

Study results show an association between diabetes and increased risk of breast cancer in postmenopausal women. A meta-analysis on diabetes and breast cancer showed that among postmenopausal women, diabetes was associated with a $16 \%$ increased risk of breast cancer. ${ }^{16}$ Similarly, another recent meta-analysis showed a significant positive association of high blood pressure and high glucose/diabetes with postmenopausal breast cancer. ${ }^{8}$ Diabetes is frequently associated with insulin resistance, increased circulating concentrations of insulin, and insulin-like growth factors. Studies have shown insulin has mitogenic effects on breast tissue. ${ }^{54}$ In addition, insulin inhibits the production of sex hormone-binding globulin, resulting in an increase in bioavailable estradiol. Increased estradiol levels have been associated with the risk of developing breast cancer. $^{16,55}$ 
The finding that postmenopausal women with high BP were at an increased risk of breast cancer is also supported by the recent meta-analysis on breast cancer risk in postmenopausal women. ${ }^{8}$ Cancer and hypertension are both characterized by the proliferation of smooth muscle cells. ${ }^{56}$ Another hypothesis indicates abnormalities of carcinogen binding to DNA in lymphocytes of hypertensive women. ${ }^{57}$

The results showed a decreased risk of overall cancer from obesity, and an elevated risk from high total cholesterol in women 50 years of age or older. However, in the sensitivity analyses, these two results were not supported. Epidemiologic evidence suggests obesity is associated with increased risk of site-specific cancers in women, such as cancers of postmenopausal breast, esophagus, pancreas, endometrium, ovary, thyroid, and kidney. 5, 15, 58-60 The question regarding the association between total cholesterol and cancer risk remains unresolved in literature. ${ }^{61}$

When combined MRFs were examined, postmenopausal women with three or four MRFs were observed to be at a higher risk of breast cancer. A recent meta-analysis showed that the combined effect of MRFs on increased risk for postmenopausal breast cancer was greater than that of individual MRFs. ${ }^{8}$ A combination of MRFs may activate different molecular pathways through metabolic, endocrine, and immune cell changes, which can result in breast tumorigenesis. $^{62}$

Among men, the only significant association observed was between obesity and elevated risk of digestive cancer. Other studies have also observed a similar association between overweight/ obesity and digestive cancers, such as pancreatic ${ }^{63,64}$ and colorectal cancers ${ }^{30}$ in men. There is also an elevated risk of adenocarcinoma of the esophagus and gastric cardia with increasing BMI. ${ }^{65}$ In obese persons, there is an increase in free fatty acids, cytokines, and 
hormones, resulting in increased insulin levels and insulin-like growth factor. High levels of insulin or insulin-like growth factors can promote digestive cancers by promoting cellular proliferation and inhibiting apoptosis. ${ }^{63}$

Several complex biological mechanisms have been proposed to show that MRFs promote carcinogenesis. The prevalence of hyper-insulinemia and insulin resistance is higher in obese individuals. Hyper-insulinemia reduces the production of insulin-like growth factor (IGF) protein, resulting in increased bioavailability of IGF- $1 .^{30}$ IGF-1 may promote tumor development by stimulating cell proliferation and inhibiting apoptosis. Increased circulating insulin can reduce the levels of sex-hormone-binding-globulin, thereby increasing endogenous sex-steroid levels. ${ }^{30}$ Breast, endometrial, and colorectal cancers may be affected by this mechanism. ${ }^{66}$ Another carcinogenic mechanism involves cytokines. Increased adiposity raises cytokine production in obese women, which in turn can induce estradiol production. ${ }^{41}$ Estradiol is a strong growth factor for breast and endometrial cancers. Leptin, another adipocyte-specific hormone, is directly related to adiposity and insulin resistance. It has direct stimulatory effects on cancer cells and may serve as an important link between obesity and carcinogenesis. ${ }^{41}$

Study results show the association of MRFs with overall and site-specific cancers varies by gender. These differences in the association between MRFs and cancer can arise for several reasons. Animal studies suggest that production of a protein, interleukin-6, which promotes inflammation, is linked to a higher incidence of liver cancer in men than in women. ${ }^{67}$

The current study has several potential limitations. For example, blood glucose levels were not measured directly, but rather, a self-reported diagnosis of diabetes indexed high levels. In addition, while total serum cholesterol levels were measured directly, there were no separate measures for triglycerides, or low and high-density lipoprotein cholesterol levels (LDL and 
HDL). This may be important, since previous research has shown that high HDL may be inversely associated with site-specific and overall cancer. ${ }^{6}$ However, a systematic review with meta-analysis showed no association between triglyceride or HDL levels and such site-specific cancers as colorectal cancer. ${ }^{9}$ Although models were adjusted for race, stratified analysis could not be performed due to small sample size for races other than white. For this reason, nonwhite were combined into one category, although studies have observed racial differences in MRFs. ${ }^{69}$ Analyses on lung and digestive cancer could not be stratified by age because of small number of cancer cases.

This study has several strengths. For example, data were derived using a strong longitudinal cohort study design with high follow-up rates. Specifically, 96\% of the study population was successfully traced at some point through the 1992 follow-up. ${ }^{46}$ It is a large, nationally representative sample of the US population. All analyses utilized complex sample survey design for results representative of the population. In addition, self-report bias tended to be minimized because MRFs, such as total serum cholesterol, as well as blood pressure and anthropometry (BMI), were based on body measurements and laboratory data.

In conclusion, MRFs, either individually or in the aggregate, were not consistently associated with cancer risk in either gender in this large, prospective cohort study. The association of individual and combined MRFs was stronger with postmenopausal breast cancer risk. 


\section{Reference List}

(1) Mukherjee S. The Emperor of All Maladies: A Biography of Cancer. Scribner; 2010.

(2) American Cancer Society. Cancer facts and figures 2013. Atlanta: American Cancer Society; 2013.

(3) Stein CJ, Colditz GA. Modifiable risk factors for cancer. Br J Cancer 2004;90(2):299303.

(4) Colditz G, DeJong D, Hunter D, Trichopoulos D, Willett W. Harvard report on cancer: Causes of human cancer. Cancer Causes Control 1996;7:1-59.

(5) Carmichael AR, Bates T. Obesity and breast cancer: a review of the literature. Breast 2004;13(2):85-92.

(6) Esposito K, Chiodini P, Colao A, Lenzi A, Giugliano D. Metabolic syndrome and risk of cancer: a systematic review and meta-analysis. Diabetes Care 2012;35(11):2402-2411.

(7) Esposito K, Chiodini P, Capuano A, Bellastella G, Maiorino MI, Giugliano D. Metabolic syndrome and endometrial cancer: a meta-analysis. Endocrine 2013.

(8) Esposito K, Chiodini P, Capuano A et al. Metabolic syndrome and postmenopausal breast cancer: systematic review and meta-analysis. Menopause 2013.

(9) Esposito K, Chiodini P, Capuano A et al. Colorectal cancer association with metabolic syndrome and its components: a systematic review with meta-analysis. Endocrine 2013.

(10) Esposito K, Chiodini P, Capuano A et al. Effect of metabolic syndrome and its components on prostate cancer risk: Meta-analysis. J Endocrinol Invest 2013;36(2):132139.

(11) Jee SH, Ohrr H, Sull JW, Yun JE, Ji M, Samet JM. Fasting serum glucose level and cancer risk in Korean men and women. JAMA 2005;293(2):194-202.

(12) Larsson SC, Orsini N, Wolk A. Diabetes mellitus and risk of colorectal cancer: a metaanalysis. J Natl Cancer Inst 2005;97(22):1679-1687.

(13) Larsson SC, Orsini N, Brismar K, Wolk A. Diabetes mellitus and risk of bladder cancer: a meta-analysis. Diabetologia 2006;49(12):2819-2823.

(14) Larsson SC, Wolk A. Overweight, obesity and risk of liver cancer: a meta-analysis of cohort studies. Br J Cancer 2007;97(7):1005-1008.

(15) Larsson SC, Orsini N, Wolk A. Body mass index and pancreatic cancer risk: A metaanalysis of prospective studies. Int J Cancer 2007;120(9):1993-1998. 
(16) Larsson SC, Mantzoros CS, Wolk A. Diabetes mellitus and risk of breast cancer: a metaanalysis. Int J Cancer 2007;121(4):856-862.

(17) Larsson SC, Wolk A. Obesity and colon and rectal cancer risk: a meta-analysis of prospective studies. Am J Clin Nutr 2007;86(3):556-565.

(18) Larsson SC, Wolk A. Obesity and the risk of gallbladder cancer: a meta-analysis. $\mathrm{Br} J$ Cancer 2007;96(9):1457-1461.

(19) Larsson SC, Wolk A. Diabetes mellitus and incidence of kidney cancer: a meta-analysis of cohort studies. Diabetologia 2011;54(5):1013-1018.

(20) Osaki Y, Taniguchi S, Tahara A, Okamoto M, Kishimoto T. Metabolic syndrome and incidence of liver and breast cancers in Japan. Cancer Epidemiol 2012;36(2):141-147.

(21) Rosato V, Bosetti C, Talamini R et al. Metabolic syndrome and the risk of breast cancer in postmenopausal women. Ann Oncol 2011;22(12):2687-2692.

(22) Rosato V, Tavani A, Bosetti C et al. Metabolic syndrome and pancreatic cancer risk: a case-control study in Italy and meta-analysis. Metabolism 2011;60(10):1372-1378.

(23) Siddiqui AA. Metabolic syndrome and its association with colorectal cancer: a review. Am J Med Sci 2011;341(3):227-231.

(24) Stocks T, Lukanova A, Johansson M et al. Components of the metabolic syndrome and colorectal cancer risk; a prospective study. Int J Obes (Lond) 2008;32(2):304-314.

(25) Stocks T, Van HM, Manjer J et al. Blood pressure and risk of cancer incidence and mortality in the Metabolic Syndrome and Cancer Project. Hypertension 2012;59(4):802810.

(26) World Health Organization. IARC Handbook of Cancer Prevention - Weight Control and Physical Activity. World Health Organization; 2002.

(27) World Cancer Research Fund/American Institute for CancerResearch. Food, Nutrition, Physical Activity, and the Prevention of Cancer: a Global Perspective. Washington DC: AICR; 2007.

(28) Renehan AG, Tyson M, Egger M, Heller RF, Zwahlen M. Body-mass index and incidence of cancer: a systematic review and meta-analysis of prospective observational studies. Lancet 2008;371(9612):569-578.

(29) Luo J, Chlebowski R, Liu S et al. Diabetes mellitus as a risk factor for gastrointestinal cancers among postmenopausal women. Cancer Causes Control 2013;24(3):577-585.

(30) Giovannucci E, Harlan DM, Archer MC et al. Diabetes and cancer: a consensus report. Diabetes Care 2010;33(7):1674-1685. 
(31) Shikata K, Ninomiya T, Kiyohara Y. Diabetes mellitus and cancer risk: review of the epidemiological evidence. Cancer Sci 2013;104(1):9-14.

(32) Luo J, Chlebowski R, Wactawski-Wende J, Schlecht NF, Tinker L, Margolis KL. Diabetes and lung cancer among postmenopausal women. Diabetes Care 2012;35(7):1485-1491.

(33) Strohmaier S, Edlinger M, Manjer J et al. Total serum cholesterol and cancer incidence in the Metabolic syndrome and Cancer Project (Me-Can). PLoS One 2013;8(1):e54242.

(34) Grundy SM. Obesity, metabolic syndrome, and cardiovascular disease. J Clin Endocrinol Metab 2004;89(6):2595-2600.

(35) Isomaa B, Almgren P, Tuomi T et al. Cardiovascular morbidity and mortality associated with the metabolic syndrome. Diabetes Care 2001;24(4):683-689.

(36) Chen W, Lu F, Liu SJ et al. Cancer risk and key components of metabolic syndrome: a population-based prospective cohort study in Chinese. Chin Med J (Engl) 2012;125(3):481-485.

(37) Kabat GC, Kim M, Chlebowski RT et al. A longitudinal study of the metabolic syndrome and risk of postmenopausal breast cancer. Cancer Epidemiol Biomarkers Prev 2009;18(7):2046-2053.

(38) Russo A, Autelitano M, Bisanti L. Metabolic syndrome and cancer risk. Eur J Cancer 2008;44(2):293-297.

(39) Grundy SM, Brewer HB, Jr., Cleeman JI, Smith SC, Jr., Lenfant C. Definition of metabolic syndrome: Report of the National Heart, Lung, and Blood Institute/American Heart Association conference on scientific issues related to definition. Circulation 2004;109(3):433-438.

(40) Ervin R. Prevalence of metabolic syndrome among adults 20 years of age and over, by sex, age, race and ethnicity, and body mass index: United States, 2003-2006. National health statistics reports; National Center for Health Statistics. Hyattsville, MD. 2009; 13.

(41) Cowey S, Hardy RW. The metabolic syndrome: A high-risk state for cancer? Am J Pathol 2006;169(5):1505-1522.

(42) Barb D, Williams CJ, Neuwirth AK, Mantzoros CS. Adiponectin in relation to malignancies: a review of existing basic research and clinical evidence. Am J Clin Nutr 2007;86(3):s858-s866.

(43) Legakis I, Syrigos K. Obesity modulation - the role in carcinogenesis. Anticancer Agents Med Chem 2010;10(6):481-490.

(44) Grundy SM. Metabolic syndrome pandemic. Arterioscler Thromb Vasc Biol 2008;28(4):629-636. 
(45) National Center for Health Statistics. National Center for Health Statistics. NHANES I Epidemiologic Followup Study (NHEFS) Public-Use Data Files. 2013.

(46) Cox CS, Mussolino ME, Rothwell ST, et al. Plan and operation of the NHANES I Epidemiologic Followup Study 1992. National Center for Health Statistics; 1997. Report No.: 1 .

(47) Kirkendall WM, Burton AC, Epstein FH, Freis ED. Recommendations for human blood pressure determination by sphygmomanometers. Circulation 1967;36(6):980-988.

(48) Albanes D, Blair A, Taylor PR. Physical activity and risk of cancer in the NHANES I population. Am J Public Health 1989;79(6):744-750.

(49) Schatzkin A, Jones DY, Hoover RN et al. Alcohol consumption and breast cancer in the epidemiologic follow-up study of the first National Health and Nutrition Examination Survey. N Engl J Med 1987;316(19):1169-1173.

(50) Schreinemachers DM, Everson RB. Aspirin use and lung, colon, and breast cancer incidence in a prospective study. Epidemiology 1994;5(2):138-146.

(51) Su LJ, Arab L. Alcohol consumption and risk of colon cancer: evidence from the national health and nutrition examination survey I epidemiologic follow-up study. Nutr Cancer 2004;50(2):111-119.

(52) United States Department of Health and Human Services CfDCaPNCI. National Program of Cancer Registries Early Release Cancer Statistics: 1999-2010, WONDER On-line Database. 2013.

(53) Landis JR, Lepkowski JM, Eklund SA, Stehouwer SA. A statistical methodology for analyzing data from a complex survey: the first National Health and Nutrition Examination Survey. Vital Health Stat 2 1982;(92):1-52.

(54) Michels KB, Solomon CG, Hu FB et al. Type 2 diabetes and subsequent incidence of breast cancer in the Nurses' Health Study. Diabetes Care 2003;26(6):1752-1758.

(55) Vigneri P, Frasca F, Sciacca L, Pandini G, Vigneri R. Diabetes and cancer. Endocr Relat Cancer 2009;16(4):1103-1123.

(56) Xie L, Wu K, Xu N, Chen D, Chen J, Lu S. Hypertension is associated with a high risk of cancer. J Hum Hypertens 1999;13(5):295-301.

(57) Norden A, Schersten B, Thulin T, Pero RW, Bryngelsson C, Mitelman F. Letter: Hypertension related to D.N.A. repair synthesis and carcinogen uptake. Lancet 1975;2(7944):1094.

(58) Reeves GK, Pirie K, Beral V, Green J, Spencer E, Bull D. Cancer incidence and mortality in relation to body mass index in the Million Women Study: cohort study. BMJ 2007;335(7630):1134. 
(59) Mathew A, George PS, Ildaphonse G. Obesity and kidney cancer risk in women: a metaanalysis (1992-2008). Asian Pac J Cancer Prev 2009;10(3):471-478.

(60) Zhao ZG, Guo XG, Ba CX et al. Overweight, obesity and thyroid cancer risk: a metaanalysis of cohort studies. J Int Med Res 2012;40(6):2041-2050.

(61) Jacobs EJ, Gapstur SM. Cholesterol and cancer: answers and new questions. Cancer Epidemiol Biomarkers Prev 2009;18(11):2805-2806.

(62) Healy LA, Ryan AM, Carroll P et al. Metabolic syndrome, central obesity and insulin resistance are associated with adverse pathological features in postmenopausal breast cancer. Clin Oncol (R Coll Radiol ) 2010;22(4):281-288.

(63) Li D, Morris JS, Liu J et al. Body mass index and risk, age of onset, and survival in patients with pancreatic cancer. JAMA 2009;301(24):2553-2562.

(64) Nothlings U, Wilkens LR, Murphy SP, Hankin JH, Henderson BE, Kolonel LN. Body mass index and physical activity as risk factors for pancreatic cancer: the Multiethnic Cohort Study. Cancer Causes Control 2007;18(2):165-175.

(65) Bianchini F, Kaaks R, Vainio H. Overweight, obesity, and cancer risk. Lancet Oncol 2002;3(9):565-574.

(66) Kaaks R, Lukanova A. Energy balance and cancer: the role of insulin and insulin-like growth factor-I. Proc Nutr Soc 2001;60(1):91-106.

(67) Naugler WE, Sakurai T, Kim S et al. Gender disparity in liver cancer due to sex differences in MyD88-dependent IL-6 production. Science 2007;317(5834):121-124.

(68) Ahn J, Lim U, Weinstein SJ et al. Prediagnostic total and high-density lipoprotein cholesterol and risk of cancer. Cancer Epidemiol Biomarkers Prev 2009;18(11):28142821.

(69) DeBoer MD, Dong L, Gurka MJ. Racial/ethnic and sex differences in the relationship between uric acid and metabolic syndrome in adolescents: an analysis of National Health and Nutrition Survey 1999-2006. Metabolism 2012;61(4):554-561. 


\section{Tables}

The working tables can be found in Appendix B. 
CHAPTER 4. ASSOCIATION BETWEEN METABOLIC RISK FACTORS AND AGE AT CANCER ONSET 


\subsection{Abstract}

\section{Introduction}

Cancer is the second most common cause of death in the United States. There is evidence that components of metabolic syndrome, a cluster of pathophysiological disorders comprising obesity, insulin resistance, hypertension, and dyslipidemia, elevate cancer risk. However, there is scant literature on the association between the components of metabolic syndrome and age at cancer onset. The aim of this study is to examine whether metabolic risk factors (MRFs), either individually or in combination, are associated with age at onset of all-site cancer, and cancer of the breast, digestive system, and lung, respectively.

\section{Methods}

Data were derived from the NHANES I Epidemiologic Follow-up Study, and comprised participants ages 25 to 74 years at baseline. The outcome variable was age at cancer onset, and the primary metabolic risk factors were obesity, high blood pressure, high total serum cholesterol, and diabetes. Analyses were adjusted for age, race, education, family income, physical activity, smoking status, and family history of cancer, and stratified by age and gender. Multiple linear regression analyses, using the general linear model, were conducted to assess the relationship between MRFs and age at cancer onset. All analyses incorporated the complex sample design and sample weights to produce national estimates.

\section{Results}

Study results showed an increased risk of diabetes associated with earlier age at (a) cancer onset in younger and older males, (b) cancer onset in older females, (c) postmenopausal breast cancer onset, and (d) lung cancer onset in both genders. Presence of a combination of three or four MRFs was associated with earlier age at onset of: (a) overall cancer in women 50 
years and older, (b) postmenopausal breast cancer, (c) digestive cancer in females, and (d) lung cancer in males.

\section{Conclusion}

Overall, diabetes and a combination of three or four MRFs were found to be associated with earlier age at onset of overall and site-specific cancers. The association with combined MRFs was stronger in women. Future research needs to determine the underlying mechanisms that may predispose people with metabolic abnormalities to cancer. 


\subsection{Introduction}

Accounting for one in four deaths, cancer is the second most common cause of death in the United States (U.S.) after heart disease. ${ }^{1}$ The National Cancer Institute estimates 1.7 million new cancer cases in $2013 .^{2}$ Annualized cancer incidence rates for 2006-2010 were 535.9 and 411.2 per 100,000 males and females, respectively. ${ }^{2}$ The World Cancer Research Fund estimates that $25-33 \%$ of new cancer cases in the U.S. in 2013 are related to behavioral and lifestyle factors such as overweight or obesity, physical inactivity, and poor nutrition. ${ }^{3}$

Metabolic syndrome is a cluster of pathophysiological disorders comprising central obesity, insulin resistance, hypertension, and dyslipidemia. Based on the application of various definitions of metabolic syndrome, an estimated one-third of US adults are afflicted by it. ${ }^{4}$ There is substantial evidence that this cluster of metabolic risk factors accelerates onset of cardiovascular diseases. ${ }^{5,6}$ In addition, studies conducted over the past decade indicate that the combined metabolic risk factors (MRFs) are positively and significantly associated with overall cancer $^{7}$ and site-specific cancers, including breast cancer, ${ }^{7-20}$ digestive cancer, ${ }^{21}$ liver cancer, ${ }^{14,22}$ prostate cancer, ${ }^{23-26}$ colorectal cancer, ${ }^{27-32}$ and endometrial cancer. ${ }^{33}$ A recent meta-analysis of prospective cohort studies concluded that metabolic syndrome is associated with an elevated overall cancer risk among adults. ${ }^{34}$ This study found a significant association between metabolic syndrome and increased risk of liver, colorectal, and bladder cancers in men, and endometrial, pancreatic, postmenopausal breast, and colorectal cancers in women. ${ }^{34}$

Few epidemiologic studies have reported associations between MRFs and age at cancer onset. A large cohort study found that obesity in adulthood was linked to increased cancer mortality risk. ${ }^{35}$ Overweight and obesity during early adulthood were also associated with earlier age at onset in obesity-related cancers, such as pancreatic cancer. ${ }^{36}$ In this large case-control 
study, obesity from the ages of 20 to 29 years was associated with earlier age of cancer onset by seven years. ${ }^{36}$ A nested case-control study suggested hypertensive adults were at risk of developing cancer ten years earlier than normotensives. ${ }^{37}$

A paucity of literature exists on the association between individual and combined MRFs and age at cancer onset. Animal studies suggest that mechanisms, which prevent metabolic abnormalities, by reducing serum insulin-like growth factor-1 or androgen concentrations, may delay the growth and progression of breast and prostate cancers. ${ }^{38}$ Another animal study found that mammary tumors developed earlier in diet-induced obese rats than in lean rats, thus supporting the role of hormones and adipokines (produced by adipose tissue) in cell proliferation and carcinogenesis. ${ }^{39}$

Given the associations between MRFs and several cancers, as suggested by epidemiologic human studies, as well as animal studies, an important research question is whether MRFs are associated with earlier age at cancer onset. This question is important for at least four reasons. First, age at onset of certain cancers is temporally decreasing. A populationbased study, using data for England and Wales covering the period 1971-1999, found earlier age at onset of breast, cervical, and prostate cancer. ${ }^{40}$ Second, earlier cancer onset signifies shorter life expectancy, and therefore, major loss of potential years of life. ${ }^{41}$ Third, younger cancer patients are likely to have more aggressive cancers, less favorable prognosis, and poorer outcomes than older patients. ${ }^{41-43}$ Fourth, earlier age at cancer onset in a family may increase the lifetime risk of developing cancer in the next generation. ${ }^{44,45}$ Therefore, it is important to understand the association between metabolic syndrome and age at cancer onset so that appropriate guidelines can be developed for cancer screening, prevention, and treatment. 
This study assessed the influence of MRFs (obesity, high blood pressure, high total serum cholesterol, and diabetes), and their combination, on age at onset of all-site cancer, and cancer of the breast, digestive system, and lung.

\subsection{Methods}

4.3.1 Data Source and Study Population: Data were derived from a cohort study, the NHANES I Epidemiologic Follow-up Study (NHEFS). ${ }^{46}$ The NHEFS is a national multi-stage, stratified probability sample of the non-institutionalized, civilian population in the US. It includes participants from the NHANES I cohort, who were ages 25 to 74 years, and completed a medical examination at baseline (1971-75). ${ }^{46}$ Participants were followed-up in 1982-84, 1986, 1987, and 1992. Only $5 \%$ of the original NHEFS sample was lost through attrition. ${ }^{47}$

Baseline data were acquired by merging five NHANES I data files on anthropometry, biochemistry, medical history, medical needs, and medical examination. Since the NHEFS follow-up was conducted for participants aged $\geq 25$ years and $\leq 74$ years at time of NHANES I interview, only this group was retained for the analysis. Cancer status was determined by merging data from each of the 1982-84, 1986, 1987, and 1992 surveys, in addition to the NHEFS vital statistics data.

The outcome variable was age at cancer onset. Cancer cases were defined using the International Classification of Diseases-9th revision (ICD-9), codes 140-208, excluding ICD-173 (skin cancer), and were followed up through interview and death certificate data. All the cancer cases occurring after the baseline period and reported in 1982-84, 1986, 1987, and 1992 interviews, were obtained from the first, second and third diagnoses of cancer along with their location (cancer-site). Skin cancer cases were not included among total cancer cases since the mechanism of skin cancer development is different and does not involve metabolic risk factors. 
For subjects with multiple cancers, only the first occurring non-skin cancer was included. All cancer cases were aligned with year of diagnosis. The final outcome variable, age at cancer onset, was computed by subtracting birth year from year of cancer diagnosis, and was computed for overall cancer and for cancer of the breast, digestive system, and lung, respectively.

A total of 14,407 persons from the NHANES I dataset were followed up in 1982-84. Of these, 684 had a cancer diagnosis at baseline (determined from the question "Has a doctor ever told you that you have malignant tumor or growth?") or who died within the year of baseline interview and were excluded from the analysis. In order to reduce the possibility of reverse causation, another 146 who developed cancer in the first two years of the study were excluded from analysis. Among those who were followed, 1,837 persons (13.5\%) were diagnosed with cancer during the study period. Participants with missing data $(\mathrm{n}=101)$ on covariates, which were included in the multivariable model, were also excluded from the analysis. The final sample was 1,736 .

Information on the following predictor variables was obtained from the baseline examination: obesity, assessed as body mass index in $\mathrm{kg} / \mathrm{m}^{2}$, resting systolic (SBP) and diastolic (DBP) blood pressure, measured as continuous variables in $\mathrm{mmHg}$, total serum cholesterol, measured as continuous variable in $\mathrm{mg} / \mathrm{dL}$, and self-reported diabetes, coded as a dichotomous variable. Consistent with American Heart Association guidelines, resting SBP and DBP were measured by a physician using a sphygmomanometer at the beginning of the physical examination while the subject was in a sitting position. ${ }^{48}$ All of these readings were retrieved from the NHANES I medical exam questionnaire. Total serum cholesterol was assessed using a semi-automated instrument in the Centers for Disease Control and Prevention's lipid standardization laboratory. Information on diabetes was gathered from the NHANES I medical 
history questionnaire (Has a doctor ever told you had diabetes?) or from the NHANES I healthcare needs questionnaire (Did a doctor tell you had diabetes? or, do you take any diabetes medicine or insulin?).

Analyses were adjusted for the following potentially confounding variables: age, race, education, family income, physical activity, smoking status, and family history of cancer. The baseline medical history questionnaire provided information on age, race, education, family income, and physical activity. At baseline, information on smoking status was very limited, and information on family history of cancer was not collected. Therefore, information on smoking status was combined from the baseline and 1982 surveys, and information on family history of cancer was derived from the latter survey. ${ }^{49-52}$

\subsection{2 $\quad$ Statistical Analysis}

Multiple linear regression analyses, using the general linear model, were used to assess the relationship between MRFs and age at cancer diagnosis. ${ }^{36,53}$ The severity of multicollinearity for each variable was assessed by calculation of the variance inflation factor. All data were analyzed using the complex samples module in IBM SPSS Statistics for Windows, version 21.0 (Armonk, NY: IBM Corp). All analyses incorporated the complex sample design and sample weights in order to produce national estimates.

The outcome variable, age at cancer onset, was computed by subtracting birth year from year of cancer diagnosis, and analyzed as a continuous variable. Metabolic risk factors were classified as: (1) obesity: $\mathrm{BMI} \geq 30 \mathrm{~kg} / \mathrm{m}^{2}$; (2) high blood pressure: systolic $\mathrm{BP} \geq 140 \mathrm{~mm} / \mathrm{Hg}$ and/or diastolic $\mathrm{BP} \geq 90 \mathrm{~mm} / \mathrm{Hg}$ ); (3) high cholesterol: total serum cholesterol $\geq 240 \mathrm{mg} / \mathrm{dL}$; and (4) diabetes: presence or absence of diabetes. Multiple linear regression models were used to examine the association between MRFs (obesity, high BP, high cholesterol, and diabetes) and 
age at cancer diagnosis. ${ }^{36,53}$ The effect of individual MRF was assessed relative to the absence of that risk factor.

Analyses were adjusted for the following potentially confounding variables: age, race (whites versus others), education (high school or less vs. above high school), family income $(<\$ 5,000, \$ 5,000$ to $\$ 14,999$, and $\geq \$ 15,000$, based on the poverty line for $1971-75$ that was set at or below $\$ 5,000$ as the annual income for a household of four members), physical activity (moderately active or very active vs. quite inactive), smoking (smoked 100 cigarettes in one's lifetime), and family history of cancer (dichotomous). In the NHANES I dataset, race was classified as white, black, or other at baseline. However, for this study, the latter two categories were combined and classified as nonwhite due to small number. ${ }^{50}$

Age was included in all models as an independent, continuous variable. In addition, analyses were further stratified by age categorized as $<50$ and $\geq 50$ years as at baseline. The rationale for this dichotomization was based on previous research that has shown that adults 50 years or older bear the greatest burden of cancer, with the largest proportions of cancers being diagnosed in this age group. ${ }^{54}$ Moreover, there are biological changes, especially in women, around age 50. Posthoc, all analyses were also stratified by gender after determining that the association between individual MRFs and age at cancer onset differed by gender. ${ }^{55,56}$

Besides examining the association between individual MRFS and age at cancer onset, analyses were performed to assess the combined effect of MRFs on age at cancer onset. An additive summary of MRF scores was created by combining the individual MRFs. A score of three was assigned to participants with three or four MRFs. The summary score ranged from 0 (no MRF, the referent category) to 3 (three or four risk factors). Analyses were adjusted for the 
following potential confounders: age, race, education, family income, physical activity, smoking, and family history of cancer, and stratified by gender and age ( $<50$ and $\geq 50$ years of age).

Site-specific cancers (breast, digestive, and lung cancers) were examined separately in evaluating an association between individual MRFs as well as the combined MRF score, and age at cancer onset. Cancers of the digestive system included those of the alimentary canal below the neck (e.g., esophagus, stomach, small and large intestines) and key digestive organs (i.e., pancreas, liver, and gallbladder).

\subsection{Results}

Table 1 presents the baseline characteristics of the study population. Among the 1,736 persons diagnosed with cancer between 1973 and 1992, approximately half were women and most were white. Almost a third of the sample had an annual family income below the poverty level, while more than three fourths had a high school education or less. About $17 \%$ were obese, over half had hypertension, and more than a third had high total cholesterol. Very few participants had three or four MRFs.

Table 2 presents the association between individual MRFs and age at cancer onset among males, after adjusting for potential confounders, and stratifying by age and gender. Among males less than 50 years of age at baseline, obesity was associated with later age at cancer onset. Mean age at cancer onset for obese men who were younger than age 50 was (mean \pm SE) $55.8 \pm 1.52$ years compared to $53.1 \pm 1.32$ years for those who were not obese. Diabetes was associated with earlier age at cancer onset in younger males. Mean age at cancer onset for men with diabetes, who were younger than age 50 , was $52.2 \pm 2.16$ years compared to $56.6 \pm 1.18$ years for those who did not have diabetes. Among males 50 years and older, diabetes was again associated with 
earlier age at cancer onset. Mean age at cancer onset for older men with diabetes was $68.1 \pm 1.42$ years compared to $70.9 \pm 0.57$ years for those who did not have diabetes.

Among women 50 years and older, diabetes was associated with earlier age at cancer onset (Table 3). Mean age at cancer onset for older women with diabetes was $70.4 \pm 1.06$ years compared to $72.4 \pm 0.81$ years for those who did not have diabetes.

Tables 4 and 5 present the association between the aggregate MRF score (ranging from 1 MRF to three or four MRFs, compared with the referent category of no MRF) and age at cancer onset among males and females, respectively, after adjusting for potential confounders, and stratifying by age. No significant association was observed among males Table 4). Among women younger than 50 years of age, presence of three or four MRFs was associated with later age at cancer onset (Table 5). Mean age at cancer onset for these women was $51.8 \pm 0.97$ years compared to $52.7 \pm 0.98$ years for those who had no MRF. This association reversed in older women. Presence of three or four MRFs in women 50 and older was associated with earlier age at cancer onset. Mean age at cancer onset for older women with combined MRFs was $70.2 \pm$ 0.89 years compared to $72.9 \pm 1.03$ years for those who had no MRF.

Table 6 presents the associations between individual MRFs and age at breast cancer onset in all women, and in postmenopausal women. Diabetes was associated with earlier age at postmenopausal breast cancer onset. Mean age at onset was $66.0 \pm 1.46$ years compared to 68.7 \pm 0.74 years for those who did not have diabetes. Presence of combined three or four MRFs was associated with earlier age at onset among all women and postmenopausal women (Table 7). Mean age at cancer onset for all women with combined MRFs was $59.1 \pm 1.22$ years compared to $62.4 \pm 1.08$ years for those who had no MRF. Among postmenopausal women with combined 
MRFs, mean age at cancer onset was $67.0 \pm 1.07$ years compared to $70.9 \pm 1.52$ years for those who had no MRF.

Table 8 presents the associations between individual MRFs and age at digestive cancer onset among males and females. No association was observed in any strata. Examining the combined MRFs, presence of one, three or four MRFs was associated with earlier age at digestive cancer onset among females (Table 9). Mean age at onset among females with three or four MRFs was $68.5 \pm 1.25$ years compared to $72.9 \pm 1.19$ years for those who did not have any MRF.

Table 10 presents the association between individual MRFs and age at lung cancer onset among males and females. Overall, diabetes was associated with earlier age at onset among both males and females. Mean age at lung cancer onset for males with diabetes was $58.7 \pm 1.77$ years compared to $66.1 \pm 0.90$ years for those who did not have diabetes. Similarly, mean age at lung cancer onset for females with diabetes was $62.9 \pm 1.78$ years compared to $67.5 \pm 1.05$ years for those who did not have diabetes. When examining the combined MRFs, presence of three or four MRFs in males was also associated with earlier age at lung cancer onset (Table 11). Mean age at onset among males with three or four MRFs was $62.5 \pm 1.57$ years compared to $66.2 \pm 1.25$ years for those who did not have any MRF.

\subsection{Discussion}

The aim of this study was to examine whether MRFs and their combination were associated with age at cancer onset. Since there are several definitions of metabolic syndrome, and thus several possible combinations, the independent effect of each single component was also examined. 
Study results show an increased risk of diabetes associated with earlier age at cancer onset in younger and older males, and in older females. Diabetes was also associated with early age at onset of postmenopausal breast cancer, and lung cancer in both genders. Epidemiologic reviews and meta-analytic studies suggest that people with diabetes were at a higher risk for overall cancer and cancers of several sites, such as liver, pancreas, endometrium, colon, rectum, breast, and bladder. ${ }^{57,58}$ Although several observational studies do not show an association between diabetes and lung cancer, the Metabolic Syndrome and Cancer project that comprises six large prospective cohorts found that a one millimole per liter increase in glucose levels in men was associated with increased risk for incidence and mortality from cancer of lung, trachea, and bronchus. ${ }^{59}$ Another cohort study found an increased risk for lung cancer mortality in diabetic women. $^{60}$

Study results also show that obesity was associated with later age at cancer onset in males less than 50 years of age. While epidemiologic evidence suggests obesity is associated with an increased risk of cancer in men, ${ }^{61}$ studies on the association between obesity and age at cancer onset are scant.

Presence of a combination of three or four MRFs was associated with later age at cancer onset among females less than 50 years of age. This association was reversed in older women. Presence of three or four MRFs was associated with earlier age at onset of: (a) overall cancer in women 50 and older, (b) postmenopausal breast cancer, (c) digestive cancer in females, and (d) lung cancer in males. A meta-analysis found that metabolic syndrome was positively associated with postmenopausal breast, endometrial, pancreatic, and colorectal cancers in women. ${ }^{34} \mathrm{~A}$ large cohort study showed that metabolic syndrome was associated with increased liver and breast cancer risk in women. ${ }^{14}$ Another cohort study concluded with a significant increase in breast 
cancer risk among older women with two or three MRFs, suggesting that the combined MRFs may elevate breast cancer risk beyond a single MRF, such as obesity. ${ }^{62}$ However, studies on the association between combined MRFs and age at cancer onset are lacking.

Studies have suggested potential biological mechanisms that link MRFs with various cancers. In brief, through various mechanisms, including obesity, increased inflammatory markers such as tumor necrosis factor $-\alpha$ and interleuken-6, increased adipokines such as leptin and decreased adiponectin, increased levels of free fatty acids and triglycerides, insulin resistance, increased insulin-like growth factor-1, and increased oxidative stress, MRFs have been shown to cause angiogenesis, cell migration, mitogenesis, and DNA damage. ${ }^{63}$ There is, therefore, an emerging hypothesis that a combination of MRFs may be an important etiologic factor for the onset of cancer. ${ }^{64}$

Gender differences in the association between MRFs and cancer can arise for several reasons. Components of metabolic syndrome operate differently by gender. ${ }^{55,56}$ Metabolic hormones that control cell growth can elevate cancer risk in women, whereas obesity-related hyperinsulinemia can increase the risk in men. ${ }^{65}$ Longitudinal studies show that the association between metabolic syndrome and elevated cancer risk is stronger in women. ${ }^{14}$ Animal studies have shown that obesity-related adipokines enhance cell proliferation and elevate breast cancer risk. $^{66}$

The current study has several potential limitations. For example, blood glucose levels were not measured directly but rather, a self-reported diagnosis of diabetes was used as an indicator of high levels. In addition, while total serum cholesterol levels were measured directly and not self-reported, there were no separate measures for triglycerides, or low and high-density lipoprotein cholesterol levels (LDL and HDL). This may be important since previous research 
has shown that high HDL may be inversely associated with site-specific and overall cancer, ${ }^{67}$ although others reported no association between triglyceride or HDL levels and such site-specific cancers as colorectal cancer. $^{32}$

Prior research has reported differences in age at cancer onset among different racial/ethnic populations for overall and site-specific cancers. ${ }^{68,69}$ However, while models were adjusted for race, a stratified analysis could not be performed due to the small sample size for races other than white. For this reason, nonwhite were combined into one category, although studies show racial differences related to MRFs. ${ }^{70}$

This study has several strengths. For example, data for this study were derived from a longitudinal cohort study design with high follow-up rates. Specifically, $96 \%$ of the study population was successfully traced at some point through the 1992 follow-up. ${ }^{47}$ It is a large nationally representative sample of the US population. In addition, self-report bias tended to be minimized because MRFs, such as total serum cholesterol, as well as blood pressure and anthropometry (BMI), were based on body measurements and laboratory data. All analyses utilized complex sample survey design for results representative of the population.

In conclusion, diabetes and a combination of three or four MRFs were found to be associated with earlier age at onset of overall and site-specific cancers. The association with combined MRFs was stronger in women. Future research needs to determine the underlying mechanisms that predispose people with metabolic abnormalities to cancer. To this end, it is essential to examine the relationship among site-specific cancers, stratified by gender and race, with detailed information on LDL and HDL cholesterol levels, abdominal and visceral adiposity, blood glucose levels, time period of each abnormality, and medications and their period of use. 


\section{Reference List}

(1) Siegel R, Naishadham D, Jemal A. Cancer statistics, 2013. CA Cancer J Clin 2013;63(1):11-30.

(2) Howlader N, Noone AM, Krapcho M, Garshell J, et al. SEER Cancer Statistics Review, 1975-2010. Bethesda, MD: National Cancer Institute; 2013.

(3) World Cancer Research Fund/American Institute for Cancer Research. Policy and Action for Cancer Prevention. Food, Nutrition, and Physical Activity: a Global Perspective. Washington DC: American Institute for Cancer Research; 2009.

(4) Ervin R. Prevalence of metabolic syndrome among adults 20 years of age and over, by sex, age, race and ethnicity, and body mass index: United States, 2003-2006. National health statistics reports; no. 13. Hyattsville, MD: National Center for Health Statistics; 2009.

(5) Mottillo S, Filion KB, Genest J et al. The metabolic syndrome and cardiovascular risk a systematic review and meta-analysis. J Am Coll Cardiol 2010;56(14):1113-1132.

(6) Galassi A, Reynolds K, He J. Metabolic syndrome and risk of cardiovascular disease: a meta-analysis. Am J Med 2006;119(10):812-819.

(7) Russo A, Autelitano M, Bisanti L. Metabolic syndrome and cancer risk. Eur J Cancer 2008;44(2):293-297.

(8) Agnoli C, Berrino F, Abagnato CA et al. Metabolic syndrome and postmenopausal breast cancer in the ORDET cohort: a nested case-control study. Nutr Metab Cardiovasc Dis 2010;20(1):41-48.

(9) Bjorge T, Lukanova A, Jonsson $\mathrm{H}$ et al. Metabolic syndrome and breast cancer in the mecan (metabolic syndrome and cancer) project. Cancer Epidemiol Biomarkers Prev 2010;19(7):1737-1745.

(10) Capasso I, Esposito E, Pentimalli F et al. Metabolic syndrome affects breast cancer risk in postmenopausal women: National Cancer Institute of Naples experience. Cancer Biol Ther 2011;10(12):1240-1243.

(11) Healy LA, Ryan AM, Carroll P et al. Metabolic syndrome, central obesity and insulin resistance are associated with adverse pathological features in postmenopausal breast cancer. Clin Oncol (R Coll Radiol ) 2010;22(4):281-288.

(12) Inoue M, Noda M, Kurahashi $\mathrm{N}$ et al. Impact of metabolic factors on subsequent cancer risk: results from a large-scale population-based cohort study in Japan. Eur J Cancer Prev 2009;18(3):240-247. 
(13) Kabat GC, Kim M, Chlebowski RT et al. A longitudinal study of the metabolic syndrome and risk of postmenopausal breast cancer. Cancer Epidemiol Biomarkers Prev 2009;18(7):2046-2053.

(14) Osaki Y, Taniguchi S, Tahara A, Okamoto M, Kishimoto T. Metabolic syndrome and incidence of liver and breast cancers in Japan. Cancer Epidemiol 2012;36(2):141-147.

(15) Porto LA, Lora KJ, Soares JC, Costa LO. Metabolic syndrome is an independent risk factor for breast cancer. Arch Gynecol Obstet 2011;284(5):1271-1276.

(16) Rosato V, Bosetti C, Talamini R et al. Metabolic syndrome and the risk of breast cancer in postmenopausal women. Ann Oncol 2011;22(12):2687-2692.

(17) Rose DP, Haffner SM, Baillargeon J. Adiposity, the metabolic syndrome, and breast cancer in African-American and white American women. Endocr Rev 2007;28(7):763777.

(18) Sinagra D, Amato C, Scarpilta AM et al. Metabolic syndrome and breast cancer risk. Eur Rev Med Pharmacol Sci 2002;6(2-3):55-59.

(19) Vona-Davis L, Howard-McNatt M, Rose DP. Adiposity, type 2 diabetes and the metabolic syndrome in breast cancer. Obes Rev 2007;8(5):395-408.

(20) Xue F, Michels KB. Diabetes, metabolic syndrome, and breast cancer: a review of the current evidence. Am J Clin Nutr 2007;86(3):s823-s835.

(21) Matthews CE, Sui X, LaMonte MJ, Adams SA, Hebert JR, Blair SN. Metabolic syndrome and risk of death from cancers of the digestive system. Metabolism 2010;59(8):1231-1239.

(22) Welzel TM, Graubard BI, Zeuzem S, El-Serag HB, Davila JA, McGlynn KA. Metabolic syndrome increases the risk of primary liver cancer in the United States: a study in the SEER-Medicare database. Hepatology 2011;54(2):463-471.

(23) Laukkanen JA, Laaksonen DE, Niskanen L, Pukkala E, Hakkarainen A, Salonen JT. Metabolic syndrome and the risk of prostate cancer in Finnish men: a population-based study. Cancer Epidemiol Biomarkers Prev 2004;13(10):1646-1650.

(24) Lund HL, Wisloff TF, Holme I, Nafstad P. Metabolic syndrome predicts prostate cancer in a cohort of middle-aged Norwegian men followed for 27 years. Am J Epidemiol 2006;164(8):769-774.

(25) Pelucchi C, Serraino D, Negri E et al. The metabolic syndrome and risk of prostate cancer in Italy. Ann Epidemiol 2011;21(11):835-841.

(26) Esposito K, Chiodini P, Capuano A et al. Effect of metabolic syndrome and its components on prostate cancer risk: Meta-analysis. J Endocrinol Invest 2013;36(2):132139. 
(27) Ahmed RL, Schmitz KH, Anderson KE, Rosamond WD, Folsom AR. The metabolic syndrome and risk of incident colorectal cancer. Cancer 2006;107(1):28-36.

(28) Chiu HM, Lin JT, Shun CT et al. Association of metabolic syndrome with proximal and synchronous colorectal neoplasm. Clin Gastroenterol Hepatol 2007;5(2):221-229.

(29) Siddiqui AA. Metabolic syndrome and its association with colorectal cancer: a review. Am J Med Sci 2011;341(3):227-231.

(30) Stocks T, Lukanova A, Johansson M et al. Components of the metabolic syndrome and colorectal cancer risk; a prospective study. Int J Obes (Lond) 2008;32(2):304-314.

(31) Sturmer T, Buring JE, Lee IM, Gaziano JM, Glynn RJ. Metabolic abnormalities and risk for colorectal cancer in the physicians' health study. Cancer Epidemiol Biomarkers Prev 2006;15(12):2391-2397.

(32) Esposito K, Chiodini P, Capuano A et al. Colorectal cancer association with metabolic syndrome and its components: a systematic review with meta-analysis. Endocrine 2013.

(33) Esposito K, Chiodini P, Capuano A, Bellastella G, Maiorino MI, Giugliano D. Metabolic syndrome and endometrial cancer: a meta-analysis. Endocrine 2013.

(34) Esposito K, Chiodini P, Colao A, Lenzi A, Giugliano D. Metabolic syndrome and risk of cancer: a systematic review and meta-analysis. Diabetes Care 2012;35(11):2402-2411.

(35) Gray L, Lee IM, Sesso HD, Batty GD. Association of body mass index in early adulthood and middle age with future site-specific cancer mortality: the Harvard Alumni Health Study. Ann Oncol 2012;23(3):754-759.

(36) Li D, Morris JS, Liu J et al. Body mass index and risk, age of onset, and survival in patients with pancreatic cancer. JAMA 2009;301(24):2553-2562.

(37) Xie L, Wu K, Xu N, Chen D, Chen J, Lu S. Hypertension is associated with a high risk of cancer. J Hum Hypertens 1999;13(5):295-301.

(38) Zhou JR, Li L, Pan W. Dietary soy and tea combinations for prevention of breast and prostate cancers by targeting metabolic syndrome elements in mice. Am J Clin Nutr 2007;86(3):s882-s888.

(39) Hakkak R, Holley AW, Macleod SL et al. Obesity promotes 7,12dimethylbenz(a)anthracene-induced mammary tumor development in female zucker rats. Breast Cancer Res 2005;7(5):R627-R633.

(40) Newby JA, Busby CC, Howard CV, Platt MJ. The cancer incidence temporality index: an index to show temporal changes in the age of onset of overall and specific cancer (England and Wales, 1971-1999). Biomed Pharmacother 2007;61(10):623-630. 
(41) Lee CH, Lee KW, Fang FM et al. The use of tobacco-free betel-quid in conjunction with alcohol/tobacco impacts early-onset age and carcinoma distribution for upper aerodigestive tract cancer. J Oral Pathol Med 2011;40(9):684-692.

(42) Ahn SH, Son BH, Kim SW et al. Poor outcome of hormone receptor-positive breast cancer at very young age is due to tamoxifen resistance: nationwide survival data in Korea--a report from the Korean Breast Cancer Society. J Clin Oncol 2007;25(17):23602368.

(43) Han W, Kang SY. Relationship between age at diagnosis and outcome of premenopausal breast cancer: age less than 35 years is a reasonable cut-off for defining young age-onset breast cancer. Breast Cancer Res Treat 2010;119(1):193-200.

(44) Brune KA, Lau B, Palmisano E et al. Importance of age of onset in pancreatic cancer kindreds. J Natl Cancer Inst 2010;102(2):119-126.

(45) Hemminki K, Li X. Familial and second primary pancreatic cancers: a nationwide epidemiologic study from Sweden. Int J Cancer 2003;103(4):525-530.

(46) National Center for Health Statistics. National Center for Health Statistics. NHANES I Epidemiologic Followup Study (NHEFS) Public-Use Data Files. 2013.

(47) Cox CS, Mussolino ME, Rothwell ST, et al. Plan and operation of the NHANES I Epidemiologic Followup Study 1992. National Center for Health Statistics; 1997. Report No.: 1.

(48) Kirkendall WM, Burton AC, Epstein FH, Freis ED. Recommendations for human blood pressure determination by sphygmomanometers. Circulation 1967;36(6):980-988.

(49) Schatzkin A, Jones DY, Hoover RN et al. Alcohol consumption and breast cancer in the epidemiologic follow-up study of the first National Health and Nutrition Examination Survey. N Engl J Med 1987;316(19):1169-1173.

(50) Albanes D, Blair A, Taylor PR. Physical activity and risk of cancer in the NHANES I population. Am J Public Health 1989;79(6):744-750.

(51) Schreinemachers DM, Everson RB. Aspirin use and lung, colon, and breast cancer incidence in a prospective study. Epidemiology 1994;5(2):138-146.

(52) Su LJ, Arab L. Alcohol consumption and risk of colon cancer: evidence from the national health and nutrition examination survey I epidemiologic follow-up study. Nutr Cancer 2004;50(2):111-119.

(53) Zisman AL, Nickolov A, Brand RE, Gorchow A, Roy HK. Associations between the age at diagnosis and location of colorectal cancer and the use of alcohol and tobacco: implications for screening. Arch Intern Med 2006;166(6):629-634. 
(54) United States Department of Health and Human Services, Centers for Disease Control and Prevention, National Cancer Institute. National Program of Cancer Registries Early Release Cancer Statistics: 1999-2010, WONDER On-line Database. 2013.

(55) Beigh SH, Jain S. Prevalence of metabolic syndrome and gender differences. Bioinformation 2012;8(13):613-616.

(56) Regitz-Zagrosek V, Lehmkuhl E, Weickert MO. Gender differences in the metabolic syndrome and their role for cardiovascular disease. Clin Res Cardiol 2006;95(3):136-147.

(57) Shikata K, Ninomiya T, Kiyohara Y. Diabetes mellitus and cancer risk: review of the epidemiological evidence. Cancer Sci 2013;104(1):9-14.

(58) Vigneri P, Frasca F, Sciacca L, Pandini G, Vigneri R. Diabetes and cancer. Endocr Relat Cancer 2009;16(4):1103-1123.

(59) Stocks T, Rapp K, Bjorge T et al. Blood glucose and risk of incident and fatal cancer in the metabolic syndrome and cancer project (me-can): analysis of six prospective cohorts. PLoS Med 2009;6(12):e1000201.

(60) Jee SH, Ohrr H, Sull JW, Yun JE, Ji M, Samet JM. Fasting serum glucose level and cancer risk in Korean men and women. JAMA 2005;293(2):194-202.

(61) Calle EE, Kaaks R. Overweight, obesity and cancer: epidemiological evidence and proposed mechanisms. Nat Rev Cancer 2004;4(8):579-591.

(62) Reeves KW, McLaughlin V, Fredman L, Ensrud K, Cauley JA. Components of metabolic syndrome and risk of breast cancer by prognostic features in the study of osteoporotic fractures cohort. Cancer Causes Control 2012;23(8):1241-1251.

(63) Cowey S, Hardy RW. The metabolic syndrome: A high-risk state for cancer? Am J Pathol 2006;169(5):1505-1522.

(64) Zhou JR, Blackburn GL, Walker WA. Symposium introduction: metabolic syndrome and the onset of cancer. Am J Clin Nutr 2007;86(3):s817-s819.

(65) Chesney ET, Davis SC, Duggan L, Natarajan S. Does metabolic syndrome increase risk for certain cancers? American Journal for Nurse Practitioners 2010;14(4):25-32.

(66) Lautenbach A, Budde A, Wrann CD et al. Obesity and the associated mediators leptin, estrogen and IGF-I enhance the cell proliferation and early tumorigenesis of breast cancer cells. Nutr Cancer 2009;61(4):484-491.

(67) Ahn J, Lim U, Weinstein SJ et al. Prediagnostic total and high-density lipoprotein cholesterol and risk of cancer. Cancer Epidemiol Biomarkers Prev 2009;18(11):28142821. 
(68) Rose DP, Royak-Schaler R. Tumor biology and prognosis in black breast cancer patients: a review. Cancer Detect Prev 2001;25(1):16-31.

(69) Karami S, Young HA, Henson DE. Earlier age at diagnosis: another dimension in cancer disparity? Cancer Detect Prev 2007;31(1):29-34.

(70) DeBoer MD, Dong L, Gurka MJ. Racial/ethnic and sex differences in the relationship between uric acid and metabolic syndrome in adolescents: an analysis of National Health and Nutrition Survey 1999-2006. Metabolism 2012;61(4):554-561. 


\section{Tables}

The working tables can be found in Appendix C. 
CHAPTER 5. DISCUSSION 


\subsection{Discussion}

The three dissertation studies were conducted with the overall goal of examining the association between individual and combined metabolic risk factors (MRFs) and subsequent risk of overall and site-specific cancers of the breast, digestive system, and lung. This chapter discusses the findings from the three studies, lists their strengths and limitations, and concludes with a suggested future course of action.

\subsection{Study 1 Discussion: Metabolic Syndrome is associated with increased breast cancer risk: A systematic review with meta-analysis}

The purpose of this aggregate data meta-analysis was to examine the association between metabolic syndrome and the risk for breast cancer in adult females. Of the 291 studies screened, 47 underwent a full-text review, of which eight studies with nine independent cohorts met the eligibility criteria. The overall results of this aggregate data meta-analysis show a modest positive association between metabolic syndrome and breast cancer risk in adult females, with a $47 \%$ elevated risk for incident breast cancer for adult females with metabolic syndrome.

This finding is strengthened by the robustness of results from other analyses. These include: (1) examination for publication bias, (2) influence analysis with each study deleted from the model once, (3) deletion of the two case-control studies with odds ratios from the overall model, (4) limiting the analysis to prospective designs, (5) restricting the study to only postmenopausal women in the analysis, and (6) limiting the results to studies that controlled for four or more of the important confounders.

Risk of bias was low for a majority of studies with respect to study design, cancer assessment, and sample size; but it was high or unclear for a majority of them concerning the handling of missing data and non-participation of subjects at each stage of follow-up. This risk 
was higher in case-control and retrospective cohort study designs compared with prospective cohort study designs. The association between metabolic syndrome and breast cancer risk was stronger when limited to postmenopausal women. These findings are supported by the recent meta-analysis on metabolic syndrome and breast cancer risk in postmenopausal women. ${ }^{1}$

The current meta-analysis identified some of the methodological challenges when pooling results from various studies examining the association between metabolic syndrome and breast cancer risk. These include (1) the different methods used to assess exposure, identify cancer, control for confounders, and define metabolic syndrome, (2) limiting studies to those published in English, which may have led to inflated results, (3) the relatively small number of studies that met the inclusion criteria, (4) the inability of a few studies to provide raw data for calculating the risk estimates, (5) the different study designs employed, and (6) the varied populations studied.

This study has several strengths. First, to the best of my knowledge, this is the first systematic review and meta-analysis to examine the association between metabolic syndrome and breast cancer risk in all adult women, with a sub-analysis of post-menopausal women. Second, all included studies were longitudinal, reported the results of multivariable analyses, and in eight of the nine cohorts, breast cancer was objectively determined. Third, with robust results, tested after conducting several analyses, the findings provide direction for future.

In conclusion, the overall results of this meta-analysis suggest that there is a modest positive association between MS and risk of breast cancer in adult females.

\subsection{Study 2 Discussion: Association between individual and combined metabolic risk factors and cancer risk}


The aim of this study was to examine whether MRFs, either individually or in combination, were associated with the risk of overall and selected site-specific cancers of the breast, digestive system, and lung. The overall results from this large, prospective cohort study showed that diabetes, high BP, and the presence of a combination of three or four MRFs were associated with higher breast cancer risk among postmenopausal women. Obesity in males less than 50 elevated the risk of digestive cancer.

Epidemiologic evidence points toward increased risk of breast cancer in postmenopausal diabetic women. ${ }^{1,2}$ Diabetes is frequently associated with insulin resistance, increased circulating concentrations of insulin, and insulin-like growth factors. Studies have shown insulin has mitogenic effects on breast tissue. ${ }^{3}$ In addition, insulin inhibits the production of sex hormone-binding globulin, resulting in an increase in bioavailable estradiol. ${ }^{4}$ Increased estradiol levels have been associated with the risk of developing breast cancer. ${ }^{5}$

The finding that postmenopausal women with high BP were at an increased risk of breast cancer is also supported by the recent meta-analysis on breast cancer risk in postmenopausal women. ${ }^{1}$ Cancer and hypertension are both characterized by the proliferation of smooth muscle cells. ${ }^{6}$ Another hypothesis indicates abnormalities of carcinogen binding to DNA in lymphocytes of hypertensive women. ${ }^{7}$

Study results showing an association between a combination of three or four MRFs and a higher risk of postmenopausal breast cancer, are supported by findings from a recent metaanalysis, suggesting that the increased risk for postmenopausal breast cancer was greater from the combined effect of MRFs than from individual MRFs. ${ }^{1}$ A combination of MRFs may activate different molecular pathways through metabolic, endocrine, and immune cell changes, which can result in breast tumorigenesis. ${ }^{8}$ 
Among men, the only significant association observed was that of obesity with elevated risk of digestive cancer. Other studies have also observed a similar association between

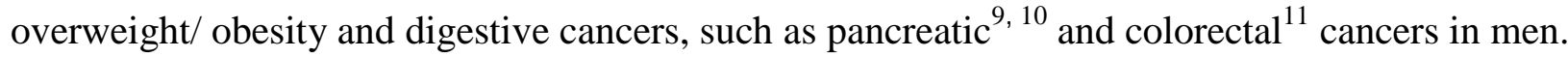

Current study has certain potential limitations. For example, blood glucose levels were self-reported. There were no separate measures for triglycerides, or low and high-density lipoprotein cholesterol levels (LDL and HDL). A stratified analysis could not be performed due to small sample size for races other than white, and nonwhite had to be combined into one category. Analyses on digestive and lung cancer could not be stratified by age because of small number of cancer cases.

This study has several strengths. For example, data were derived using a strong longitudinal cohort study design with high follow-up rates. In addition, self-report bias tended to be minimized by measuring serum total cholesterol as well as blood pressure and anthropometry (body mass index).

\subsection{Study 3 Discussion: Association between metabolic risk factors and age at cancer onset}

The aim of this study was to examine whether MRFs, either individually or in combination, were associated with age at onset of all-site cancer, and cancer of the breast, digestive system, and lung, respectively.

Study results showed an increased risk of diabetes associated with earlier age at cancer onset in younger and older males, and in older females. Diabetes was also associated with earlier age at onset of postmenopausal breast cancer, and lung cancer in both genders. Presence of a combination of three or four MRFs was associated with earlier age at onset of: (a) overall cancer 
in women 50 years and older, (b) postmenopausal breast cancer, (c) digestive cancer in females, and (d) lung cancer in males.

Epidemiologic studies show an association between individual and combined MRFs and elevated cancer risk. However, there are very few studies on the association of these risk factors with age at cancer onset. Epidemiologic reviews and meta-analytic studies show people with diabetes were at a higher risk for overall cancer and cancers of several sites, such as liver, pancreas, endometrium, colon, rectum, breast, and bladder. ${ }^{5,12}$ The Metabolic Syndrome and Cancer project that comprises six large prospective cohorts found an association between increasing levels of glucose and increased risk for incidence and mortality from cancer of lung, trachea, and bronchus in men. ${ }^{13}$ Another cohort study found an increased risk for lung cancer mortality in diabetic women. ${ }^{14}$

Study results show earlier age at cancer onset among older women with a combination of three or four MRFs. This finding is supported in the literature. A meta-analysis found that metabolic syndrome was positively associated with postmenopausal breast, endometrial, pancreatic, and colorectal cancers in women. ${ }^{15}$ A large cohort study showed that metabolic syndrome was associated with increased liver and breast cancer risk in women. ${ }^{16}$ Another cohort study concluded with a significant increase in breast cancer risk among older women with two or three MRFs, suggesting that the combined MRFs may elevate breast cancer risk beyond a single MRF, such as obesity. ${ }^{17}$ However, studies on the association between combined MRFs and age at cancer onset are lacking.

Studies have suggested potential biological mechanisms that link MRFs with various cancers. In brief, through various mechanisms, including obesity, increased inflammatory markers such as tumor necrosis factor $-\alpha$ and interleuken- 6 , increased adipokines such as leptin, 
decreased adiponectin, increased levels of free fatty acids and triglycerides, insulin resistance, increased insulin-like growth factor-1, and increased oxidative stress, MRFs have been shown to cause angiogenesis, cell migration, mitogenesis, and DNA damage. ${ }^{18}$ There is, therefore, an emerging hypothesis that a combination of MRFs may be an important etiologic factor for the onset of cancer. ${ }^{19}$

This study shares similar strengths and limitations as those from the previous study. Some of the potential limitations include self-reported diabetes diagnosis, no separate measures for triglycerides, or low and high-density lipoprotein cholesterol levels, and small sample size for races other than white. The study has strengths that include a longitudinal cohort study design with high follow-up rates, and MRFs, such as total serum cholesterol as well as blood pressure and anthropometry (body mass index) based on body measurements and laboratory data. More importantly, there is very little research conducted on this subject.

\subsection{Conclusion}

The prevalence of MRFs, individually and in the aggregate, is growing rapidly. ${ }^{20}$ There is limited biologic and epidemiologic evidence indicating an association between MRFs and cancer. The goal of this dissertation was to examine the association between individual and combined MRFs with subsequent risk of overall and site-specific cancers of the breast, digestive system, and lung. Results from the meta-analysis show that the combined MRFs (metabolic syndrome) are modestly associated with an increased risk for breast cancer in all adult women. Results from the association between individual and combined MRFs showed that diabetes, high $\mathrm{BP}$, and the presence of a combination of three or four MRFs were associated with higher breast cancer risk among postmenopausal women. Diabetes was also associated with earlier age at (a) cancer onset in younger and older males, (b) cancer onset in older females, (c) postmenopausal 
breast cancer onset, and (d) lung cancer onset in both genders. Lastly, presence of a combination of three or four MRFs was associated with earlier age at onset of: (a) overall cancer in women 50 and older, (b) postmenopausal breast cancer, (c) digestive cancer in females, and (d) lung cancer in males.

In conclusion, study results suggest that diabetes and metabolic syndrome (or a combination of MRFs) may serve as markers for postmenopausal breast cancer risk, but not for overall or any other site-specific cancer risk. The association between diabetes and a combination of three or four MRFs and earlier age at onset was observed not only for postmenopausal breast cancer, but also for overall cancer in women 50 and older, digestive cancer in women, and lung cancer in males.

Future research needs to determine the underlying mechanisms that may predispose people with metabolic abnormalities to cancer. To this end, it is essential to examine the relationship among site-specific cancers, stratified by age, gender and race, with detailed information on triglycerides, low and high-density lipoprotein cholesterol levels, abdominal and visceral adiposity, blood glucose levels, duration of each abnormality, and medications and their period of use.

The positive association of a combination of MRFs with breast cancer in the metaanalysis points toward the need to develop public health strategies to manage these risk factors. Diabetes may also serve as a marker for postmenopausal breast cancer risk. Given the increasingly large global burden of metabolic risk factors, even a small association with breast cancer can have a substantial public health impact. Risk assessment tools can be developed that incorporate MRFs as a risk factor for breast cancer. Healthcare providers will then be better equipped to identify high-risk women for primary and secondary prevention. 


\section{Reference List}

(1) Esposito K, Chiodini P, Capuano A et al. Metabolic syndrome and postmenopausal breast cancer: systematic review and meta-analysis. Menopause 2013.

(2) Larsson SC, Mantzoros CS, Wolk A. Diabetes mellitus and risk of breast cancer: a metaanalysis. Int J Cancer 2007;121(4):856-862.

(3) Michels KB, Solomon CG, Hu FB et al. Type 2 diabetes and subsequent incidence of breast cancer in the Nurses' Health Study. Diabetes Care 2003;26(6):1752-1758.

(4) Kaaks R, Lukanova A. Energy balance and cancer: the role of insulin and insulin-like growth factor-I. Proc Nutr Soc 2001;60(1):91-106.

(5) Vigneri P, Frasca F, Sciacca L, Pandini G, Vigneri R. Diabetes and cancer. Endocr Relat Cancer 2009;16(4):1103-1123.

(6) Xie L, Wu K, Xu N, Chen D, Chen J, Lu S. Hypertension is associated with a high risk of cancer. J Hum Hypertens 1999;13(5):295-301.

(7) Norden A, Schersten B, Thulin T, Pero RW, Bryngelsson C, Mitelman F. Letter: Hypertension related to D.N.A. repair synthesis and carcinogen uptake. Lancet 1975;2(7944):1094.

(8) Healy LA, Ryan AM, Carroll P et al. Metabolic syndrome, central obesity and insulin resistance are associated with adverse pathological features in postmenopausal breast cancer. Clin Oncol (R Coll Radiol ) 2010;22(4):281-288.

(9) Li D, Morris JS, Liu J et al. Body mass index and risk, age of onset, and survival in patients with pancreatic cancer. JAMA 2009;301(24):2553-2562.

(10) Nothlings U, Wilkens LR, Murphy SP, Hankin JH, Henderson BE, Kolonel LN. Body mass index and physical activity as risk factors for pancreatic cancer: the Multiethnic Cohort Study. Cancer Causes Control 2007;18(2):165-175.

(11) Giovannucci E. Insulin, insulin-like growth factors and colon cancer: a review of the evidence. J Nutr 2001;131(11 Suppl):3109S-3120S.

(12) Shikata K, Ninomiya T, Kiyohara Y. Diabetes mellitus and cancer risk: review of the epidemiological evidence. Cancer Sci 2013;104(1):9-14.

(13) Stocks T, Rapp K, Bjorge T et al. Blood glucose and risk of incident and fatal cancer in the metabolic syndrome and cancer project (me-can): analysis of six prospective cohorts. PLoS Med 2009;6(12):e1000201.

(14) Jee SH, Ohrr H, Sull JW, Yun JE, Ji M, Samet JM. Fasting serum glucose level and cancer risk in Korean men and women. JAMA 2005;293(2):194-202. 
(15) Esposito K, Chiodini P, Colao A, Lenzi A, Giugliano D. Metabolic syndrome and risk of cancer: a systematic review and meta-analysis. Diabetes Care 2012;35(11):2402-2411.

(16) Osaki Y, Taniguchi S, Tahara A, Okamoto M, Kishimoto T. Metabolic syndrome and incidence of liver and breast cancers in Japan. Cancer Epidemiol 2012;36(2):141-147.

(17) Reeves KW, McLaughlin V, Fredman L, Ensrud K, Cauley JA. Components of metabolic syndrome and risk of breast cancer by prognostic features in the study of osteoporotic fractures cohort. Cancer Causes Control 2012;23(8):1241-1251.

(18) Cowey S, Hardy RW. The metabolic syndrome: A high-risk state for cancer? Am J Pathol 2006;169(5):1505-1522.

(19) Zhou JR, Blackburn GL, Walker WA. Symposium introduction: metabolic syndrome and the onset of cancer. Am J Clin Nutr 2007;86(3):s817-s819.

(20) Grundy SM. Metabolic syndrome pandemic. Arterioscler Thromb Vasc Biol 2008;28(4):629-636. 
APPENDIX A 
Appendix A: Table 1. Criteria for Risk of Bias Assessment.

\begin{tabular}{|c|c|c|c|}
\hline Criteria & Low Risk & High Risk & Unclear Risk \\
\hline Study design & $\begin{array}{l}\text { Prospective or retrospective cohort, } \\
\text { nested case-control }\end{array}$ & Case-control & $\begin{array}{l}\text { Information not } \\
\text { reported }\end{array}$ \\
\hline Adjustment of confounders & $\begin{array}{l}\text { Adjusted for } 4 \text { or more of the } \\
\text { following: age, education/income, } \\
\text { family history of cancer, hormone } \\
\text { therapy use/oral contraceptive } \\
\text { use/reproductive history, smoking } \\
\text { status, and alcohol consumption }\end{array}$ & $\begin{array}{l}\text { Adjusted for } 3 \text { or less of the following: } \\
\text { age, education/income, family history } \\
\text { of cancer, hormone therapy use/oral } \\
\text { contraceptive use/reproductive history, } \\
\text { smoking status, and alcohol } \\
\text { consumption }\end{array}$ & $\begin{array}{l}\text { Information not } \\
\text { reported }\end{array}$ \\
\hline $\begin{array}{l}\text { Selection of participants and } \\
\text { their eligibility criteria }\end{array}$ & $\begin{array}{l}\text { Studies clearly stating their eligibility } \\
\text { criteria and the sources and methods of } \\
\text { selection of participants }\end{array}$ & $\begin{array}{l}\text { Studies not clearly stating their } \\
\text { eligibility criteria and the sources and } \\
\text { methods of selection of participants }\end{array}$ & $\begin{array}{l}\text { Information not } \\
\text { reported }\end{array}$ \\
\hline $\begin{array}{l}\text { Measurement of predictor } \\
\text { variables }\end{array}$ & Identified through objective measures & $\begin{array}{l}\text { Self-reported or pharmaceutical } \\
\text { prescriptions }\end{array}$ & $\begin{array}{l}\text { Information not } \\
\text { reported }\end{array}$ \\
\hline Breast cancer diagnosis & $\begin{array}{l}\text { Histologically confirmed or identified } \\
\text { through cancer registry/ medical } \\
\text { records }\end{array}$ & Self-reported & $\begin{array}{l}\text { Information not } \\
\text { reported }\end{array}$ \\
\hline Study size & Large enough for adequate power & Not large enough for adequate power & $\begin{array}{l}\text { Information not } \\
\text { reported }\end{array}$ \\
\hline Handling of missing data & Missing data analysis specified & Missing data deleted from analysis & $\begin{array}{l}\text { Information not } \\
\text { reported }\end{array}$ \\
\hline $\begin{array}{l}\text { Reasons for non- } \\
\text { participation of individuals } \\
\text { at each stage of the study }\end{array}$ & $\begin{array}{l}\text { Reasons clearly reported for each stage } \\
\text { of study }\end{array}$ & $\begin{array}{l}\text { Reasons not reported for each stage of } \\
\text { study }\end{array}$ & $\begin{array}{l}\text { Information not } \\
\text { reported }\end{array}$ \\
\hline
\end{tabular}


Appendix A: Table 2. Characteristics of Studies.

\begin{tabular}{|c|c|c|c|c|c|c|c|c|c|c|}
\hline Author & Year & Country & $\begin{array}{l}\text { Study } \\
\text { Design }\end{array}$ & $\begin{array}{l}\text { Sample } \\
\text { Size }\end{array}$ & $\begin{array}{l}\text { Baseline } \\
\text { Year }\end{array}$ & $\begin{array}{l}\text { Follow- } \\
\text { up } \\
\text { Years }\end{array}$ & Age & $\begin{array}{l}\text { Breast } \\
\text { Cancer } \\
\text { Cases }\end{array}$ & $\begin{array}{l}\text { Menopausal } \\
\text { Status }\end{array}$ & Statistic \\
\hline Agnoli et al. ${ }^{43}$ & 2010 & Italy & $\begin{array}{l}\text { Prospective } \\
\text { nested case- } \\
\text { control }\end{array}$ & 792 & $1987-92$ & 2003 & $35-69$ & 163 & Post & Rate ratios \\
\hline Bosco $^{61}$ & 2011 & USA & $\begin{array}{l}\text { Prospective } \\
\text { cohort }\end{array}$ & 49,172 & 1995 & 2007 & $21-69$ & 1228 & Mixed, post & $\begin{array}{l}\text { Incidence rate } \\
\text { ratios }\end{array}$ \\
\hline Inoue et al. ${ }^{62}$ & 2009 & Japan & $\begin{array}{l}\text { Prospective } \\
\text { cohort }\end{array}$ & 18,176 & $1990-94$ & 2004 & $40-69$ & 120 & Mixed, post & Hazard ratios \\
\hline Kabat et al. ${ }^{48}$ & 2009 & USA & $\begin{array}{l}\text { Prospective } \\
\text { cohort }\end{array}$ & 4,888 & 1993-98 & 2005 & $50-79$ & 165 & Post & Hazard ratios \\
\hline Osaki et al. ${ }^{13}$ & 2012 & Japan & $\begin{array}{l}\text { Retrospectiv } \\
\text { e cohort }\end{array}$ & 15,386 & $\begin{array}{l}1992- \\
2000\end{array}$ & 2007 & $20+$ & 77 & Mixed, post & Hazard ratios \\
\hline Ronco et al. ${ }^{51}$ & 2012 & Uruguay & Case-control & 912 & 2004 & 2009 & $<70$ & 367 & Post & Odds ratios \\
\hline $\begin{array}{l}\text { Rosato et al. - } \\
\text { Cohort I }{ }^{14}\end{array}$ & 2011 & Italy & Case-control & 3,858 & 1983 & 1994 & $33-86$ & 1,988 & Post & Odds ratios \\
\hline $\begin{array}{l}\text { Rosato et al.- } \\
\text { Cohort II }^{14}\end{array}$ & 2011 & $\begin{array}{l}\text { Italy and } \\
\text { Switzerland }\end{array}$ & Case-control & 4,093 & 1991 & 2007 & $33-79$ & 1,881 & Post & Odds ratios \\
\hline Russo et al. ${ }^{63}$ & 2008 & Italy & $\begin{array}{l}\text { Prospective } \\
\text { cohort }\end{array}$ & $\begin{array}{l}\text { Not } \\
\text { reported }\end{array}$ & 1999 & 2005 & $\geq 40$ & 99 & Mixed & $\begin{array}{l}\text { Standardized } \\
\text { incidence } \\
\text { ratios }\end{array}$ \\
\hline
\end{tabular}

\footnotetext{
Note: Citations for the included studies are in the reference section of Chapter 2, pages 28-36.
} 
Appendix A: Table 2 (continued).

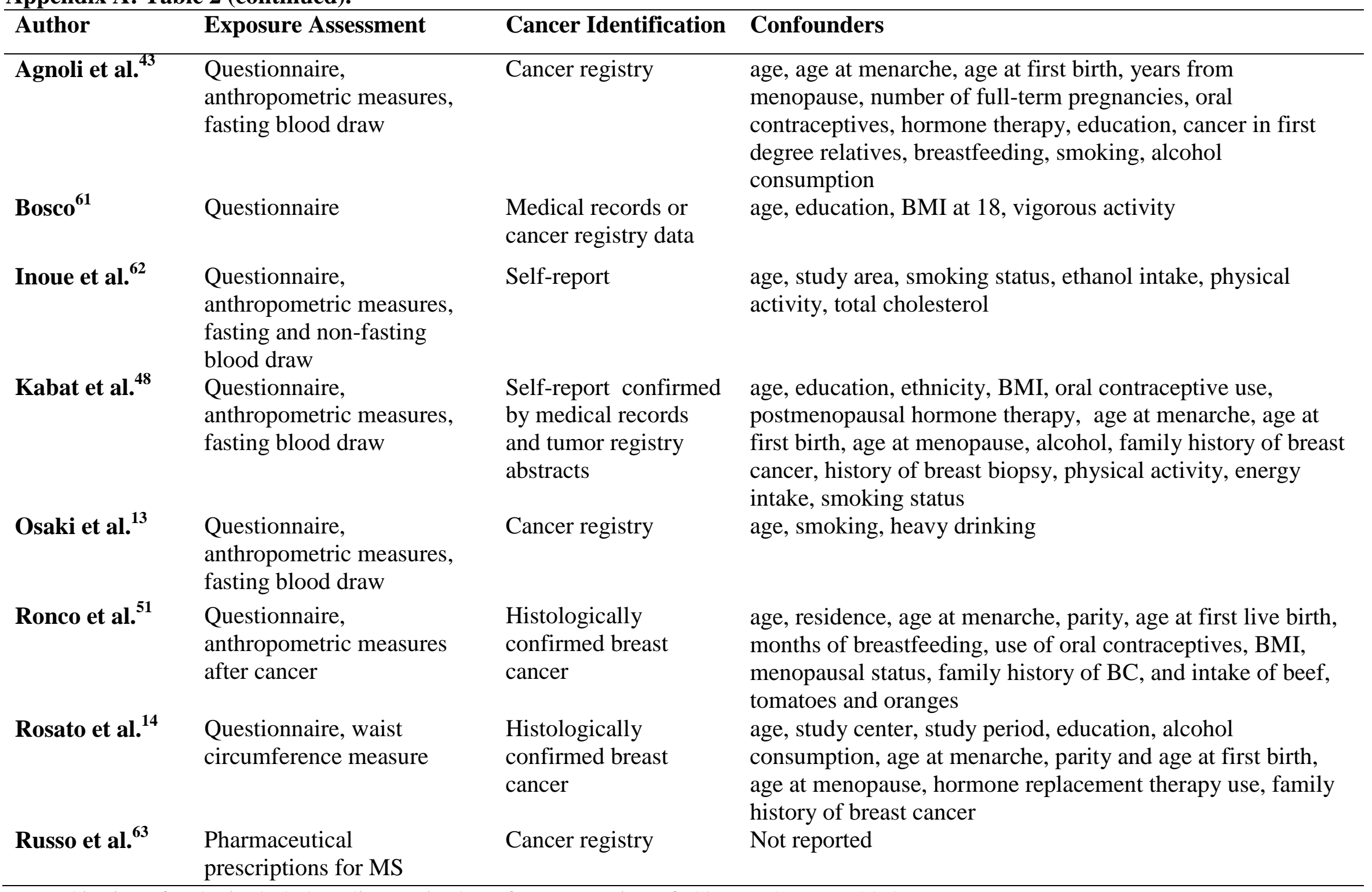

Note: Citations for the included studies are in the reference section of Chapter 2, pages 28-36. 


\section{Appendix A: Table 3. Definitions and Criteria for Metabolic Syndrome in the Included Studies.}

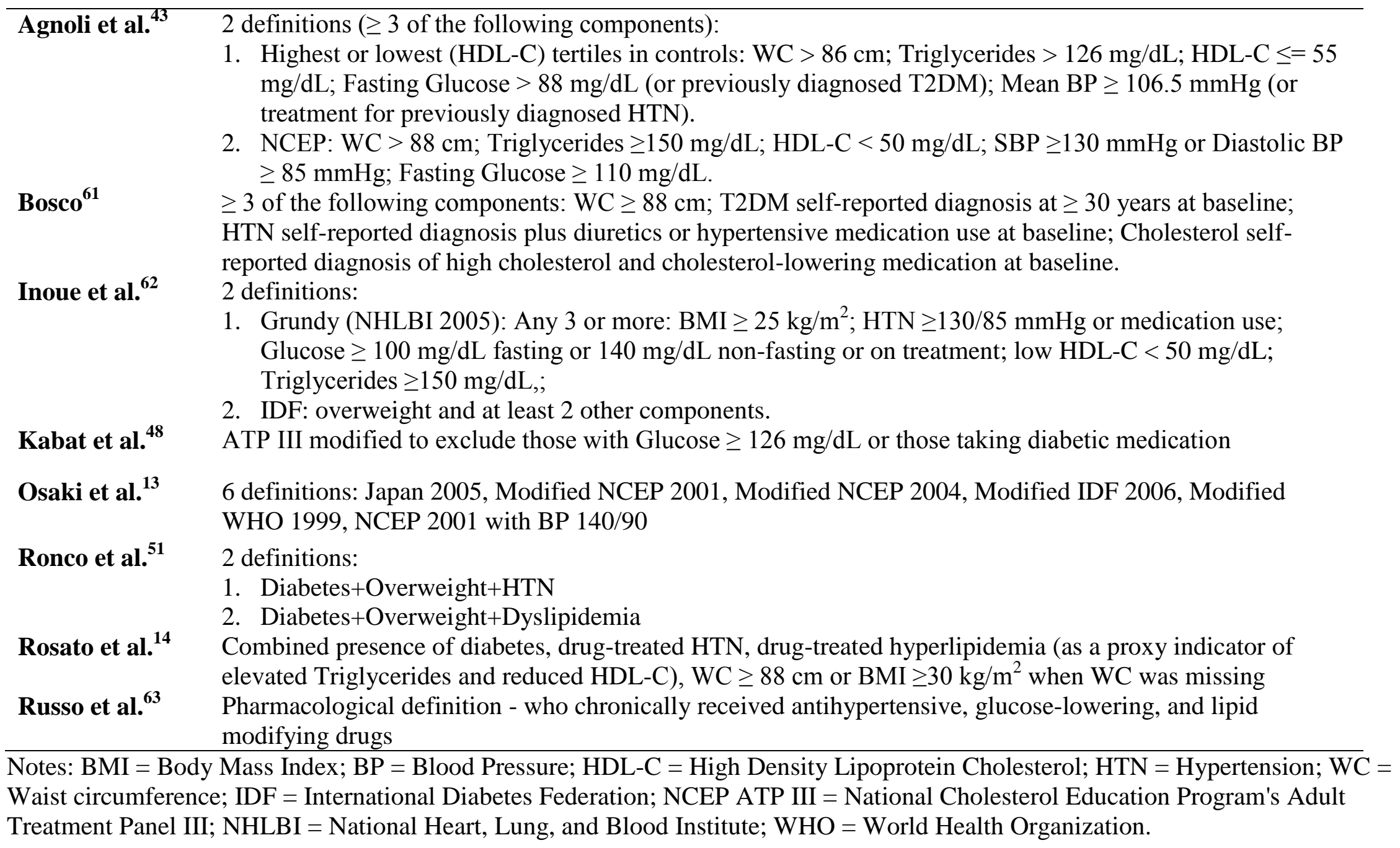

Note: Citations for the included studies are in the reference section of Chapter 2, pages 28-36. 
Appendix A: Table 4. Study-Level Results for Risk of Bias Assessment.

\begin{tabular}{|c|c|c|c|c|c|c|c|c|}
\hline Methods & $\begin{array}{l}\text { Agnoli } \\
\text { et al. }{ }^{43}\end{array}$ & Bosco $^{61}$ & $\begin{array}{l}\text { Inoue } \\
\text { et al. }{ }^{62}\end{array}$ & $\begin{array}{l}\text { Kabat } \\
\text { et al. }{ }^{48}\end{array}$ & $\begin{array}{l}\text { Osaki } \\
\text { et al. }\end{array}$ & $\begin{array}{l}\text { Ronco } \\
\text { et al. } 51\end{array}$ & $\begin{array}{l}\text { Rosato } \\
\text { et al. }{ }^{14}\end{array}$ & $\begin{array}{l}\text { Russo et } \\
\text { al. }^{63}\end{array}$ \\
\hline Study design & Low & Low & Low & Low & Low & High & High & Low \\
\hline Variables (confounders) & Low & High & High & Low & High & Low & Low & Unclear \\
\hline Participants (eligibility, selection) & Low & Low & Low & Low & Low & Low & Low & Low \\
\hline Data sources/ predictor measurement & Low & High & Low & Low & Low & High & High & High \\
\hline Data sources/ outcome measurement & Low & Low & High & Low & Low & Low & Low & Low \\
\hline Study size (adequate power) & Low & Low & Low & Low & Low & Low & Low & Low \\
\hline Missing data analysis & High & High & High & Low & High & Low & Unclear & Unclear \\
\hline \multicolumn{9}{|l|}{ Results } \\
\hline Participants (non-participation) & High & High & High & High & Low & Low & High & High \\
\hline
\end{tabular}

Note: Citations for the included studies are in the reference section of Chapter 2, pages 28-36. 


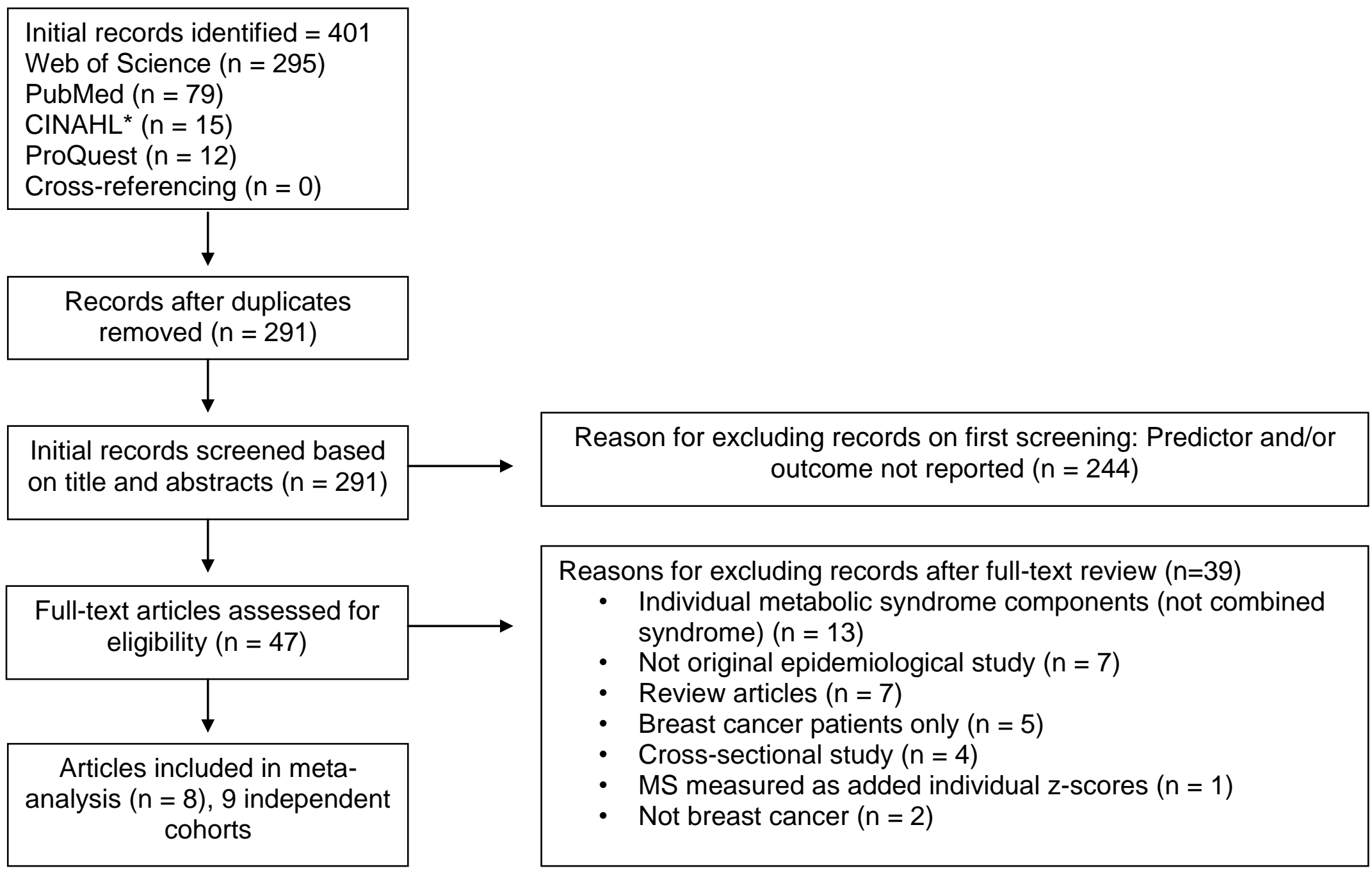

Figure 1. Flow diagram describing the selection of studies.

*CINAHL: Cumulated Index to Nursing and Allied Health Literature. 


\begin{tabular}{lccr} 
Study name & \multicolumn{3}{c}{ Statistics for each study } \\
& $\begin{array}{c}\text { Risk } \\
\text { ratio }\end{array}$ & $\begin{array}{c}\text { Lower } \\
\text { limit }\end{array}$ & $\begin{array}{c}\text { Upper } \\
\text { limit }\end{array}$ \\
Agnoli, 2010 & 1.58 & 1.07 & 2.33 \\
Bosco, 2011 & 1.14 & 0.79 & 1.64 \\
Inoue, 2009 & 0.82 & 0.50 & 1.35 \\
Kabat, 2009 & 1.12 & 0.78 & 1.61 \\
Osaki, 2012 & 2.87 & 1.67 & 4.94 \\
Ronco, 2012 & 5.79 & 1.52 & 22.03 \\
Rosato-I, 2011 & 1.76 & 1.03 & 3.01 \\
Rosato-II, 2011 & 1.87 & 1.42 & 2.47 \\
Russo, 2008 & 1.17 & 0.95 & 1.44 \\
& 1.47 & 1.15 & 1.87
\end{tabular}

Risk ratio and $95 \% \mathrm{Cl}$

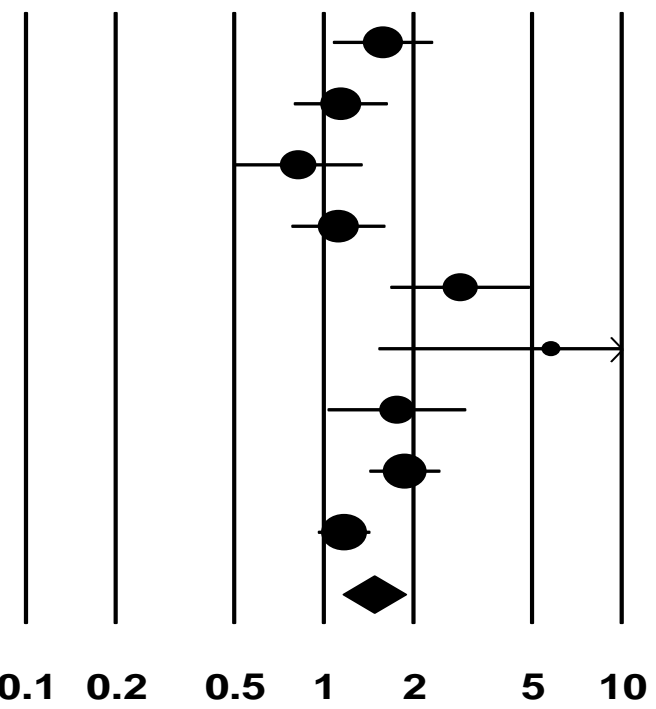

Reduced Risk

Increased Risk

Figure 2. Forest plot for metabolic syndrome and breast cancer risk (random-effects model).

The black circles represent the weighted risk ratio (RR) for each result from each study while the horizontal lines represent the lower and upper 95\% confidence intervals (CI) for the RR. The black diamond represents the overall pooled RR while the left and right sides of the diamond represent the lower and upper $95 \%$ CI for the pooled RR. For studies that included more than one definition of metabolic syndrome, the following were used: Agnoli et al. (tertile definition), Bosco (time-independent definition), Osaki et al. (modified NCEP 2001 definition), Ronco et al. (diabetes, overweight and hypertension definition). 


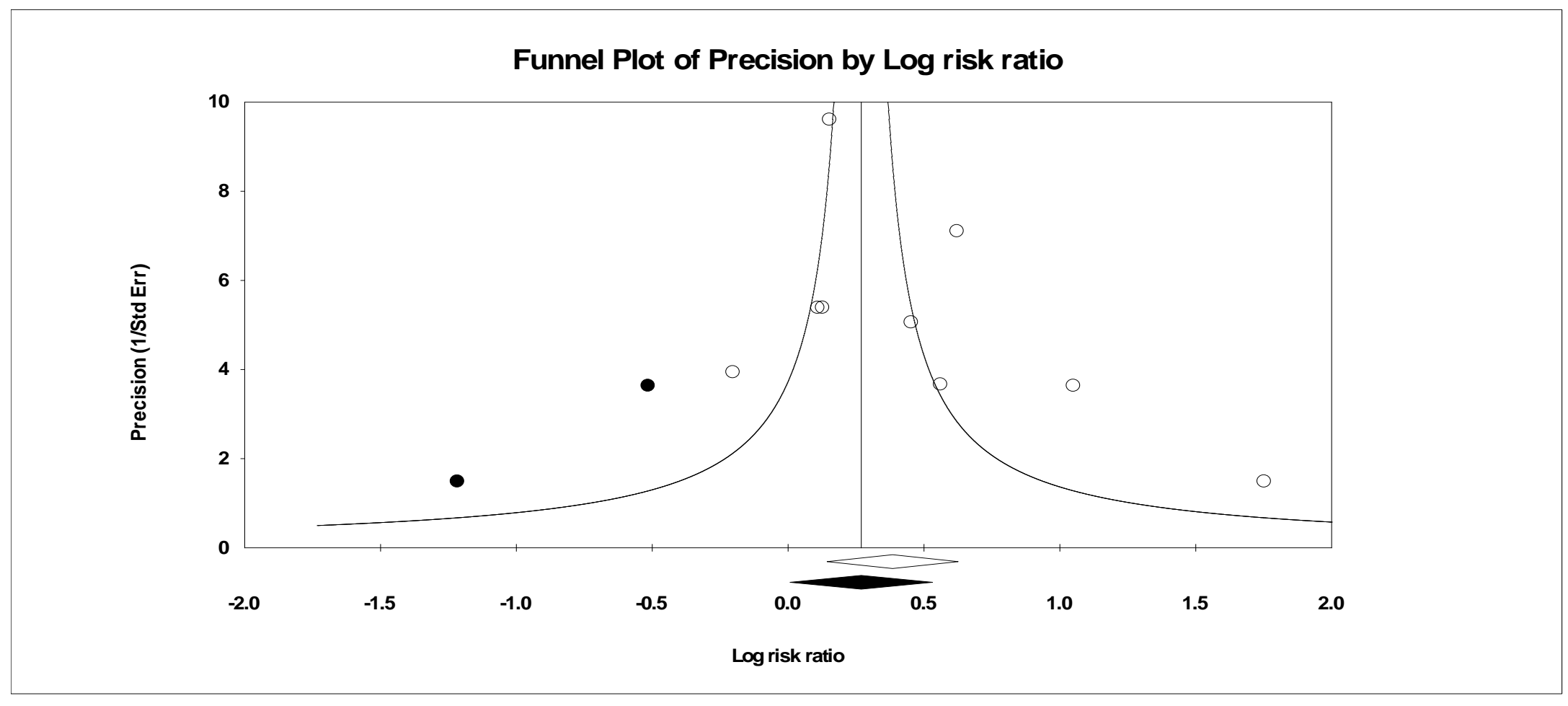

Figure 3. Funnel plot and Trim and Fill procedure for assessing publication bias.

The white circles represent the log risk ratios (LRR) for each result from each study while the black circles represent the imputed LRR (n $=$ 2). The white diamond represents the pooled LRR while the black diamond represents the pooled LRR, including the two imputed values. The left and right sides of each diamond represent the lower and upper 95\% confidence intervals. For those studies that included more than one definition of metabolic syndrome, the following were used: Agnoli et al. (tertile definition), Bosco (time independent definition), Osaki et al. (modified NCEP 2001 definition), and Ronco et al. (diabetes, overweight and hypertension definition). 


\begin{tabular}{lccc} 
Study name & \multicolumn{3}{c}{ Statistics with study removed } \\
\cline { 2 - 4 } & Point & $\begin{array}{c}\text { Lower } \\
\text { limit }\end{array}$ & $\begin{array}{c}\text { Upper } \\
\text { limit }\end{array}$ \\
Osaki, 2012 & 1.36 & 1.09 & 1.70 \\
Rosato-II, 2011 & 1.41 & 1.09 & 1.82 \\
Ronco, 2012 & 1.41 & 1.12 & 1.77 \\
Rosato-I, 2011 & 1.44 & 1.11 & 1.88 \\
Agnoli, 2010 & 1.46 & 1.11 & 1.92 \\
Bosco, 2011 & 1.53 & 1.17 & 2.01 \\
Kabat, 2009 & 1.54 & 1.17 & 2.01 \\
Russo, 2008 & 1.54 & 1.16 & 2.05 \\
Inoue, 2009 & 1.56 & 1.22 & 1.99 \\
& 1.47 & 1.15 & 1.87
\end{tabular}

Risk ratio $(95 \% \mathrm{Cl})$ with study removed

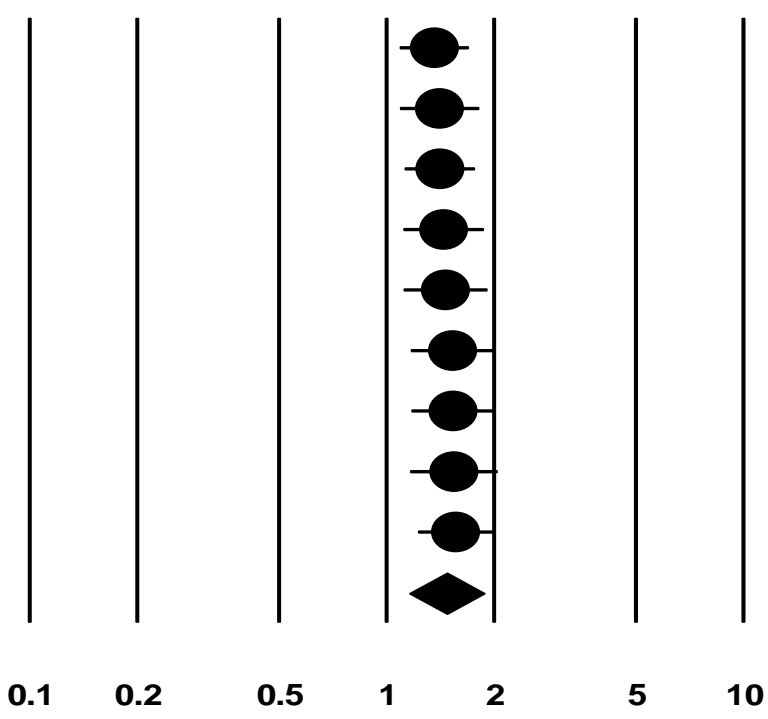

Reduced Risk Increased Risk

Figure 4. Influence analysis with each result from each study deleted from the random-effects model once.

The black circles represent the risk ratio (RR) for each result from each study while the horizontal lines represent the lower and upper 95\% confidence interval (CI) for the RR. The black diamond represents the overall pooled result while the left and right sides of the diamond represent the lower and upper 95\% CI for the pooled RR. For studies that included more than one definition of metabolic syndrome, the following were used: Agnoli et al. (tertile definition), Bosco (time-independent definition), Osaki et al. (modified NCEP 2001 definition), and Ronco et al. (diabetes, overweight and hypertension definition). 


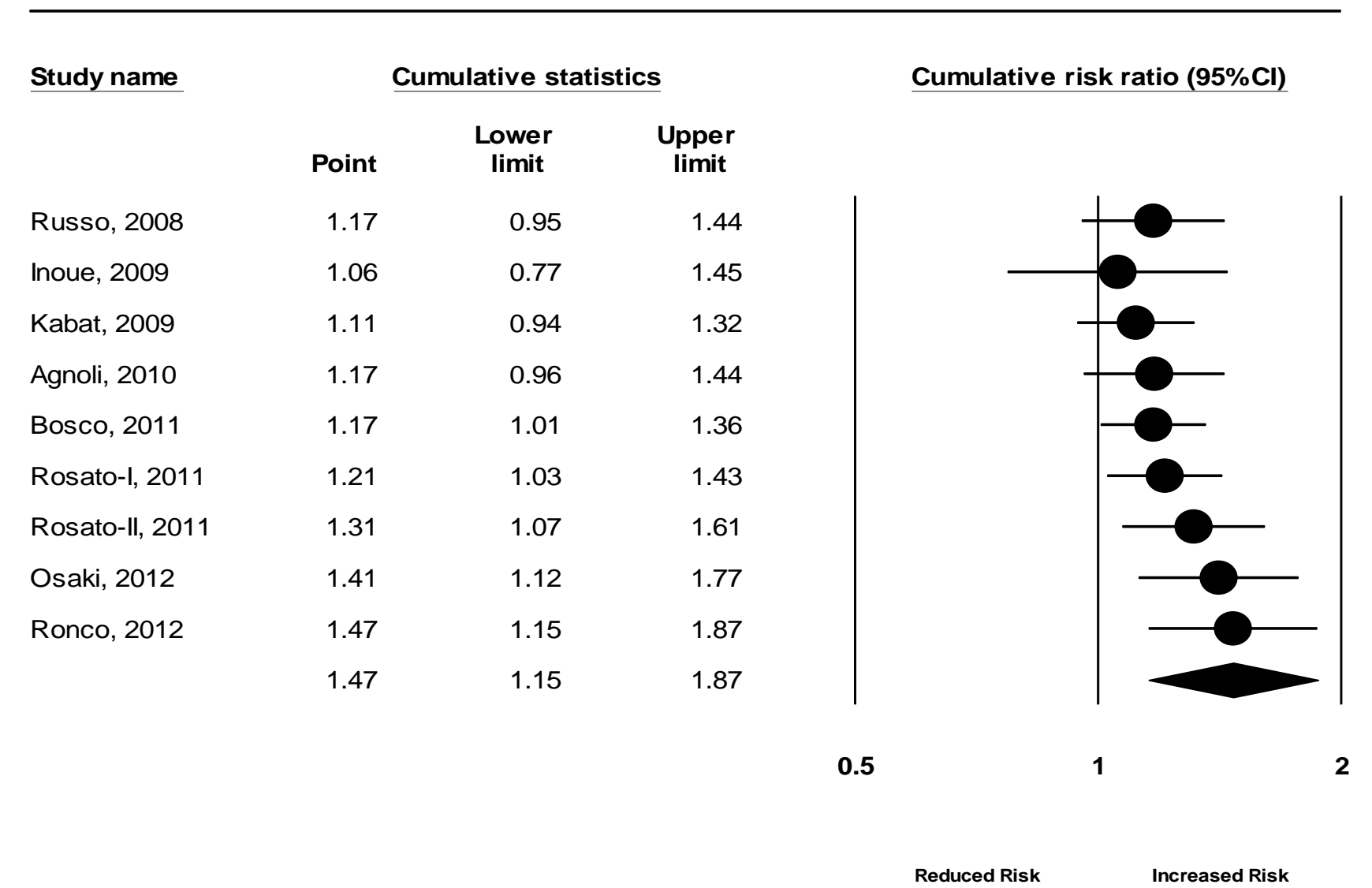

Figure 5. Cumulative meta-analysis, ranked by year and based on a random-effects model.

The black circles represent the cumulative risk ratios (RR) for each result from each study while the horizontal lines represent the lower and upper $95 \%$ confidence intervals for the RR. The black diamond represents the overall pooled RR while the left and right sides of the diamond represent the lower and upper 95\% confidence intervals for the pooled RR. For those studies that included more than one definition of metabolic syndrome, the following were used: Agnoli et al. (tertile definition), Bosco (time independent definition), Osaki et al. (modified NCEP 2001 definition), and Ronco et al. (diabetes, overweight and hypertension definition). 
APPENDIX B 
Appendix B: Association between metabolic risk factors and cancer risk

Table 1: Characteristics of the Study Population, National Health and Nutrition Examination Survey I (NHANES I) Epidemiologic Follow-up Study, 1971-1992 (Unweighted sample size $=10,694$ )

\begin{tabular}{|c|c|c|c|}
\hline $\begin{array}{l}\text { Characteristics of the study } \\
\text { population }\end{array}$ & Total & $\%$ & Mean (SE) \\
\hline Age at baseline (years) & & & $48.78(0.15)$ \\
\hline Women & 6339 & 59.3 & \\
\hline Men & 4355 & 40.7 & \\
\hline \multicolumn{4}{|l|}{ Race/ethnicity } \\
\hline White & 9125 & 85.3 & \\
\hline Non-white & 1569 & 14.7 & \\
\hline \multicolumn{4}{|l|}{ Family income } \\
\hline Below $\$ 5,000$ & 2794 & 26.1 & \\
\hline$\$ 5,001-\$ 15,000$ & 5558 & 52.0 & \\
\hline Above $\$ 15,000$ & 2342 & 21.9 & \\
\hline \multicolumn{4}{|l|}{ Education } \\
\hline High school or less & 8159 & 76.3 & \\
\hline Above high school & 2535 & 23.7 & \\
\hline \multicolumn{4}{|l|}{ Physical activity } \\
\hline Moderately or very active & 9652 & 90.3 & \\
\hline Quite inactive & 1042 & 9.7 & \\
\hline \multicolumn{4}{|c|}{ Smoked 100 cigarettes in lifetime } \\
\hline Yes & 5786 & 54.1 & \\
\hline No & 4477 & 41.9 & \\
\hline Missing & 431 & 4.0 & \\
\hline \multicolumn{4}{|l|}{ Family history of cancer } \\
\hline Yes & 3763 & 35.2 & \\
\hline No & 6006 & 56.2 & \\
\hline Missing & 925 & 8.6 & \\
\hline BMI, $\mathrm{kg} / \mathrm{m}^{2}$ & & & $25.68(0.05)$ \\
\hline \multicolumn{4}{|l|}{ BMI categories } \\
\hline Underweight & 333 & 3.1 & \\
\hline Healthy weight & 5020 & 46.9 & \\
\hline Overweight & 3562 & 33.3 & \\
\hline Obese & 1779 & 16.6 & \\
\hline \multicolumn{4}{|l|}{ Blood pressure } \\
\hline High BP & 4851 & 45.4 & \\
\hline No high BP & 5843 & 54.6 & \\
\hline Diastolic (mmHg) & & & $83.54(0.13)$ \\
\hline Systolic (mmHg) & & & $134.03(0.23)$ \\
\hline
\end{tabular}




\begin{tabular}{|c|c|c|c|}
\hline Serum cholesterol (mg/dL) & & & $220.82(0.47)$ \\
\hline $\operatorname{High}(>=240 \mathrm{mg} / \mathrm{dL})$ & 3383 & 31.6 & \\
\hline Not high cholesterol & 7311 & 68.4 & \\
\hline \multicolumn{4}{|l|}{ Diabetes } \\
\hline Yes & 518 & 4.8 & \\
\hline No & 7969 & 74.5 & \\
\hline Missing & 2207 & 20.6 & \\
\hline \multicolumn{4}{|l|}{ Metabolic Risk Factor (MRF) } \\
\hline MRF 0 & 3031 & 28.3 & \\
\hline MRF 1 & 2925 & 27.4 & \\
\hline MRF 2 & 1924 & 18.0 & \\
\hline MRF 3 or 4 & 607 & 5.7 & \\
\hline Missing & 2322 & 21.7 & \\
\hline
\end{tabular}

Abbreviations: BMI, Body Mass Index; BP, Blood Pressure; MRF, Metabolic Risk Factor; SE, Standard Error. 


\section{Appendix B}

Table 2: Association between Individual Metabolic Risk Factors and Cancer Risk among Males

\begin{tabular}{|c|c|c|c|c|c|c|}
\hline & \multicolumn{3}{|c|}{ Age $<50$ Years $(n=1972$, Cancer cases $=140)$} & \multicolumn{3}{|c|}{ Age $\geq 50$ Years $(n=2383$, Cancer cases $=691)$} \\
\hline Variable & Cancer cases & Sample size & $\begin{array}{c}\text { Hazard ratio }^{a} \\
(95 \% \mathrm{CI})\end{array}$ & Cancer cases & Sample size & $\begin{array}{l}\text { Hazard ratio }^{\mathrm{a}} \\
(95 \% \mathrm{CI})\end{array}$ \\
\hline $\mathrm{BMI} \geq 30$ & 18 & 244 & $1.00(0.57,1.76)$ & 89 & 323 & $1.08(0.81,1.46)$ \\
\hline $\mathrm{BMI}<30$ & 122 & 1728 & Referent & 602 & 2060 & Referent \\
\hline High BP & 56 & 741 & $0.89(0.63,1.25)$ & 398 & 1498 & $0.84(0.68,1.05)$ \\
\hline$<$ High BP & 84 & 1231 & Referent & 293 & 885 & Referent \\
\hline Cholesterol $\geq 240$ & 44 & 484 & $1.21(0.85,1.72)$ & 232 & 855 & $1.00(0.81,1.23)$ \\
\hline Cholesterol<240 & 96 & 1488 & Referent & 459 & 1528 & Referent \\
\hline Diabetes & 4 & 37 & $1.02(0.32,3.29)$ & 34 & 175 & $1.05(0.60,1.84)$ \\
\hline No Diabetes & 102 & 1350 & Referent & 524 & 1794 & Referent \\
\hline Missing & 34 & 585 & & 133 & 414 & \\
\hline
\end{tabular}

Abbreviations: BMI, Body Mass Index; BP, Blood Pressure; CI, Confidence Interval.

${ }^{\mathrm{a}}$ Hazard ratios were adjusted for age (years, continuous), race (White, others), education (high school or less, college), family income $(\langle \$ 5,000, \$ 5,000$ to $\langle \$ 15,000$, and $>=\$ 15,000)$, smoking status (smoked 100 cigarettes in one's lifetime, yes, no or missing data), family history of cancer (yes, no or missing data), and physical activity (moderately or very active, quite inactive). 


\section{Appendix B}

Table 3: Association between Individual Metabolic Risk Factors and Cancer Risk among Females

\begin{tabular}{|c|c|c|c|c|c|c|}
\hline & \multicolumn{3}{|c|}{ Age $<50$ Years $(n=3722$, Cancer cases $=364)$} & \multicolumn{3}{|c|}{ Age $\geq 50$ Years $(n=2617$, Cancer cases $=572)$} \\
\hline Variable & Cancer cases & Sample size & $\begin{array}{c}\text { Hazard ratio }^{\mathrm{a}} \\
(95 \% \mathrm{CI})\end{array}$ & Cancer cases & Sample size & $\begin{array}{l}\text { Hazard ratio }^{\mathrm{a}} \\
(95 \% \mathrm{CI})\end{array}$ \\
\hline $\mathrm{BMI} \geq 30$ & 70 & 575 & $1.18(0.80,1.74)$ & 129 & 637 & $0.74(0.54,0.99)$ \\
\hline $\mathrm{BMI}<30$ & 294 & 3147 & Referent & 443 & 1980 & Referent \\
\hline High BP & 96 & 843 & $1.02(0.71,1.46)$ & 375 & 1769 & $0.97(0.78,1.21)$ \\
\hline$<$ High BP & 268 & 2879 & Referent & 197 & 848 & Referent \\
\hline Cholesterol $\geq 240$ & 83 & 617 & $1.20(0.89,1.61)$ & 322 & 1427 & $1.27(1.01,1.58)$ \\
\hline Cholesterol<240 & 281 & 3105 & Referent & 250 & 1190 & Referent \\
\hline Diabetes & 10 & 72 & $0.91(0.38,2.17)$ & 39 & 234 & $1.12(0.70,1.78)$ \\
\hline No Diabetes & 293 & 2898 & Referent & 441 & 1927 & Referent \\
\hline Missing & 61 & 752 & & 92 & 456 & \\
\hline
\end{tabular}

Abbreviations: BMI, Body Mass Index; BP, Blood Pressure; CI, Confidence Interval.

${ }^{\mathrm{a}}$ Hazard ratios were adjusted for age (years, continuous), race (White, others), education (high school or less, college), family income $(<5,000, \$ 5,000$ to $\langle \$ 15,000$, and $\rangle=\$ 15,000)$, smoking status (smoked 100 cigarettes in one's lifetime, yes, no or missing data), family history of cancer (yes, no or missing data), and physical activity (moderately or very active, quite inactive). 


\section{Appendix B}

Table 4: Association between Combined Metabolic Risk Factors Score and Cancer Risk among Males

\begin{tabular}{|lrrcrrr|}
\hline & \multicolumn{2}{c}{ Age $<50$ Years $(\mathrm{n}=1987$, Cancer cases $=141)$} & \multicolumn{2}{c|}{ Age $\geq 50$ Years $(\mathrm{n}=2396$, Cancer cases $=692)$} \\
\hline Variable & Cancer cases & Sample size & $\begin{array}{c}\text { Hazard ratio } \\
(95 \% \text { CI })\end{array}$ & $\begin{array}{c}\text { Cancer cases } \\
\text { Sample size }\end{array}$ & $\begin{array}{c}\text { Hazard ratio }^{\mathrm{a}} \\
(95 \% \text { CI })\end{array}$ \\
\hline MRF 3 or 4 & 5 & 53 & $1.09(0.40,2.98)$ & 23 & 120 & $0.63(0.35,1.12)$ \\
MRF 2 & 21 & 205 & $1.11(0.68,1.80)$ & 148 & 591 & $0.81(0.59,1.12)$ \\
MRF 1 & 37 & 501 & $0.92(0.55,1.55)$ & 250 & 850 & $0.93(0.67,1.28)$ \\
MRF 0 & 43 & 628 & Referent & 137 & 408 & Referent \\
Missing & 35 & 600 & & 134 & 427 & \\
\hline
\end{tabular}

Abbreviations: CI, Confidence Interval; MRF, Metabolic Risk Factor.

${ }^{\mathrm{a}}$ Hazard ratios were adjusted for age (years, continuous), race (White, others), education (high school or less, college), family income $(\langle \$ 5,000, \$ 5,000$ to $\langle \$ 15,000$, and $\rangle=\$ 15,000)$, smoking status (smoked 100 cigarettes in one's lifetime, yes, no or missing data), family history of cancer (yes, no or missing data), and physical activity (moderately or very active, quite inactive). 


\section{Appendix B}

Table 5: Association between Combined Metabolic Risk Factors Score and Cancer Risk among Females

\begin{tabular}{|lrrcrrr|}
\hline & \multicolumn{2}{c}{ Age $<50$ Years $(\mathrm{n}=3773$, Cancer cases $=371)$} & \multicolumn{2}{c|}{ Age $\geq 50$ Years $(\mathrm{n}=2653$, Cancer cases $=580)$} \\
\hline Variable & Sample size & Cancer cases & $\begin{array}{c}\text { Hazard ratio } \\
(95 \% \text { CI })\end{array}$ & $\begin{array}{c}\text { Sample size } \\
\text { Cancer cases }\end{array}$ & $\begin{array}{c}\text { Hazard ratio }^{\mathrm{a}} \\
(95 \% \text { CI })\end{array}$ \\
\hline MRF 3 or 4 & 13 & 70 & $1.30(0.65,2.60)$ & 75 & 364 & $1.14(0.69,1.90)$ \\
MRF 2 & 50 & 351 & $1.41(0.90,2.20)$ & 175 & 165 & $0.99(0.68,1.44)$ \\
MRF 1 & 81 & 816 & $1.04(0.75,1.43)$ & 65 & 758 & $0.92(0.64,1.32)$ \\
MRF 0 & 159 & 1733 & Referent & 100 & 262 & Referent \\
Missing & 68 & 803 & & & 492 & \\
\hline
\end{tabular}

Abbreviations: CI, Confidence Interval; MRF, Metabolic Risk Factor.

${ }^{\mathrm{a}}$ Hazard ratios were adjusted for age (years, continuous), race (White, others), education (high school or less, college), family income $(\langle \$ 5,000, \$ 5,000$ to $\langle \$ 15,000$, and $\rangle=\$ 15,000)$, smoking status (smoked 100 cigarettes in one's lifetime, yes, no or missing data), family history of cancer (yes, no or missing data), and physical activity (moderately or very active, quite inactive). 


\section{Appendix B}

Table 6: Association between Individual Metabolic Risk Factors and Breast Cancer Risk among Females

\begin{tabular}{|c|c|c|c|c|c|c|}
\hline & \multicolumn{3}{|c|}{ All women $(n=6339$, Cancer cases $=236)$} & \multicolumn{3}{|c|}{$\begin{array}{c}\text { Postmenopausal women } \\
(\mathrm{n}=2954, \text { Cancer cases }=124)\end{array}$} \\
\hline Variable & Cancer cases & Sample size & $\begin{array}{l}\text { Hazard ratio }^{a} \\
(95 \% \mathrm{CI})\end{array}$ & Cancer cases & Sample size & $\begin{array}{l}\text { Hazard ratio }^{\mathrm{a}} \\
(95 \% \mathrm{CI})\end{array}$ \\
\hline $\mathrm{BMI} \geq 30$ & 50 & 1212 & $0.81(0.51,1.31)$ & 33 & 700 & $0.80(0.43,1.50)$ \\
\hline $\mathrm{BMI}<30$ & 186 & 5127 & Referent & 91 & 2254 & Referent \\
\hline High BP & 107 & 2612 & $1.19(0.81,1.73)$ & 83 & 1847 & $1.70(1.001,2.88)$ \\
\hline$<$ High BP & 129 & 3727 & Referent & 41 & 1107 & Referent \\
\hline Cholesterol $\geq 240$ & 89 & 2044 & $1.13(0.78,1.63)$ & 66 & 1487 & $1.16(0.75,1.79)$ \\
\hline Cholesterol<240 & 147 & 4295 & Referent & 58 & 1467 & Referent \\
\hline Diabetes & 14 & 306 & $1.63(0.81,3.29)$ & 13 & 245 & $2.32(1.09,4.95)$ \\
\hline No Diabetes & 177 & 4825 & Referent & 83 & 2171 & Referent \\
\hline Missing & 45 & 1208 & & 28 & 538 & \\
\hline
\end{tabular}

Abbreviations: BMI, Body Mass Index; BP, Blood Pressure; CI, Confidence Interval.

${ }^{\mathrm{a}}$ Hazard ratios were adjusted for age (years, continuous), race (White, others), education (high school or less, college), family income $(<5,000, \$ 5,000$ to $\langle \$ 15,000$, and $\rangle=\$ 15,000)$, smoking status (smoked 100 cigarettes in one's lifetime, yes, no or missing data), family history of cancer (yes, no or missing data), and physical activity (moderately or very active, quite inactive). 


\section{Appendix B}

Table 7: Association between Combined Metabolic Risk Factors Score and Breast Cancer Risk among Females

\begin{tabular}{|c|c|c|c|c|c|c|}
\hline \multirow[b]{2}{*}{ Variable } & \multicolumn{3}{|c|}{$\begin{array}{c}\text { All women } \\
(\mathrm{n}=6426, \text { Cancer cases }=239)\end{array}$} & \multicolumn{3}{|c|}{$\begin{array}{c}\text { Postmenopausal women } \\
(\mathrm{n}=2998, \text { Cancer cases }=126)\end{array}$} \\
\hline & Cancer cases & Sample size & $\begin{array}{l}\text { Hazard ratio }^{\mathrm{a}} \\
\quad(95 \% \mathrm{CI})\end{array}$ & Cancer cases & Sample size & $\begin{array}{c}\text { Hazard ratio }^{\mathrm{a}} \\
(95 \% \mathrm{CI}) \\
\end{array}$ \\
\hline MRF 3 or 4 & 21 & 434 & $1.44(0.68,3.04)$ & 19 & 365 & $3.26(1.23,8.65)$ \\
\hline MRF 2 & 46 & 1128 & $1.09(0.62,1.92)$ & 34 & 819 & $2.16(0.89,5.22)$ \\
\hline MRF 1 & 56 & 1574 & $0.93(0.57,1.52)$ & 30 & 837 & $1.53(0.64,3.62)$ \\
\hline MRF 0 & 68 & 1995 & Referent & 13 & 395 & Referent \\
\hline Missing & 48 & 1295 & & 30 & 582 & \\
\hline
\end{tabular}

Abbreviations: CI, Confidence Interval; MRF, Metabolic Risk Factor.

${ }^{\mathrm{a}}$ Hazard ratios were adjusted for age (years, continuous), race (White, others), education (high school or less, college), family income $(\langle \$ 5,000, \$ 5,000$ to $\langle \$ 15,000$, and $\rangle=\$ 15,000)$, smoking status (smoked 100 cigarettes in one's lifetime, yes, no or missing data), family history of cancer (yes, no or missing data), and physical activity (moderately or very active, quite inactive). 


\section{Appendix B}

Table 8: Association between Individual Metabolic Risk Factors and Digestive Cancer Risk by Gender

\begin{tabular}{|c|c|c|c|c|c|c|}
\hline \multicolumn{4}{|c|}{ Males $(n=4355$, Cancer cases $=196)$} & \multicolumn{3}{|c|}{ Females $(n=6339$, Cancer cases $=207)$} \\
\hline Variable & Cancer cases & Sample size & $\begin{array}{c}\text { Hazard ratio }^{\mathrm{a}} \\
(95 \% \mathrm{CI})\end{array}$ & Cancer cases & Sample size & $\begin{array}{l}\text { Hazard ratio }^{\mathrm{a}} \\
(95 \% \mathrm{CI})\end{array}$ \\
\hline $\mathrm{BMI} \geq 30$ & 36 & 567 & $1.92(1.15,3.21)$ & 52 & 1212 & $0.86(0.58,1.29)$ \\
\hline $\mathrm{BMI}<30$ & 160 & 3788 & Referent & 155 & 5127 & Referent \\
\hline High BP & 116 & 2239 & $1.02(0.65,1.59)$ & 132 & 2612 & $1.36(0.93,1.99)$ \\
\hline$<$ High BP & 80 & 2116 & Referent & 75 & 3727 & Referent \\
\hline Cholesterol $\geq 240$ & 57 & 1339 & $0.90(0.58,1.38)$ & 107 & 2044 & $1.32(0.93,1.87)$ \\
\hline Cholesterol $<240$ & 139 & 3016 & Referent & 100 & 4295 & Referent \\
\hline Diabetes & 9 & 212 & $1.47(0.54,4.01)$ & 13 & 306 & $0.89(0.36,2.17)$ \\
\hline No Diabetes & 148 & 3144 & Referent & 168 & 4825 & Referent \\
\hline Missing & 39 & 999 & & 26 & 1208 & \\
\hline
\end{tabular}

Abbreviations: BMI, Body Mass Index; BP, Blood Pressure; CI, Confidence Interval.

${ }^{\mathrm{a}}$ Hazard ratios were adjusted for age (years, continuous), race (White, others), education (high school or less, college), family income $(<5,000, \$ 5,000$ to $\langle \$ 15,000$, and $\rangle=\$ 15,000)$, smoking status (smoked 100 cigarettes in one's lifetime, yes, no or missing data), family history of cancer (yes, no or missing data), and physical activity (moderately or very active, quite inactive). 


\section{Appendix B}

Table 9: Association between Combined Metabolic Risk Factors and Digestive Cancer Risk by Gender

\begin{tabular}{|c|c|c|c|c|c|c|}
\hline \multicolumn{4}{|c|}{ Males $(n=4383$, Cancer cases $=196)$} & \multicolumn{3}{|c|}{ Females $(n=6426$, Cancer cases $=211)$} \\
\hline Variable & Cancer cases & Sample size & $\begin{array}{c}\text { Hazard ratio }^{\mathrm{a}} \\
(95 \% \mathrm{CI})\end{array}$ & Cancer cases & Sample size & $\begin{array}{l}\text { Hazard ratio }^{\mathrm{a}} \\
(95 \% \mathrm{CI})\end{array}$ \\
\hline MRF 3 or 4 & 7 & 173 & $1.32(0.42,4.16)$ & 28 & 434 & $1.05(0.54,2.05)$ \\
\hline MRF 2 & 43 & 796 & $1.32(0.66,2.65)$ & 67 & 1128 & $0.98(0.58,1.65)$ \\
\hline MRF 1 & 69 & 1351 & $1.35(0.71,2.56)$ & 44 & 1574 & $0.49(0.26,0.91)$ \\
\hline MRF 0 & 38 & 1036 & Referent & 42 & 1995 & Referent \\
\hline Missing & 39 & 1027 & & 30 & 1295 & \\
\hline
\end{tabular}

Abbreviations: CI, Confidence Interval; MRF, Metabolic Risk Factor.

${ }^{\mathrm{a}}$ Hazard ratios were adjusted for age (years, continuous), race (White, others), education (high school or less, college), family income $(\langle \$ 5,000, \$ 5,000$ to $\langle \$ 15,000$, and $\rangle=\$ 15,000)$, smoking status (smoked 100 cigarettes in one's lifetime, yes, no or missing data), family history of cancer (yes, no or missing data), and physical activity (moderately or very active, quite inactive). 


\section{Appendix B}

Table 10: Association between Individual Metabolic Risk Factors and Lung Cancer Risk by Gender

\begin{tabular}{|c|c|c|c|c|c|c|}
\hline & \multicolumn{3}{|c|}{ Males $(n=4355$, Cancer cases $=174)$} & \multicolumn{3}{|c|}{ Females $(n=6339$, Cancer cases $=81)$} \\
\hline Variable & Cancer cases & Sample size & $\begin{array}{l}\text { Hazard ratio }^{\mathrm{a}} \\
(95 \% \mathrm{CI})\end{array}$ & Cancer cases & Sample size & $\begin{array}{l}\text { Hazard ratio }^{\mathrm{a}} \\
(95 \% \mathrm{CI})\end{array}$ \\
\hline $\mathrm{BMI} \geq 30$ & 20 & 567 & $0.97(0.48,1.95)$ & 15 & 1212 & $0.85(0.38,1.91)$ \\
\hline $\mathrm{BMI}<30$ & 154 & 3788 & Referent & 66 & 5127 & Referent \\
\hline High BP & 86 & 2239 & $0.86(0.60,1.24)$ & 39 & 2612 & $0.62(0.33,1.14)$ \\
\hline$<$ High BP & 88 & 2116 & Referent & 42 & 3727 & Referent \\
\hline Cholesterol $\geq 240$ & 56 & 1339 & $1.22(0.85,1.75)$ & 38 & 2044 & $1.51(0.80,2.84)$ \\
\hline Cholesterol $<240$ & 118 & 3016 & Referent & 43 & 4295 & Referent \\
\hline Diabetes & 9 & 212 & $1.14(0.45,2.87)$ & 6 & 306 & $1.70(0.52,5.56)$ \\
\hline No Diabetes & 131 & 3144 & Referent & 58 & 4825 & Referent \\
\hline Missing & 34 & 999 & & 17 & 1208 & \\
\hline
\end{tabular}

Abbreviations: BMI, Body Mass Index; BP, Blood Pressure; CI, Confidence Interval.

${ }^{\mathrm{a}}$ Hazard ratios were adjusted for age (years, continuous), race (White, others), education (high school or less, college), family income $(<5,000, \$ 5,000$ to $\langle \$ 15,000$, and $\rangle=\$ 15,000)$, smoking status (smoked 100 cigarettes in one's lifetime, yes, no or missing data), family history of cancer (yes, no or missing data), and physical activity (moderately or very active, quite inactive). 


\section{Appendix B}

Table 11: Association between Combined Metabolic Risk Factors and Lung Cancer Risk by Gender

\begin{tabular}{|c|c|c|c|c|c|c|}
\hline \multicolumn{4}{|c|}{ Males $(n=4383$, Cancer cases $=175)$} & \multicolumn{3}{|c|}{ Females $(n=6426$, Cancer cases $=83)$} \\
\hline Variable & Cancer cases & Sample size & $\begin{array}{l}\text { Hazard ratio }^{\mathrm{a}} \\
(95 \% \mathrm{CI})\end{array}$ & Cancer cases & Sample size & $\begin{array}{c}\text { Hazard ratio }^{\mathrm{a}} \\
(95 \% \mathrm{CI})\end{array}$ \\
\hline MRF 3 or 4 & 5 & 173 & $1.05(0.25,4.46)$ & 6 & 434 & $0.66(0.14,3.09)$ \\
\hline MRF 2 & 30 & 796 & $0.93(0.51,1.68)$ & 20 & 1128 & $0.76(0.31,1.84)$ \\
\hline MRF 1 & 65 & 1351 & $1.22(0.66,2.26)$ & 20 & 1574 & $0.63(0.26,1.57)$ \\
\hline MRF 0 & 40 & 1036 & Referent & 18 & 1995 & Referent \\
\hline Missing & 35 & 1027 & & 19 & 1295 & \\
\hline
\end{tabular}

Abbreviations: CI, Confidence Interval; MRF, Metabolic Risk Factor.

${ }^{\mathrm{a}}$ Hazard ratios were adjusted for age (years, continuous), race (White, others), education (high school or less, college), family income $(\langle \$ 5,000, \$ 5,000$ to $\langle \$ 15,000$, and $\rangle=\$ 15,000)$, smoking status (smoked 100 cigarettes in one's lifetime, yes, no or missing data), family history of cancer (yes, no or missing data), and physical activity (moderately or very active, quite inactive). 
APPENDIX C 
Appendix C: Association between metabolic risk factors and age at cancer onset

Table 1. Characteristics of the Study Population, National Health and Nutrition Examination Survey I (NHANES I) Epidemiologic Follow-up Study, 1971-1992 (Unweighted sample size $=1,736$ )

\begin{tabular}{|c|c|c|c|}
\hline Characteristics of the study population & Frequency & $\%$ & Mean (SE) \\
\hline Age at baseline (years) & & & $56.4(0.31)$ \\
\hline Age at cancer (years) & & & $67.9(0.31)$ \\
\hline Women & 914 & 52.6 & \\
\hline Men & 822 & 47.4 & \\
\hline \multicolumn{4}{|l|}{ Race/ethnicity } \\
\hline White & 1502 & 86.5 & \\
\hline Non-white & 234 & 13.5 & \\
\hline \multicolumn{4}{|l|}{ Family income } \\
\hline Below $\$ 5,000$ & 543 & 31.3 & \\
\hline$\$ 5,001-\$ 15,000$ & 864 & 49.8 & \\
\hline Above $\$ 15,000$ & 329 & 19.0 & \\
\hline \multicolumn{4}{|l|}{ Education } \\
\hline High school or less & 1400 & 80.6 & \\
\hline Above high school & 336 & 19.4 & \\
\hline \multicolumn{4}{|l|}{ Physical activity } \\
\hline Moderately or very active & 1559 & 89.8 & \\
\hline Quite inactive & 177 & 10.2 & \\
\hline \multicolumn{4}{|l|}{ Smoked 100 cigarettes in lifetime } \\
\hline Yes & 984 & 56.7 & \\
\hline No & 673 & 38.8 & \\
\hline Missing & 79 & 4.6 & \\
\hline \multicolumn{4}{|l|}{ Family history of cancer } \\
\hline Yes & 707 & 40.7 & \\
\hline No & 845 & 48.7 & \\
\hline Missing & 184 & 10.6 & \\
\hline BMI, $\mathrm{kg} / \mathrm{m}^{2}$ & & & $26.0(0.12)$ \\
\hline \multicolumn{4}{|l|}{ BMI categories } \\
\hline Underweight & 31 & 1.8 & \\
\hline Healthy weight & 765 & 44.1 & \\
\hline Overweight & 641 & 36.9 & \\
\hline Obese & 299 & 17.2 & \\
\hline \multicolumn{4}{|l|}{ Blood pressure (mmHg) } \\
\hline Diastolic & & & $84.3(0.31)$ \\
\hline Systolic & & & $137.7(0.57)$ \\
\hline High BP & 902 & 52.0 & \\
\hline No high BP & 834 & 48.0 & \\
\hline
\end{tabular}




\begin{tabular}{|c|c|c|c|}
\hline Serum cholesterol (mg/dL) & & & $228.7(1.23)$ \\
\hline $\operatorname{High}(>=240 \mathrm{mg} / \mathrm{dL})$ & 668 & 38.5 & \\
\hline Low $(<240 \mathrm{mg} / \mathrm{dL})$ & 1068 & 61.5 & \\
\hline \multicolumn{4}{|l|}{ Diabetes } \\
\hline Yes & 84 & 4.8 & \\
\hline No & 1334 & 76.8 & \\
\hline Missing & 318 & 18.3 & \\
\hline \multicolumn{4}{|l|}{ Metabolic Risk Factor (MRF) } \\
\hline MRF 0 & 400 & 23.0 & \\
\hline MRF 1 & 522 & 30.1 & \\
\hline MRF 2 & 383 & 22.1 & \\
\hline MRF 3 or 4 & 113 & 6.5 & \\
\hline Missing & 335 & 19.3 & \\
\hline
\end{tabular}

Abbreviations: BMI, Body mass index; SE, Standard error. 


\section{Appendix C}

Table 2: Association between Individual Metabolic Risk Factors and Age at Cancer Onset among Males

\begin{tabular}{|c|c|c|c|c|}
\hline & \multicolumn{2}{|c|}{ Age $<50$ Years $(n=140)$} & \multicolumn{2}{|c|}{ Age $\geq 50$ Years $(n=682)$} \\
\hline Variable & Cancer cases & $\begin{array}{c}\text { Mean difference } \\
(95 \% \mathrm{CI})\end{array}$ & Cancer cases & $\begin{array}{c}\text { Mean difference } \\
(95 \% \mathrm{CI})\end{array}$ \\
\hline $\mathrm{BMI} \geq 30 \mathrm{~kg} / \mathrm{m}^{2}$ & 18 & $2.71(0.96,4.47)$ & 87 & $0.27(-0.99,1.53)$ \\
\hline $\mathrm{BMI}<30 \mathrm{~kg} / \mathrm{m}^{2}$ & 122 & Referent & 595 & Referent \\
\hline High BP & 56 & $1.47(-0.25,3.20)$ & 391 & $0.04(-0.96,1.05)$ \\
\hline$<$ High BP & 84 & Referent & 291 & Referent \\
\hline Cholesterol $\geq 240 \mathrm{mg} / \mathrm{dL}$ & 44 & $-1.47(-3.45,0.51)$ & 230 & $0.45(-0.39,1.30)$ \\
\hline Cholesterol<240 mg/dL & 96 & Referent & 452 & Referent \\
\hline Diabetes & 4 & $-4.36(-7.77,-0.96)$ & 33 & $-2.78(-5.34,-0.22)$ \\
\hline No Diabetes & 102 & Referent & 517 & Referent \\
\hline Missing & 34 & & 132 & \\
\hline
\end{tabular}

Abbreviations: BMI, Body Mass Index; BP, Blood Pressure; CI, Confidence Interval.

${ }^{a}$ Adjusted for age (years, continuous), race (White, others), education (high school or less, college), family income ( $<\$ 5,000$, $\$ 5,000$ to $\langle \$ 15,000$, and $>=\$ 15,000$ ), smoking status (smoked 100 cigarettes in one's lifetime, yes, no or missing data), family history of cancer (yes, no or missing data), and physical activity (moderately or very active, quite inactive). 


\section{Appendix C}

Table 3: Association between Individual Metabolic Risk Factors and Age at Cancer Onset among Females

\begin{tabular}{|lrcrc|}
\hline & \multicolumn{2}{c}{ Age $<50$ Years $(\mathrm{n}=362)$} & \multicolumn{2}{c|}{ Age $\geq 50$ Years $(\mathrm{n}=552)$} \\
\hline Variable & Cancer cases & $\begin{array}{c}\text { Mean difference } \\
(95 \% \mathrm{CI})\end{array}$ & Cancer cases $^{\mathrm{a}}$ & $\begin{array}{c}\text { Mean difference }^{\mathrm{a}} \\
(95 \% \mathrm{CI})\end{array}$ \\
\hline BMI $\geq 30 \mathrm{~kg} / \mathrm{m}^{2}$ & 69 & $-0.80(-2.39,0.79)$ & 125 & $-0.89(-2.29,0.51)$ \\
$\mathrm{BMI}<30 \mathrm{~kg} / \mathrm{m}^{2}$ & 293 & Referent & 427 & Referent \\
High BP & 96 & $1.25(-0.10,2.61)$ & 359 & $-0.05(-1.13,1.02)$ \\
$<$ High BP & 266 & Referent & 193 & Referent \\
Cholesterol $\geq 240 \mathrm{mg} / \mathrm{dL}$ & 83 & $0.32(-0.77,1.41)$ & 311 & $-0.20(-1.12,0.72)$ \\
Cholesterol $<240 \mathrm{mg} / \mathrm{dL}$ & 279 & Referent & 241 & Referent \\
Diabetes & 9 & $-0.20(-3.47,3.08)$ & 38 & $\mathbf{- 1 . 9 7}(\mathbf{- 3 . 7 2 , - 0 . 2 1 )}$ \\
No Diabetes & 292 & Referent & 423 & Referent \\
Missing & 61 & & 91 & \\
\hline
\end{tabular}

Abbreviations: BMI, Body Mass Index; BP, Blood Pressure; CI, Confidence Interval.

${ }^{a}$ Adjusted for age (years, continuous), race (White, others), education (high school or less, college), family income $(<\$ 5,000$, $\$ 5,000$ to $\langle \$ 15,000$, and $>=\$ 15,000$ ), smoking status (smoked 100 cigarettes in one's lifetime, yes, no or missing data), family history of cancer (yes, no or missing data), and physical activity (moderately or very active, quite inactive). 


\section{Appendix C}

Table 4: Association between Combined Metabolic Risk Factors and Age at Cancer Onset among Males

\begin{tabular}{|lrcrc|}
\hline & \multicolumn{2}{c}{ Age $<50$ Years $(\mathrm{n}=141)$} & \multicolumn{2}{c|}{ Age $\geq 50$ Years $(\mathrm{n}=683)$} \\
\hline Variable & Cancer cases & $\begin{array}{c}\text { Mean difference } \\
(95 \% \text { CI })\end{array}$ & Cancer cases $^{\mathrm{a}}$ & $\begin{array}{c}\text { Mean difference } \\
(95 \% \text { CI })\end{array}$ \\
\hline MRF 3 or 4 & 5 & $2.65(-0.79,6.10)$ & 22 & $0.73(-2.36,3.82)$ \\
MRF 2 & 21 & $0.90(-2.50,4.30)$ & 146 & $0.13(-1.35,1.61)$ \\
MRF 1 & 37 & $-0.18(-2.30,1.95)$ & 247 & $-0.40(-1.71,0.92)$ \\
MRF 0 & 43 & Referent & 135 & Referent \\
Missing & 35 & & 133 & \\
\hline
\end{tabular}

Abbreviations: CI, Confidence Interval, MRF, Metabolic Risk Factor.

${ }^{a}$ Adjusted for age (years, continuous), race (White, others), education (high school or less, college), family income ( $<\$ 5,000$, $\$ 5,000$ to $\langle \$ 15,000$, and $\rangle=\$ 15,000$ ), smoking status (smoked 100 cigarettes in one's lifetime, yes, no or missing data), family history of cancer (yes, no or missing data), and physical activity (moderately or very active, quite inactive). 


\section{Appendix C}

Table 5: Association between Combined Metabolic Risk Factors and Age at Cancer Onset among Females

\begin{tabular}{|c|c|c|c|c|}
\hline & \multicolumn{2}{|c|}{ Age $<50$ Years $(n=369)$} & \multicolumn{2}{|c|}{ Age $\geq 50$ Years $(n=560)$} \\
\hline Variable & Cancer cases & $\begin{array}{c}\text { Mean difference }{ }^{\mathrm{a}} \\
(95 \% \text { CI })\end{array}$ & Cancer cases & $\begin{array}{c}\text { Mean difference }{ }^{\mathrm{a}} \\
(95 \% \mathrm{CI})\end{array}$ \\
\hline MRF 3 or 4 & 13 & $2.78(0.41,5.14)$ & 73 & $-2.64(-4.60,-0.68)$ \\
\hline MRF 2 & 50 & $0.48(-1.08,2.05)$ & 166 & $0.29(-1.62,2.20)$ \\
\hline MRF 1 & 79 & $-0.77(-2.38,0.85)$ & 159 & $-0.25(-2.05,1.55)$ \\
\hline MRF 0 & 159 & Referent & 63 & Referent \\
\hline Missing & 68 & & 99 & \\
\hline
\end{tabular}

Abbreviations: CI, Confidence Interval, MRF, Metabolic Risk Factor.

${ }^{a}$ Adjusted for age (years, continuous), race (White, others), education (high school or less, college), family income ( $<\$ 5,000$, $\$ 5,000$ to $\langle \$ 15,000$, and $>=\$ 15,000$ ), smoking status (smoked 100 cigarettes in one's lifetime, yes, no or missing data), family history of cancer (yes, no or missing data), and physical activity (moderately or very active, quite inactive). 


\section{Appendix C}

Table 6: Association between Individual Metabolic Risk Factors and Age at Breast Cancer Onset among Females

\begin{tabular}{|c|c|c|c|c|}
\hline & \multicolumn{2}{|c|}{ All women $(n=223)$} & \multicolumn{2}{|c|}{ Postmenopausal women $(\mathrm{n}=112)$} \\
\hline Variable & Cancer cases & $\begin{array}{c}\text { Mean difference }{ }^{\mathrm{a}} \\
(95 \% \mathrm{CI})\end{array}$ & Cancer cases & $\begin{array}{c}\text { Mean difference }{ }^{\mathrm{a}} \\
(95 \% \mathrm{CI})\end{array}$ \\
\hline $\mathrm{BMI} \geq 30 \mathrm{~kg} / \mathrm{m}^{2}$ & 48 & $-1.78(-3.78,0.23)$ & 31 & $-0.37(-2.64,1.90)$ \\
\hline $\mathrm{BMI}<30 \mathrm{~kg} / \mathrm{m}^{2}$ & 181 & Referent & 81 & Referent \\
\hline High BP & 101 & $1.02(-0.96,3.00)$ & 75 & $0.10(-2.30,2.50)$ \\
\hline$<$ High BP & 128 & Referent & 37 & Referent \\
\hline Cholesterol $\geq 240 \mathrm{mg} / \mathrm{dL}$ & 88 & $-0.60(-2.53,1.33)$ & 60 & $-0.93(-3.30,1.43)$ \\
\hline Cholesterol<240 mg/dL & 141 & Referent & 52 & Referent \\
\hline Diabetes & 14 & $-2.78(-5.82,0.25)$ & 13 & $-2.61(-4.89,-0.33)$ \\
\hline No Diabetes & 169 & Referent & 72 & Referent \\
\hline Missing & 46 & & 27 & \\
\hline
\end{tabular}

Abbreviations: BMI, Body Mass Index; BP, Blood Pressure; CI, Confidence Interval.

${ }^{a}$ Adjusted for age (years, continuous), race (White, others), education (high school or less, college), family income ( $<\$ 5,000$, $\$ 5,000$ to $\langle \$ 15,000$, and $>=\$ 15,000$ ), smoking status (smoked 100 cigarettes in one's lifetime, yes, no or missing data), family history of cancer (yes, no or missing data), and physical activity (moderately or very active, quite inactive). 


\section{Appendix C}

Table 7: Association between Combined Metabolic Risk Factors and Age at Breast Cancer Onset among Females

\begin{tabular}{|c|c|c|c|c|}
\hline & \multicolumn{2}{|c|}{ All women $(n=226)$} & \multicolumn{2}{|c|}{ Postmenopausal women $(\mathrm{n}=114)$} \\
\hline Variable & Cancer cases & $\begin{array}{c}\text { Mean difference }{ }^{\mathrm{a}} \\
(95 \% \mathrm{CI})\end{array}$ & Cancer cases & $\begin{array}{c}\text { Mean difference } \\
(95 \% \mathrm{CI})\end{array}$ \\
\hline MRF 3 or 4 & 21 & $-3.31(-6.12,-0.50)$ & 19 & $-3.84(-6.71,-0.96)$ \\
\hline MRF 2 & 44 & $-0.98(-4.08,2.13)$ & 29 & $-2.55(-6.31,1.20)$ \\
\hline MRF 1 & 51 & $-2.13(-4.27,0.01)$ & 26 & $-2.46(-5.41,0.48)$ \\
\hline MRF 0 & 67 & Referent & 11 & Referent \\
\hline Missing & 50 & & 29 & \\
\hline
\end{tabular}

Abbreviations: CI, Confidence Interval, MRF, Metabolic Risk Factor.

${ }^{a}$ Adjusted for age (years, continuous), race (White, others), education (high school or less, college), family income $(<\$ 5,000$, $\$ 5,000$ to $\langle \$ 15,000$, and $>=\$ 15,000$ ), smoking status (smoked 100 cigarettes in one's lifetime, yes, no or missing data), family history of cancer (yes, no or missing data), and physical activity (moderately or very active, quite inactive). 


\section{Appendix C}

Table 8: Association between Individual Metabolic Risk Factors and Age at Digestive Cancer Onset by Gender

\begin{tabular}{|lrcrcc|}
\hline \multicolumn{2}{|c}{ Males $(\mathrm{n}=194)$} & \multicolumn{2}{c|}{ Females $^{(\mathrm{n}=203)}$} \\
\hline Variable & Cancer cases & $\begin{array}{c}\text { Mean difference } \\
(95 \% \mathrm{CI})\end{array}$ & Cancer cases $^{\mathrm{a}}$ & $\begin{array}{c}\text { Mean difference } \\
(95 \% \mathrm{CI})\end{array}$ \\
\hline BMI $\geq 30 \mathrm{~kg} / \mathrm{m}^{2}$ & 34 & $0.17(-2.01,2.36)$ & 51 & $-1.66(-3.45,0.13)$ \\
BMI $<30 \mathrm{~kg} / \mathrm{m}^{2}$ & 160 & Referent & 152 & Referent \\
High BP & 114 & $0.79(-1.08,2.66)$ & 128 & $-1.03(-2.80,0.75)$ \\
$<$ High BP & 80 & Referent & 75 & Referent \\
Cholesterol $\geq 240 \mathrm{mg} / \mathrm{dL}$ & 57 & $0.34(-1.53,2.22)$ & 104 & $0.17(-1.75,2.08)$ \\
Cholesterol $<240 \mathrm{mg} / \mathrm{dL}$ & 137 & Referent & 99 & Referent \\
Diabetes & 9 & $-0.21(-3.04,2.62)$ & 13 & $-2.21(-4.88,0.46)$ \\
No Diabetes & 147 & Referent & 164 & Referent \\
Missing & 38 & & 26 & \\
\hline
\end{tabular}

Abbreviations: BMI, Body Mass Index; BP, Blood Pressure; CI, Confidence Interval.

${ }^{a}$ Adjusted for age (years, continuous), race (White, others), education (high school or less, college), family income ( $<\$ 5,000$, $\$ 5,000$ to $\langle \$ 15,000$, and $>=\$ 15,000$ ), smoking status (smoked 100 cigarettes in one's lifetime, yes, no or missing data), family history of cancer (yes, no or missing data), and physical activity (moderately or very active, quite inactive). 


\section{Appendix C}

Table 9: Association between Combined Metabolic Risk Factors and Age at Digestive Cancer Onset by Gender

\begin{tabular}{|lrcrc|}
\hline & \multicolumn{2}{c}{ Males $(\mathrm{n}=194)$} & \multicolumn{2}{c|}{ Females $_{(\mathrm{n}=207)}$} \\
\hline Variable & Cancer cases & $\begin{array}{c}\text { Mean difference } \\
(95 \% \text { CI })\end{array}$ & Cancer cases $^{\mathrm{a}}$ & $\begin{array}{c}\text { Mean difference }^{\mathrm{a}} \\
(95 \% \text { CI })\end{array}$ \\
\hline MRF 3 or 4 & 7 & $0.98(-2.26,4.22)$ & 27 & $\mathbf{- 4 . 4 2}(\mathbf{- 6 . 6 3 , - 2 . 2 2})$ \\
MRF 2 & 42 & $1.04(-1.73,3.82)$ & 65 & $-1.35(-3.64,0.95)$ \\
MRF 1 & 69 & $-0.67(-2.83,1.50)$ & 43 & $\mathbf{- 3 . 0 9}(\mathbf{- 5 . 4 1 , - 0 . 7 7 )}$ \\
MRF 0 & 38 & Referent & 42 & Referent \\
Missing & 38 & & 30 & \\
\hline
\end{tabular}

Abbreviations: CI, Confidence Interval, MRF, Metabolic Risk Factor.

${ }^{a}$ Adjusted for age (years, continuous), race (White, others), education (high school or less, college), family income ( $<\$ 5,000$, $\$ 5,000$ to $\langle \$ 15,000$, and $\rangle=\$ 15,000$ ), smoking status (smoked 100 cigarettes in one's lifetime, yes, no or missing data), family history of cancer (yes, no or missing data), and physical activity (moderately or very active, quite inactive). 


\section{Appendix C}

Table 10: Association between Individual Metabolic Risk Factors and Age at Lung Cancer Onset by Gender

\begin{tabular}{|c|c|c|c|c|}
\hline & \multicolumn{2}{|c|}{ Males $(\mathrm{n}=174)$} & \multicolumn{2}{|c|}{ Females $(\mathrm{n}=80)$} \\
\hline Variable & Cancer cases & $\begin{array}{c}\text { Mean difference } \\
(95 \% \mathrm{CI})\end{array}$ & Cancer cases & $\begin{array}{c}\text { Mean difference }{ }^{a} \\
(95 \% \mathrm{CI})\end{array}$ \\
\hline $\mathrm{BMI} \geq 30 \mathrm{~kg} / \mathrm{m}^{2}$ & 20 & $-0.44(-2.78,1.91)$ & 15 & $1.34(-0.73,3.40)$ \\
\hline $\mathrm{BMI}<30 \mathrm{~kg} / \mathrm{m}^{2}$ & 154 & Referent & 65 & Referent \\
\hline High BP & 86 & $0.66(-1.02,2.34)$ & 38 & $1.07(-0.90,3.04)$ \\
\hline$<$ High BP & 88 & Referent & 42 & Referent \\
\hline Cholesterol $\geq 240 \mathrm{mg} / \mathrm{dL}$ & 56 & $0.29(-1.60,2.17)$ & 37 & $0.46(-1.71,2.62)$ \\
\hline Cholesterol $<240 \mathrm{mg} / \mathrm{dL}$ & 118 & Referent & 43 & Referent \\
\hline Diabetes & 9 & $-7.40(-10.37,-4.43)$ & 6 & $-4.59(-8.18,-1.01)$ \\
\hline No Diabetes & 131 & Referent & 57 & Referent \\
\hline Missing & 34 & & 17 & \\
\hline
\end{tabular}

Abbreviations: BMI, Body Mass Index; BP, Blood Pressure; CI, Confidence Interval.

${ }^{a}$ Adjusted for age (years, continuous), race (White, others), education (high school or less, college), family income $(<\$ 5,000$, $\$ 5,000$ to $\langle \$ 15,000$, and $>=\$ 15,000$ ), smoking status (smoked 100 cigarettes in one's lifetime, yes, no or missing data), family history of cancer (yes, no or missing data), and physical activity (moderately or very active, quite inactive). 


\section{Appendix C}

Table 11: Association between Combined Metabolic Risk Factors and Age at Lung Cancer Onset by Gender

\begin{tabular}{|lrcrcc|}
\hline & \multicolumn{2}{c}{ Males $(\mathrm{n}=175)$} & \multicolumn{2}{c|}{ Females $^{(\mathrm{n}=82)}$} \\
\hline Variable & Cancer cases & $\begin{array}{c}\text { Mean difference } \\
(95 \% \text { CI })\end{array}$ & Cancer cases $^{\mathrm{a}}$ & $\begin{array}{c}\text { Mean difference } \\
(95 \% \text { CI })\end{array}$ \\
\hline MRF 3 or 4 & 5 & $\mathbf{- 3 . 7 6 ( - 6 . 6 3 , - 0 . 8 8 )}$ & 6 & $-2.92(-8.93,3.10)$ \\
MRF 2 & 30 & $0.44(-2.44,3.32)$ & 19 & $-0.05(-3.53,3.44)$ \\
MRF 1 & 65 & $-1.36(-3.53,0.82)$ & 20 & $-0.87(-4.00,2.25)$ \\
MRF 0 & 40 & Referent & 18 & Referent \\
Missing & 35 & & 19 & \\
\hline
\end{tabular}

Abbreviations: CI, Confidence Interval, MRF, Metabolic Risk Factor.

${ }^{a}$ Adjusted for age (years, continuous), race (White, others), education (high school or less, college), family income ( $<\$ 5,000$, $\$ 5,000$ to $\langle \$ 15,000$, and $\rangle=\$ 15,000$ ), smoking status (smoked 100 cigarettes in one's lifetime, yes, no or missing data), family history of cancer (yes, no or missing data), and physical activity (moderately or very active, quite inactive). 